University of Wollongong

Research Online

Australian Institute for Innovative Materials -

Papers

Australian Institute for Innovative Materials

$1-1-2016$

Thermoelectric enhancement of different kinds of metal chalcogenides

Chao Han

University of Wollongong, ch861@uowmail.edu.au

Qiao Sun

Soochow University, China, qsun@uow.edu.au

Zhen Li

University of Wollongong, zhenl@uow.edu.au

S X. Dou

University of Wollongong, shi@uow.edu.au

Follow this and additional works at: https://ro.uow.edu.au/aiimpapers

Part of the Engineering Commons, and the Physical Sciences and Mathematics Commons

Research Online is the open access institutional repository for the University of Wollongong. For further information contact the UOW Library: research-pubs@uow.edu.au 


\title{
Thermoelectric enhancement of different kinds of metal chalcogenides
}

\begin{abstract}
Due to the urgency of our energy and environmental issues, a variety of cost-effective and pollution-free technologies have attracted considerable attention, among which thermoelectric technology has made enormous progress. Substantial numbers of new thermoelectric materials are created with high figure of merit (ZT) by using advanced nanoscience and nanotechnology. This is especially true in the case of metal-chalcogenide-based materials, which possess both relatively high ZT and low cost among all the different kinds of thermoelectric materials. Here, comprehensive coverage of recent advances in metal chalcogenides and their correlated thermoelectric enhancement mechanisms are provided. Several new strategies are summarized with the hope that they can inspire further enhancement of performance, both in metal chalcogenides and in other materials.
\end{abstract}

\section{Disciplines}

Engineering | Physical Sciences and Mathematics

\section{Publication Details}

Han, C., Sun, Q., Li, Z. \& Dou, S. X. (2016). Thermoelectric enhancement of different kinds of metal chalcogenides. Advanced Energy Materials, 6 (15), 1600498-1-1600498-36. 


\title{
Thermoelectric enhancement of different kinds of metal chalcogenides
}

Chao Han, Qiao Sun, Zhen Li, * and Shi Xue Dou

Mr. Chao Han, Prof. Qiao Sun, Prof. Zhen Li

Center for Molecular Imaging and Nuclear Medicine, School of Radiation Medicine and Protection, Medical College of Soochow University, Collaborative Innovation Center of Radiation Medicine of Jiangsu Higher Education Institutions, 199 Renai Road, Industrial Park, Suzhou, Jiangsu 215123, P.R. China

Email: zhenli@suda.edu.cn

Mr. Chao Han, Prof. Zhen Li, Prof. Shi Xue Dou

Institute for Superconducting and Electronic Materials, Australian Institute for Innovative Materials, University of Wollongong, Squires Way, North Wollongong, NSW 2500, Australia.

Keywords: metal chalcogenides, thermoelectrics, enhanced $Z T$, energy conversion, new strategies

\begin{abstract}
Due to the urgency of our energy and environmental issues, a variety of cost-effective and pollution-free technologies have attracted considerable attention, among which thermoelectric technology has made enormous progress. Substantial numbers of new thermoelectric materials have been created with high figure of merit (ZT) by using advanced nanoscience and nanotechnology. This is especially true in the case of metal chalcogenide based materials, which possess both relatively high $Z T$ and low cost among all the different kinds of thermoelectric materials. This review provides comprehensive coverage of recent advances in metal chalcogenides and their correlated thermoelectric enhancement mechanisms. Several new strategies are summarized with the hope that they can inspire further enhancement of performance, both in metal chalcogenides and in other materials.
\end{abstract}




\section{Introduction}

As might be expected, nowadays, more than half of our primary energy is utilized in the form of heat. Examples include the usage of fossil fuels to power engines; the generation of electricity from steam power generators, etc. Nevertheless, the majority of energy actually produced by humans is lost in the form of waste heat. One example is in vehicles, where only $\sim 10 \%$ of the energy produced from burning petrol in the internal combustion engine is converted to useful work, while the rest is wasted. ${ }^{[1]}$ Another example is in steel works. According to the statistics, ${ }^{[2]}$ around $10^{9} \mathrm{~J}$ of heat would be wasted in the course of producing 1 ton of crude steel. The technologies for recovering waste heat are of great interest, because huge amounts of energy would be saved.

The phenomenon of thermoelectricity (TE), which has been known since the discoveries made by Seebeck, Peltier, and Thomson in the early 1800s, is such a technology that can convert heat into electricity directly via a solid-state conversion. Its basic working mechanism is very simple, i.e. when a material is heated, its charge carriers will flow from the hot side to the cold side to produce a voltage between them. A current will be produced when a load is connected, and the material works as a thermoelectricity generator (TEG); on the other hand, if the material is connected to a power source, the material works as a thermoelectric refrigerator (TER) when the temperature difference is maintained. The main metric for characterizing the performance of thermoelectric materials is the dimensionless "figure of merit" (ZT), which can be expressed by Equation (1):

$Z T=\frac{s^{2} \sigma}{\kappa} T$

In which $S$ is the Seebeck coefficient, $\sigma$ is the electrical conductivity, $\kappa$ is the thermal conductivity, and $S^{2} \sigma$ is defined as the power factor (PF).

Thermoelectric technology has a few distinct advantages, including: (1) it is reliable and operates in silence compared with other energy conversion technologies, as it works without mechanical movement; (2) thermoelectric devices are simple, compact, and safe; (3) it is an environmentally friendly green technology, because no heat, no gases, and no chemical waste are produced during operation; (4) it can be 
widely used in places where other energy conversion technologies are unavailable, such as in remote outer space. ${ }^{[3]}$

Although some typical applications of thermoelectric generators (TEGs) are illustrated in Figure 1, their current usage is in niche applications due to their extremely low energy conversion efficiency $(\eta)$, which is defined in Equation (2):

$\mathrm{\eta}=\mathrm{\eta}_{e} \times \frac{\sqrt{1+2 T-1}}{\sqrt{1+Z T+T_{c}} / T_{r}}$

where $\eta$ is the conversion efficiency of heat to electricity, $T_{\mathrm{c}}$ and $T_{\mathrm{h}}$ are the temperatures of the cold and the hot sides of a thermoelectric generator, respectively, and $\eta_{c}$ represents the Carnot efficiency and can be expressed as $\eta_{\mathrm{c}}=1-T_{\mathrm{c}} / T_{\mathrm{h}}$. The equation clearly shows that conversion efficiency could be improved by increasing ZT. Unfortunately, $S, \sigma$, and $\kappa$ are dependent on each other [as shown by Equations (3-5)], and it is very difficult to simultaneously optimize these three factors.

$\sigma=n \Theta \mu$

$S=A \times T \times \frac{m^{*}}{n^{3 / 2}}$

$\kappa=k_{1}+L \sigma e$

$n, e$, and $\mu$ represent the charge carrier density, charge of the electron, and mobility of the charge carriers, respectively. $A$ is a constant and equals to be $\frac{8 \pi^{2} k_{B}^{\frac{\pi}{3}}}{3 e h^{2}}$, where $k_{B}, e$ and $h$ are the Boltzmann constant, charge of electron, and the Plank constant, respectively. $m^{*}$ is the effective mass of charge carriers near the Fermi level, which is related to the band structure of the material. The thermal conductivity $(\kappa)$ is composed of the phonon contribution (lattice thermal conductivity $\kappa_{\mathrm{L}}$ ) and the contribution from the charge carriers $\left(\kappa_{\mathrm{e}}=L \sigma e\right.$, where $L$ is the temperature dependent Lorenz number). From Equations (3-5), it is easy to conclude that only $\kappa_{\mathrm{L}}$ is independent on $S$ and $\sigma$.

The first generation of bulk thermoelectric materials was developed over four decades ago, with a $Z T$ of $\sim 0.8-1.0$ and conversion efficiency $(\eta)$ of $5-6 \%$ (from the 1950 s to the 1990 s). From a wide variety of research approaches to increase $Z T$, a near doubling of $Z T$ at high temperatures has emerged and thus given rise to the second generation of bulk thermoelectric materials with $Z T$ ranging from 1.3 to 1.7 and 
an efficiency of $10 \%$ (1990s to 2010s). ${ }^{[4]}$ The boosting of $Z T$ is due to the optimization of existing materials using nanoscale precipitates and compositional inhomogeneity, in which abundant grain boundaries or defects can significantly decrease the lattice thermal conductivity $\left(\kappa_{\mathrm{L}}\right)$ while preserving a relatively high power factor. Continued progress has raised the $Z T$ by a factor of 2, with the predicted efficiency increasing to over $20 \%$, a highly exciting prospect which will surely have a large impact in the energy production and conservation fields. ${ }^{[4]}$ There have been many reviews on the development of different kinds of thermoelectric materials, including PbTe,${ }^{[5]}$ oxides, ${ }^{[6]}$ sulfides, ${ }^{[7]}$ nanostructured thermoelectric materials, ${ }^{[8]}$ etc.

There has been no comprehensive specific review, however, on all the different kinds of metal chalcogenide (MC) based thermoelectric materials despite their varieties, complexity and importance in the field of thermoelectrics. In this review, all kinds of MCs are first categorized based on the recent literatures. Then, their latest developments and the strategies behind their high performances are respectively demonstrated and discussed according to the classification.

\section{Merits of metal chalcogenide based thermoelectric materials}

The metal chalcogenides, a series of materials composed of both metal and chalcogen elements (S, Se, Te), have been attracting significant attention in a variety of energy applications, including solar cells, light-emitting diodes, sensors, batteries, supercapacitors, thermoelectric devices, etc. ${ }^{[9]}$ Compared with oxides, metal chalcogenide based thermoelectric materials possess a higher power factor $\left(\mathrm{PF}=S^{2} \sigma\right)$ due to the less covalent nature of their bonds, arising from low electronegativity. Their heavy atomic weight compared to some other thermoelectric materials is of benefit for reducing thermal conductivity. In addition, the chalcogenides are easy to form into different kinds of structures, which offer a good platform for investigating and improving thermoelectric performance. Moreover, the chalcogenides are easily doped into $n$-type (by halides) or $p$-type (by pnictides) materials, which is important for the fabrication of TEGs. It has been proved by many reports that metal chalcogenide based thermoelectric materials possess excellent performance. For example, hitherto, the highest $Z T$ value $(Z T=3.6$ at $580 \mathrm{~K})$ 
was obtained in $\mathrm{PbSe}_{0.98} \mathrm{Te}_{0.02} / \mathrm{PbTe}$ quantum-dot superlattices (QDSLs) grown by the molecular beam epitaxy (MBE) approach; ${ }^{[10]}$ a $Z T$ of 2.6 was obtained at $923 \mathrm{~K}$ for a single crystal of SnSe $;^{[11]}$ and $\mathrm{Na}$ doped full-scale-structured PbTe exhibited a maximum $Z T$ of 2.2 at $915 \mathrm{~K}^{[12]}$

The superiority of metal chalcogenide based thermoelectric materials also lies in their low cost, both for material fabrication and for operation. As elucidated by Figure 2, Yadav et al. calculated the efficiency ratios of different kinds of materials, using their $Z T$ values divided by their fabrication cost. ${ }^{[13]}$ The efficiency ratios of metal chalcogenides (typically $\mathrm{Bi}_{2} \mathrm{Te}_{3}$ and $\mathrm{PbTe}$, which are marked by red circles) are slightly lower than for oxides (e.g. $\mathrm{ZnO}$ ) and $\mathrm{Zn}_{4} \mathrm{Sb}_{3}$ (marked by green circle) despite the relatively high price of Te element. $\mathrm{ZnO}, \mathrm{NaCoO}_{2}$, and $\mathrm{Zn}_{4} \mathrm{Sb}_{3}$ are unstable, however, at high temperature or in humid air. ${ }^{[13]}$ LeBlanc et al. ${ }^{[14]}$ evaluated the operating costs for TERs made from different thermoelectric materials under a constant temperature difference. They found that metal chalcogenide based materials possess both the highest $Z T$ values and the lowest operating costs, as shown by Figure 3.

\section{Statistics from reports on MC based TE materials}

Due to the large numbers of reports on the thermoelectric performance of metal chalcogenides, we mainly focus on the thermoelectric performance of bulk metal chalcogenides reported since 2009 . To give a comprehensive review, according to the statistics from 400 references, we have divided the MCs into nine groups based on their compositions and crystal structures (Figure 4); their thermoelectric performance as well as the strategies used to enhance thermoelectric performance are summarized and discussed.

Groups 1-2 are bismuth and lead chalcogenides, respectively. More than $27 \%$ of the selected references are related to the traditional $\mathrm{Bi}-\mathrm{X}(\mathrm{X}=\mathrm{S}, \mathrm{Se}, \mathrm{Te})$ based thermoelectric materials due to their excellence. More than $12 \%$ are related to the $\mathrm{Pb}-\mathrm{X}$ system, which is another group of traditional high performance thermoelectric materials. ${ }^{[5]}$ Several different new strategies have been developed to enhance their performance, which are summarized in the section of 4.1 " $B i-X$ and $P b-X$ thermoelectric materials". 
Group 3 is from the ternary A-B-X system, in which A is mainly $\mathrm{Ag}$ and $\mathrm{Cu}$ (group 11 or $\mathrm{I}_{\mathrm{B}}$ ), B is an element from the $\mathrm{III}_{\mathrm{A}}, \mathrm{IV}_{\mathrm{A}}$, and $\mathrm{V}_{\mathrm{A}}$ group (groups 13-15, Al, Ga, In, Ge, Sn, As, Sb, Bi), and $\mathrm{X}$ is the chalcogen $\left(\mathrm{S}, \mathrm{Se}\right.$, Te in group 16 or $\left.\mathrm{VI}_{\mathrm{A}}\right)$. Group 3 takes up around $14 \%$ in the total reports. Due to their complex compositions, the structures of A-B-X thermoelectric materials are varied, and can be generally classified into three types. The first type has diamond-like (or distorted diamond structures) and is usually stoichiometric $\mathrm{ABX}_{2}$ compounds. The distorted crystal structures lead to relatively low thermal conductivity, and the medium bonding strength offers moderate electrical conductivity. The second type is from "non-stoichiometric" $\mathrm{A}-\mathrm{B}-\mathrm{X}$ (atomic ratio of $\mathrm{A}: \mathrm{B}: \mathrm{X}$ is not 1:1:2) compounds, which own complex crystal structures and behave like the so-called phonon glass electron crystals (PGECs). The third type has an amorphous structure with total random atomic arrangements, which usually shows extremely low thermal and electrical conductivity. By controlling the degree of crystallinity, the electrical conductivity of this type of A-B-X compounds can be improved while preserving relatively low thermal conductivity.

It should be noted that Tl-M-X, Mo-Sb-Te, Chevrel phase, and quaternary Cu-C-B-X compounds (with $\mathrm{C}$ another metal element) are also included in this group due to their similar mechanisms for achieving good thermoelectric performance. They take up around 4\% of the total reports.

Groups 4-5 are tin and indium based materials, which have rather simple compositions and are newly identified as thermoelectric materials with high $Z T$ values. For example, Rhyee et al. ${ }^{[15]}$ reported that single crystal $\mathrm{In}_{4} \mathrm{Se}_{2.78}$ was a good $n$-type thermoelectric material with a $Z T$ of 1.48 at $705 \mathrm{~K}$. A $Z T$ of 2.6 at $923 \mathrm{~K}$ was obtained for $p$-type SnSe single crystal. ${ }^{[11]}$ The high $Z T$ of these materials is due to their unique zigzag bonding arrangement (i.e. Peierls distortion). About $4 \%$ and $3 \%$ of the total 400 references are for tin and indium chalcogenides, respectively.

Group 6 consists of materials with layered structure, which have long been identified as excellent thermoelectric materials because there is some separation of charge carriers and phonons by the layer structure. The charge carriers could be effectively transferred within the layers while the phonons may be significantly scattered due to the weak van der Waal bonding between the adjacent layers. The layered 
structure materials in this group are mainly sodium cobalt oxides (e.g. $\mathrm{NaCoO}_{2}$ ), transition metal chalcogenides (such as $\mathrm{TiS}_{2}, \mathrm{MoSe}_{2}, \mathrm{ZrSe}_{2}, \mathrm{MoS}_{2}, \mathrm{WSe}$, etc.), and ternary $\mathrm{ACrX}$ materials, in which A is $\mathrm{Cu}, \mathrm{Ag}$, or $\mathrm{Ni}$. The thermoelectric enhancement of these materials mainly depends on the intercalation of other species into the layers. This group accounts for $6 \%$ of the thermoelectric literature.

Group 7 includes binary GeTe, ternary $\mathrm{AgSbTe}_{2}$, and quaternary Ag-Sb-Pb-Te (LAST), Ag-Sb-Ge-Te (TAGS) based materials. The common factor in this group is that the enhancement of their thermoelectric performance (i.e. ZT) is due to the formation of nano-inclusions via self-formed inhomogeneities on the nanoscale, driven by phase segregation such as spinodal decomposition, and nucleation and growth. They occupy approximately $9 \%$ of reported references.

Group 8 contains the compounds of $\mathrm{Cu}(\mathrm{Ag})-\mathrm{X}$ system having the "phonon liquid electron crystal (PLEC)" property, ${ }^{[16]}$ which is very similar to the "phonon glass electron crystal (PGEC)" property. The PLEC compounds usually are superionic materials, such as some binary and ternary cuprous and silver chalcogenides. In contrast to the structure of other metal chalcogenides, cuprous and silver chalcogenides have a special structure at higher temperature, where the chalcogen anions form a crystalline lattice and provide pathways for the charge carriers, while the cuprous or silver cations are highly disordered around the chalcogen. Cuprous or silver ions can move fast and behave like a liquid at high temperature, which leads to their extremely low thermal conductivity while preserving good electrical conductivity. As a benefit of this PLEC feature, extremely high $Z T$ values are acquired in PLEC materials. ${ }^{[16-17]}$ There are around $8 \%$ of thermoelectric references for this group of materials.

In addition to above mentioned metal chalcogenides, there are some other metal chalcogenide thermoelectric materials (around 13\% of thermoelectric references), which are included in group 9. These materials are also good candidates as TE materials for several reasons, such as the unique properties of variable bonds of transition metals (e.g. tellurides of rare earth metals), vacancy planes (e.g. gallium chalcogenides), special band structures, tunable modulation, etc. 
In the following parts, the thermoelectric enhancement, and the enhancement strategies and mechanisms for these materials will be discussed one by one according to the category.

\section{Thermoelectric performance of MCs from different groups}

\section{1. $\mathrm{Bi}-\mathrm{X}$ and $\mathrm{Pb}-\mathrm{X}$ thermoelectric materials}

\subsubsection{Bi-X compounds (Group 1)}

\section{Bismuth telluride based thermoelectric materials}

As the most promising thermoelectric materials at room temperature, $\mathrm{Bi}_{2} \mathrm{Te}_{3}$ and its alloys with $\mathrm{Sb}$ and Se, with a $Z T$ of 0.6 at $300 \mathrm{~K}$, were commercialized and used in thermoelectric refrigerators several decades ago. Advances in nanotechnology have recently boosted the $Z T$ values of these conventional thermoelectric materials to a new record, as demonstrated by a $Z T$ of 2.4 at $300 \mathrm{~K}$ obtained from a superlattice film of $\mathrm{Bi}_{2} \mathrm{Te}_{3}-\mathrm{Sb}_{2} \mathrm{Te}_{3}$ in $2000{ }^{[18]}$ This breakthrough not only demonstrates the nanoscale effects towards the improvement of thermoelectric performance of conventional materials, but also has led to a burst of research on thermoelectric nanomaterials.

$\mathrm{Bi}_{2} \mathrm{Te}_{3}$ is a narrow-gap (indirect band gap of $160 \mathrm{meV}$ ) layered semiconductor possessing a trigonal unit cell with space group R-3m and lattice constants $a=4.38 \AA$ and $c=30.36 \AA$. The detailed crystal structure is shown in Figure $\mathbf{5}(\mathrm{a})$, where $\mathrm{Bi}_{2} \mathrm{Te}_{3}$ is composed of Te and $\mathrm{Bi}$ atomic layers arranged in the order of - $\mathrm{Te}(1)-\mathrm{Bi}-\mathrm{Te}(2)-\mathrm{Bi}-\mathrm{Te}(1)-$ along the $c$-axis direction. The $\mathrm{Bi}-\mathrm{Te}(2)$ bond is covalent, while the $\mathrm{Bi}-\mathrm{Te}(1)$ bond is a covalent-ionic bond. The interaction between two adjacent $\mathrm{Te}(1)$ layers is based on weak van der Waals forces. Therefore, $\mathrm{Bi}_{2} \mathrm{Te}_{3}$ crystals exhibit easy cleavage and high thermoelectric properties along the $(00 l)$ planes.

The valence and conduction band structures can be described by a many-ellipsoid model with 6 constant-energy ellipsoids that are centered on the reflection planes. Furthermore, the Seebeck coefficient of bulk $\mathrm{Bi}_{2} \mathrm{Te}_{3}$ becomes compensated, with a sharp rise of thermal conductivity at around room temperature, driving the material used in power generation devices to be an alloy of bismuth, antimony, tellurium, and selenium to further improve its performance. ${ }^{[19]}$ Alloys of $\mathrm{Bi}_{0.5} \mathrm{Sb}_{1.5} \mathrm{Te}_{3}$ and $\mathrm{Bi}_{2} \mathrm{Se}_{0.3} \mathrm{Te}_{2.7}$ 
are the best $p$ - and $n$-type thermoelectric materials at room temperature, respectively. The recently reported $Z T$ values of BiSbTe and BiSeTe based materials are summarized in Table 1, which shows that the maximum $Z T$ for bulk p-type $\mathrm{Bi}_{0.5} \mathrm{Sb}_{1.5} \mathrm{Te}_{3}$ and $n$-type $\mathrm{Bi}_{2} \mathrm{Se}_{0.3} \mathrm{Te}_{2.7}$ reached 1.86 at $320 \mathrm{~K}$ and 1.20 at $445 \mathrm{~K}$, respectively. ${ }^{[20]}$

It should be noted that the enhancement of $Z T$ in $p$-type materials is much easier than in their $n$-type analogues due to the strong texture and highly anisotropic properties of $n$-type materials. ${ }^{[21]}$ Several strategies to enhance the thermoelectric performance of $\mathrm{Bi}$-Te based materials can be summarized as follows:

\section{(1) Nanostructuring}

Nanostructuring is an effective method to enhance thermoelectric performance due to the decreased thermal conductivity resulting from the presence of abundant grain boundaries. For example, by combining the melt spinning and spark plasma sintering techniques, a high density of nanostructures was achieved in $p$-type $\mathrm{Bi}_{0.5} \mathrm{Sb}_{1.5} \mathrm{Te}_{3}$, and the maximum $Z T$ of 1.56 at $300 \mathrm{~K}$ was reached. ${ }^{[22]}$ Flower-like $n$ type $\mathrm{Bi}_{2} \mathrm{Te}_{3}$ nanostructures were synthesized by a wet chemical method and sintered into a bulk, which exhibited a $Z T$ of 1.16 at $420 \mathrm{~K} .^{[23]}$

There are several new developments in the nanostructuring of $\mathrm{Bi}-\mathrm{X}$ materials. The first development lies in the bottom-up fabrication of nanobulks of Bi-Te based thermoelectric materials. ${ }^{[24]}$ Mehta et al. ${ }^{[24 a]}$ reported a microwave assisted synthesis of nanostructured $\mathrm{Bi}(\mathrm{Sb})_{2} \mathrm{Te}(\mathrm{Se})_{3}$, in which thioglycolic acid (TGA) was simultaneously used as a stabilizer and sulphur dopant, with a $Z T$ of 1.1 reported for the final product synthesized by this method. From their description, the TGA not only can act as an S dopant for the product, it also could protect the nanostructures from oxidation. They got the highest reported $Z T$ for an $n$-type BiSeTe material, and the product could be processed in air, which offers great convenience for further applications of these nanostructures.

The second development is the consolidation method, e.g., the hot pressing or spark plasma sintering (SPS) techniques, which significantly influence the thermoelectric performance of the nanobulks. For 
example, although samples were prepared from same batch of $\mathrm{Bi}_{0.5} \mathrm{Sb}_{1.5} \mathrm{Te}_{3}$ nanopowder, the electrical conductivity of the hot pressed nanobulk decreased with increasing temperature, ${ }^{[25]}$ while in the case of the sample sintered by the SPS technique, an opposite trend was observed. This difference is ascribed to the different features of the two techniques. During the SPS process, the local high temperature from the electric spark causes evaporation of elements and the formation of more defects, which significantly modifies the thermoelectric properties of the final product. On the contrary, the temperature during hot pressing is more controllable and uniform. ${ }^{[25]}$

The third development is the introduction of nanostructures into the matrix of bulk materials. Several different nanostructures were introduced and their effects are reported in details. One example is that Liu et al. ${ }^{[26]}$ tried to enhance the thermoelectric performance of $n$ - and $p$-type $\mathrm{Bi}_{2} \mathrm{Te}_{3}$ by introducing nanostructured $\mathrm{SiC}$. The $Z T$ of $p$-type $\mathrm{Bi}_{0.5} \mathrm{Sb}_{1.5} \mathrm{Te}_{3}$ was successfully enhanced from 0.88 to 0.97 at $323 \mathrm{~K}$, but the $Z T$ of $n$-type $\mathrm{Bi}_{2} \mathrm{Se}_{0.3} \mathrm{Te}_{2.7}$ was decreased after nano-SiC was introduced into it. This is because $\mathrm{SiC}$ is a $p$-type semiconductor, so the mobility of electrons in the $n$-type matrix was strongly decreased by the SiC particles. Besides SiC nanoparticles, many kinds of other nanostructures have been investigated. $^{[27]}$

Parallel to the experimental progress, several new theories have also been developed based on the introduction of nanostructures into the matrix. An interesting example is a composite made of $\mathrm{Cu}_{3} \mathrm{SbSe}_{4}$ with $p$-type $\mathrm{Bi}_{0.5} \mathrm{Sb}_{1.5} \mathrm{Te}_{3}$, in which $\mathrm{Cu}_{3} \mathrm{SbSe}_{4}$ particles not only played the role of phonon scattering centers, but also significantly increased the Seebeck coefficient due to the energy filtering effect (EFE), as shown in Figure 6. Through the embedding of nanostructured impurities with a slightly larger band gap than the matrix, a moderate energy barrier (usually lower than $100 \mathrm{meV}$ ) is introduced at the matriximpurity boundaries. Thus, only the charge carriers with higher energy and larger effective mass $\left(m^{*}\right)$ could pass through these barriers, leading to an increase in the Seebeck coefficient. In addition, the large surface area of nanograins also provides a high density of trap states (or an energy barrier) caused by surface adsorbents. ${ }^{[28]}$ The electrical conductivity could decrease, however, due to the filtering effect and 
scattering at grain boundaries. Therefore, there is a trade-off between the benefits from EFE and the detrimental effects from the nanostructure.

\section{(2) Resonant level doping}

In the most traditional way, doping with different elements could also lead to enhancement of thermoelectric materials. The doping could result in defects in the matrix, change the carrier concentration $(n)$, and decrease the thermal conductivity. Hitherto, the doping effects of many different elements, such as $\mathrm{Fe}, \mathrm{In}, \mathrm{Cu}, \mathrm{Ag}, \mathrm{Cl}, \mathrm{Ga}, \mathrm{Sn}$, and $\mathrm{Ag}$ on $\mathrm{Bi}-\mathrm{Te}$ based thermoelectric materials have been reported. ${ }^{[29]}$ Compared with cases where the same carrier concentration is obtained by doping with other impurities, however, Sn doping remarkably increased the Seebeck coefficient in $\mathrm{Bi}_{2} \mathrm{Te}_{3}$ single crystal at a given carrier concentration. This phenomenon is ascribed to the effect of resonant level doping, which is illustrated in Figure 7. It occurs because tin offers a resonant valence band state, which is $15 \mathrm{meV}$ below the top of the upper valence band of $\mathrm{Bi}_{2} \mathrm{Te}_{3} .{ }^{[29 \mathrm{~d}, 30]}$ The Seebeck coefficient is thus significantly increased by the increased density of states $[\mathrm{DOS}, \mathrm{g}(\mathrm{E})]$ near the Fermi level (indicated by the solid red line) in comparison with the original DOS of $\mathrm{Bi}_{2} \mathrm{Te}_{3}$ (indicated by the red dashed line).

As one of the most important strategies of band engineering, resonant level doping shows obvious advantages towards improving the thermoelectric performance, as it distorts the band structure and only increases the Seebeck coefficient without affecting the electrical conductivity. Instead of the resonant effect, however, only normal impurity effects (doping effects) were observed in Sn doped $p$-type BiSbTe and $n$-type BiSeTe materials. ${ }^{[29 \mathrm{~d}, 29 \mathrm{e}]}$ This is because the formation of a resonant level, which depends critically on the amount of overlap between the impurity states and the band structure of the matrix, is very hard to realize and predict. ${ }^{[31]}$ The distortion of the band must take place near the Fermi level (usually within $0.5 \mathrm{eV}$ ) after hybridizing with the impurity band. Too much overlap may distort the band too much and cause a shift in the Fermi level, while too little overlap may not distort the band. Only a few elements or specific materials have been identified as capable of resonant doping, such as $\mathrm{Tl}$ and $\mathrm{Sb}$ for PbTe, Sn for $\mathrm{Bi}_{2} \mathrm{Te}_{3}$, and In for SnTe. ${ }^{[29 d, 32]}$ Although some dopants are not capable of resonant doping, 
they could modify the band structure of the matrix, such as by causing band degeneracy or affecting the band gap, and detailed examples will be discussed in connection with the $\mathrm{Pb}-\mathrm{X}$ system. Effects that could modify the band structure, including resonant doping, are summarized as another common route to enhance thermoelectric performance in band structure engineering.

(3) Increasing the degree of orientation of the microstructures

Bismuth chalcogenides such as $\mathrm{Bi}_{2} \mathrm{Te}_{3}$ have a layered structure [Figure 5(a)], so they show anisotropic thermoelectric properties along different crystal directions and a high $Z T$ along the plane perpendicular to the $c$-axis. Commonly, $\mathrm{Bi}_{2} \mathrm{Te}_{3}$ based ingots with high $Z T$ values are single crystalline or highly aligned polycrystals fabricated by the Bridgman, Zone melting, and Czochralsky techniques, with a preferred crystal orientation. ${ }^{[33]}$ Therefore, one way to enhance the $Z T$ and mechanical properties of the Bi-Te compounds is to increase the degree of orientation of crystals in their polycrystalline bulks, which has attracted considerable attention in recent years. The preferential factor, which is also called the Lotgering Factor $(F)$, is employed to characterize the orientation of crystals and can be expressed by the following equations:

$F=\frac{P-P_{0}}{1-P_{0}}$

$P=\frac{I_{(000)}}{\sum I_{(B R E)}}$

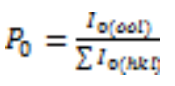

Where $I(00 l)$ and $I_{0}(00 l)$ is the intensity of the $(00 l)$ peak for preferentially and randomly oriented samples, respectively. There are several approaches to enhance $F$.

The first approach is hot deformation, which has been proved to be an effective method to increase $F$ in the polycrystalline bulk materials. ${ }^{[20 a, 33-34]}$ External strains may cause reorientation or induce preferential growth of crystals. For example, by combining the densification of nanostructured powders with two-step hot forging processes, the orientation degree (i.e. $F$ ) of nanostructured $p$-type $\mathrm{Bi}_{0.5} \mathrm{Sb}_{1.5} \mathrm{Te}_{3}$ was significantly improved from less than 0.1 to 0.3 , and the $Z T$ value was increased from 1.0 to $1.5 .^{\text {[35] }}$ 
The second approach to reorienting the crystals in bulk materials is the use of high magnetic field. ${ }^{[33 \text {, }}$

${ }^{36]}$ When a crystal with anisotropic magnetic susceptibility is placed in a strong magnetic field, it will be rotated to an angle that minimizes the magnetization energy $(U)$ associated with the magnetic anisotropy of the crystal, as given by the following equation ${ }^{[36 a]}$ :

$U=-\frac{X_{12}}{2 \mu_{0}^{2}} B^{2}-\frac{\left(X_{12}-Z_{12}\right)}{2 \mu_{0}} B^{2} \cos ^{2} \theta$

where $\chi_{11}$ and $\chi_{33}$ are the magnetic susceptibilities along the $a / b$ axis and the $c$ axis, respectively; $\mu_{0}$ is the permeability in vacuum, $B$ is the magnetic field, and $\theta$ is the angle between the direction of the magnetic field and the $c$-axis of the crystal. For $\mathrm{Bi}_{0.4} \mathrm{Sb}_{1.6} \mathrm{Te}_{3}$ at room temperature, $\chi_{11}$ and $\chi_{33}$ are $-0.368 \times 10^{-6}$ $\mathrm{cm}^{3} / \mathrm{g}$ and $-0.457 \times 10^{-6} \mathrm{~cm}^{3} / \mathrm{g}$, respectively. ${ }^{[36 \mathrm{a}]}$ Thus, under a high magnetic field, the crystallographic $c$ axis of single crystal $\mathrm{Bi}_{0.6} \mathrm{Sb}_{1.4} \mathrm{Te}_{3}$ can be aligned perpendicularly to the direction of an applied magnetic field. Kim et al. fabricated polycrystalline $\mathrm{Bi}_{0.6} \mathrm{Sb}_{1.4} \mathrm{Te}_{3}$ by a "bottom up" route; e.g. the pellet of nanostructured $\mathrm{Bi}_{0.6} \mathrm{Sb}_{1.4} \mathrm{Te}_{3}$ was first fabricated under a magnetic field using the slip-casting method and then consolidated by SPS. ${ }^{[36]}$ The obtained bulk material indeed showed preferential orientation under a magnetic field of $10 \mathrm{~T}$, and the maximum $Z T$ reached 1.2 at $323 \mathrm{~K}$, which is a $30 \%$ increase over the sample synthesized in the absence of magnetic field. ${ }^{[36 \mathrm{~b}]}$ Luo et al. imposed a variable intensity high static magnetic field during a traditional melt-solidification (MS) process to prepare $p$-type $\mathrm{Bi}_{0.5} \mathrm{Sb}_{1.5} \mathrm{Te}_{3}{ }^{[33]} \mathrm{A}$ $c$-axis alignment of the bismuth antimony telluride in the direction perpendicular to the magnetic field was observed in the sample fabricated under $2 \mathrm{~T}$ magnetic field, as shown in Figure 8. This is related to the enhanced convection of the melt under high magnetic field. ${ }^{[33]}$ Finally, this well aligned material yielded a $Z T$ of 1.71 at $323 \mathrm{~K}$, which is nearly two times higher than for the sample prepared without magnetic field. ${ }^{[33]}$

The third approach is a combination of chemical exfoliation and spark plasma sintering (CE-SPS). Puneet et al. ${ }^{[21]}$ used this approach to transform bulk $n$-type $\mathrm{Bi}_{2} \mathrm{Te}_{3}$ microparticles into well oriented layered nanostructures, which exhibited increased electrical conductivity and ZT. Zhu et al. ${ }^{[37]}$ adopted a similar hydrothermal exfoliation and SPS process (HE-SPS) to obtain well oriented nanostructured $p$-type 
$\mathrm{Bi}_{0.48} \mathrm{Sb}_{1.52} \mathrm{Te}_{3}$. The maximum $Z T$ of $p$-type $\mathrm{Bi}_{0.48} \mathrm{Sb}_{1.52} \mathrm{Te}_{3}$ increased from 1.2 to 1.4 at $300 \mathrm{~K}$ due to the increasing orientation $(F)$.

(4) Severe plastic deformation

Severe plastic deformation (SPD) is a "top down" process to achieve materials with ultra-fine grains in the sub-micrometer or nanometer range, which is a general approach to enhancing $Z T$ in half-Heusler, skutteridite, and Bi-Te systems. ${ }^{[20 a, 34 a, 34 c, 34 e, 35,38]}$ This method includes several different techniques, such as high pressure torsion, equal-channel angular pressing, direct cold pressing, hot forging, hot extrusion, etc. The extremely large plastic strains induced by the significantly high hydrostatic pressure at the evaluated temperature have a great effect on the microstructure of materials. This method involves several different mechanisms to enhance the thermoelectric properties, including (i) breaking of crystals down to

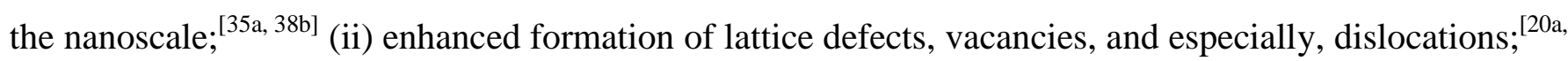
35a] (iii) and re-orientation of the crystals. ${ }^{[35]}$ In addition, the SPD method also improves the mechanical properties of Bi-Te based materials due to the formation of nanocrystallites. ${ }^{[34 \mathrm{~d}]}$ For example, the samples extruded at $360{ }^{\circ} \mathrm{C}$ showed the highest Vickers hardness of HV 108, which is 2.5 times higher than that of hot-pressed $\mathrm{Bi}_{2} \mathrm{Te}_{3}$ compound. ${ }^{[34 \mathrm{e}]}$

\section{Defect engineering}

Defect engineering is an effective way to modify the thermoelectric performance of Bi-Te compounds. It is well known that antisite defects and anion vacancies play important roles in controlling the conduction type of the Bi-Te system. Although the effects of defects on thermoelectric performance have been investigated in terms of the doping effect, the important effect of point defects on thermoelectric performance has never been fully recognized. Recently, Hu et al. ${ }^{[20 \mathrm{a}]}$ proposed defect engineering as an effective and important route to enhance the thermoelectric performance of the Bi-Te compounds besides the traditional nanoengineering and band structure engineering. In this report, the defects are well controlled in two ways: (i) the concentration of antisite defects or vacancies in the Bi-Te system strongly depends on the composition and can be adjusted by changing the composition. The smaller the 
differences in electronegativity and atomic size between the cation and anion atoms, the less resistance there is to the formation of antisite defects, while by increasing the size difference between the cation and anion atoms, anion vacancies increase. Hence, the composition related formation energies of antisite defects $\left(E_{\mathrm{A}}\right)$ and anion vacancies $\left(E_{\mathrm{v}}\right)$ follow the order of:

$$
\begin{aligned}
& E_{A}(S b-T e)<E_{A}(B i-T e)<E_{A}(S b-S e)<E_{A}(B i-S e) \\
& E_{V}(S b-T e)<E_{V}(B i-T e)<E_{V}(S b-S e)<E_{V}(B i-S e)
\end{aligned}
$$

(ii) The defect concentration could also be controlled by sample deformation due to induced non-basal slippage across the crystals, which could lead to the formation of $3 \mathrm{Te}_{(\mathrm{vacancy})}-2 \mathrm{Bi}_{\text {(interstitial) }}$ pairs $\left(V_{E \mathrm{i}}^{t s p}-V_{T \varepsilon}^{*}\right) .{ }^{[20 \mathrm{a}, 35 \mathrm{a}]}$ With more Bi vacancies $\left(B i_{E \mathrm{i}}^{\mathrm{X}}\right)$, the Bi atoms occupying Te sites $\left(B i_{T \varepsilon}^{s}\right)$ will diffuse backwards to $\mathrm{Bi}$ sites to form many Te vacancies $\left(V_{T e}^{*}\right)$ and excess electrons $(e)$. The process can be described by Equation (12):

$2 V_{B i}^{t r b}+3 V_{T e}^{s}+B i_{T e}^{s} \rightarrow V_{E i}^{t s D}+B i_{E i}^{X}+4 V_{T e}^{v}+6 e$

$\mathrm{Hu}$ et al. ${ }^{[20 \mathrm{a}]}$ carefully controlled the concentrations and kinds of defects in these two ways, and achieved the maximum $Z T$ values of 1.3 and 1.2 for $p$-type $\mathrm{Bi}_{0.5} \mathrm{Sb}_{1.5} \mathrm{Te}_{3}$ and $n$-type $\mathrm{Bi}_{2} \mathrm{Se}_{0.3} \mathrm{Te}_{2.7}$, respectively.

(6) Introduction of dislocation arrays

The $Z T$ is reciprocal to the thermal conductivity, which is transferred via vibration of phonons. The heat-carrying phonons cover a broad spectrum of frequencies, and the lattice thermal conductivity can be expressed as a sum of the contributions from different frequencies. According to the Umklapp scattering mechanism and Debye approximation, the lattice thermal conductivity remains constant with increasing temperature. ${ }^{[20 \mathrm{~b}]}$ In the nanostructured Bi-Te system, the point defects are highly efficient for scattering the high frequency phonons, and the grain boundaries, as well as nanoparticles, could be effective for scattering low frequency phonons, while only dislocation arrays are effective for scattering phonons from low to high frequencies [Figure 9(a)]. In 2015, Sang et al. ${ }^{[20 \mathrm{~b}]}$ reported a liquid-phase compaction method to create dislocation arrays between adjacent nanostructures to obtain obviously decreased thermal conductivity, as presented in Figure 9(b). The first step of this method is mixing nanoribbons of 
$\mathrm{Bi}_{0.5} \mathrm{Sb}_{1.5} \mathrm{Te}_{3}$ with a $25 \mathrm{wt} \%$ Te powder, followed by sintering the mixture through the SPS technique under $480{ }^{\circ} \mathrm{C}$ and $70 \mathrm{MPa}$. Te powder was melted into a liquid during the SPS sintering, as its melting point is $450{ }^{\circ} \mathrm{C}$. The liquid Te was expelled, which caused the movement of $\mathrm{Bi}_{0.5} \mathrm{Sb}_{1.5} \mathrm{Te}_{3}$ nanograins. As shown in Figure 9(c), when the sample was cooled, dislocation arrays formed between the grain boundaries, and excess Te was expelled completely due to its extremely low solubility in the $\mathrm{Bi}_{0.5} \mathrm{Sb}_{1.5} \mathrm{Te}_{3}$ matrix. The maximum $Z T$ of 1.86 at $323 \mathrm{~K}$ was reached for the liquid-phase compacted samples (Te-MS), and only 1.3 at $323 \mathrm{~K}$ was obtained for the solid-phase compacted sample (S-MS).

\section{Bismuth sulfide and selenide based thermoelectric materials}

Since the elements Se and $\mathrm{S}$ are less expensive and less toxic than $\mathrm{Te},{ }^{[13,39]}$ great efforts have been made to investigate the thermoelectric performance of $\mathrm{Bi}-\mathrm{Se}$ and $\mathrm{Bi}-\mathrm{S}$ systems. Their detailed $\mathrm{TE}$ performance is illustrated in Table 2.

As presented in Figure 5(b), $\mathrm{Bi}_{2} \mathrm{Se}_{3}$ has a layered rhombohedral structure (R3m) similar to that of $\mathrm{Bi}_{2} \mathrm{Te}_{3}$, which is often described as a trigonal structure with 15 atoms per unit cell and lattice parameters $a$ $=4.14 \AA, c=28.64 \AA$. In a unit cell, there are two different types of Se layers, denoted as $\operatorname{Se}(1)$ and $\operatorname{Se}(2)$. The unit cell is packed with two Bi layers and three Se layers in the following pattern: $\mathrm{Se}(1)-\mathrm{Bi}-\mathrm{Se}(2)-$ $\mathrm{Bi}-\mathrm{Se}(1)$. There are only the van der Waals forces to provide bonding between the neighboring $\mathrm{Se}(1)$ planes. $\mathrm{Bi}_{2} \mathrm{Se}_{3}$ has a similar two-dimensional (2D) structure to that of $\mathrm{Bi}_{2} \mathrm{Te}_{3}$. It is a narrow-band-gap semiconductor with an energy gap of $0.3 \mathrm{eV}$. Although they have similar crystal structures, the thermoelectric performance of $\mathrm{Bi}_{2} \mathrm{Se}_{3}$ is much worse than that of $\mathrm{Bi}_{2} \mathrm{Te}_{3}$ due to the high thermal conductivity caused by the lighter atomic weight of Se. Hitherto, the highest $Z T$ values for $p$-and $n$-type $\mathrm{Bi}_{2} \mathrm{Se}_{3}$ have reached 0.41 and 0.75 , respectively. ${ }^{[40]}$

Due to the small size and high electronegativity of $\mathrm{S}, \mathrm{Bi}_{2} \mathrm{~S}_{3}$ possesses a three-dimensional (3D) orthorhombic structure [Figure 5(c)], which is totally different from that of its analogues, and no van der Waals interaction exists. It is a semiconductor with a $1.3 \mathrm{eV}$ direct band gap, high Seebeck coefficient, and low thermal conductivity at room temperature. The extremely low electrical conductivity of $\mathrm{Bi}_{2} \mathrm{~S}_{3}$, 
caused by the high electronegativity of $\mathrm{S}$, is still the main reason for its low thermoelectric properties. Liu et al. ${ }^{[41]}$ fabricated a net-like nanostructured $\mathrm{Bi}_{2} \mathrm{~S}_{3}$ sample via a simple hydrothermal method, and it yielded a $Z T$ of 0.5 at $623 \mathrm{~K}$, which is the highest value for a pure $\mathrm{Bi}_{2} \mathrm{~S}_{3}$ sample.

Apart from using pure $\mathrm{Bi}_{2} \mathrm{Se}_{3}$ and $\mathrm{Bi}_{2} \mathrm{~S}_{3}$, several strategies, including doping with $\mathrm{Ag}, \mathrm{Cu}, \mathrm{Cl}$, and $\mathrm{Br},{ }^{[42]}$ forming composites with other nanostructures (such as $\mathrm{ZnO}$ ),${ }^{[43]}$ and creating a deficiency of the chalcogen element, ${ }^{[44]}$ as well as the formation of solid solutions, ${ }^{[42 b, 42 e, 45]}$ have been investigated to improve the performance of the Bi-S and Bi-Se compounds. The detailed $Z T$ values and mechanisms are listed in Table 2. The highest ZT achieved in the Bi-S and Bi-Se systems was 0.8 at $773 \mathrm{~K}$ for the alloyed $\mathrm{Bi}_{2} \mathrm{SeS}_{2}$, which possesses extremely low thermal conductivity. $\mathrm{Br}$ doped $\mathrm{Bi}_{2} \mathrm{~S}_{3}$ yielded the maximum $Z T$ of 0.72 at $773 \mathrm{~K}$. The improved thermoelectric properties can be attributed to the optimized carrier concentration and the lower thermal conductivity caused by $\mathrm{Cu}^{+}$intercalation, $\mathrm{Br}$ substitution, and $\mathrm{Cu}$ nanoparticles. $^{[42 \mathrm{f}]}$

\subsubsection{Pb-X compounds (Group 2)}

The $\mathrm{Pb}-\mathrm{X}$ chalcogenides, especially $\mathrm{PbTe}$, are traditional high performance thermoelectric materials for mid-range temperature (600-800 K) applications. They crystallize in the $\mathrm{NaCl}$ crystal structure, with $\mathrm{Pb}$ atoms occupying the cation sites and $\mathrm{X}$ forming the anionic lattice. A small band gap of $0.32 \mathrm{eV}$ for PbTe allows it to be optimized for power-generation applications and easily doped to be either $n$ - or $p$ type with appropriate dopants. Although $\mathrm{PbTe}$ was one of the first materials investigated for $\mathrm{TE}$ generators, with an average $Z T$ around 1 , the full potential of the $\mathrm{Pb}-\mathrm{X}$ system for thermoelectric applications has recently been revealed to be far greater than commonly believed, as is listed in Table 3. Several strategies to enhance their TE performance are summarized in the following part.

(1) Band engineering

As schematically shown in Figure 10(a), the valence band of PbTe is composed of the orange light hole band (L) and the blue heavy hole band $(\Sigma)$ (with the heavy band located $0.2 \mathrm{eV}$ below the light band). At lower temperature, the transport properties are dominated by the $L$ band, which possesses 8 valley 
pockets with the same energy. This band structure allows easy and effective band structure engineering. ${ }^{[5]}$ With increasing temperature, the energy difference between the L and $\Sigma$ bands decreases, and once the difference is below $k_{\mathrm{B}} T$ (where $k_{\mathrm{B}}$ is Boltzmann's constant), band degeneracy occurs, and an increasing Seebeck coefficient is observed according to Equation (13), in which

$m^{*}, m_{b}^{*}$ and $N_{\mathrm{V}}$, are the effective mass after band degeneracy, the effective mass before band degeneracy, and the number of degenerate valley pockets with the same energy $\left[N_{\mathrm{V}}(\mathrm{L})=4\right.$ due to the symmetry structure of $\left.\mathrm{PbTe} ; N_{\mathrm{V}}(\Sigma)=12\right]$, respectively. ${ }^{[46]}$

$m^{*}=N_{V}^{2 / a} \times m_{b}^{*}$

As shown in Figure 10(b), ${ }^{[5]}$ the degeneracy of the $\mathrm{L}$ and $\Sigma$ bands is also sensitive to carrier concentration, which is easy to adjust by element doping.

With the advantages of this unique band structure, band structure engineering is easy to achieve with different dopants in PbTe, such as $\mathrm{Na}, \mathrm{K}, \mathrm{Cd}, \mathrm{Sm}, \mathrm{Sb}, \mathrm{Ag}$, etc. ${ }^{[32 c, 47]}$ It was found that $\mathrm{Na}$ is an effective dopant for the $p$-type $\mathrm{Pb}-\mathrm{X}$ system. The effects of $\mathrm{Na}$, as well as its solubility in the $\mathrm{Pb}$-X system, were investigated by He et al.. ${ }^{[48]}$ Their results show that $\mathrm{Na}$ has the highest solubility $(2 \mathrm{~mol} \%)$ in $\mathrm{PbS}$ and the lowest solubility $(0.5 \mathrm{~mol} \%)$ in PbTe and that doping with $\mathrm{Na}$ not only can lead to band degeneracy by tuning the carrier concentration, but also can introduce point defects and precipitates. In addition, segregation of $\mathrm{Na}$ at $\mathrm{PbTe} / \mathrm{PbS}$ interfaces resulted in cuboidal and truncated cuboidal morphologies for $\mathrm{PbS}$, because $\mathrm{Na}$ as a solute in PbTe has a higher energy than in $\mathrm{PbS}$, and its segregation at the (100) $\mathrm{PbTe} / \mathrm{PbS}$ interface decreased the total energy of the matrix/precipitate system. ${ }^{[49]}$ Besides tuning the carrier concentration to cause the band degeneracy, doping with elements such as $\mathrm{K}$ with a big size difference from the original $\mathrm{Pb}$ or Se atoms, ${ }^{[47 \mathrm{a}]}$ may cause distortion of the original cubic lattice and lead to asymmetry of the Brillouin zone, which finally increases $N_{\mathrm{V}}$ and the Seebeck coefficient.

Another important strategy in band structure engineering is resonant doping, which was explained in the case of $\mathrm{Sn}$ doped $\mathrm{Bi}_{2} \mathrm{Te}_{3}$ and elucidated in Figure 7. Tl was first resonantly doped into $p$-type PbTe. ${ }^{[32 b]}$ Then, Sb was both theoretically and experimentally proved to be an effective resonant dopant 
for $n$-type PbTe. ${ }^{[32 c, 50]} \mathrm{Al}$ was also resonantly doped into PbSe, leading to a ZT of 1.3 at $850 \mathrm{~K}$, which is close to the reported maximum value in the $n$-type $\mathrm{Pb}-\mathrm{X}$ system. ${ }^{[51]}$

\section{(2) Formation of endotaxial nanoprecipitates}

Compared with previous descriptions of nanostructure engineering in $\mathrm{Bi}-\mathrm{Te}$ system, endotaxial nanoprecipitates can be easily introduced into $\mathrm{Pb}-\mathrm{X}$ system by formation of solid solution. The pseudobinary $\mathrm{PbSe}-\mathrm{PbS},{ }^{[52]} \mathrm{PbTe}-\mathrm{PbS},{ }^{[31,47 \mathrm{~b}, 53]}$ and $\mathrm{PbTe}-\mathrm{PbSe}{ }^{[46]}$ systems have been studied and developed to a state of remarkably high performance. $\mathrm{PbTe}-\mathrm{PbS}$ exhibits well-defined nanostructures both on the PbTe-rich side and on the PbS-rich side. This system is known to exhibit bulk phase separation by nucleation and growth processes or spinodal decomposition, depending on the relative phase fraction. Similarly, in the $\mathrm{PbSe}-\mathrm{PbS}$ system, ${ }^{[52 \mathrm{c}]}$ which was previously believed to be a solid solution, it was discovered that nanostructures did occur and could be used to account for the low expected thermal conductivity.

The $\mathrm{PbTe}-\mathrm{PbSe}$ system is also a high performance thermoelectric system, but it is believed to be a solid solution due to the lack of nanostructure. Its low lattice thermal conductivity has been explained on the basis of point defects created by the Te/Se mixed occupation in the rock-salt structure and by the presence of dopants. ${ }^{[49,52 a, 53]}$ Besides the pseudo-binary system, the thermoelectric performance of ternary PbTeSeS was also investigated and proved to show high ZT over a broad temperature range. ${ }^{\text {[52a, 54] }}$

The endotaxial nanoprecipitates formed by the various compositions of lead chalcogenides can be divided into "coherent" precipitates, which are slightly mismatched with the matrix, and "semi-coherent" and "incoherent" precipitates [Figure 11], which show a clear boundary with the host. All kinds of precipitates can significantly reduce the thermal conductivity by different mechanisms and different effects. The coherent precipitates act as point defects and scatter short wavelength phonons due to their slight mismatch with the matrix. They also have a slight effect on the electrical conductivity. Since the incoherent nano-inclusions possess a large mismatch with the matrix, they selectively scatter mid- to long-wavelength phonons. The maximum $Z T$ of 2.3 was achieved in $3 \% \mathrm{Na}$ doped $(\mathrm{PbTe})_{0.8}(\mathrm{PbS})_{0.2}{ }^{[53]}$ 
due to the extremely low thermal conductivity arising from the various boundaries that ranged from coherent to incoherent, as well as the carrier concentration modulation. ${ }^{[53,54 \mathrm{~b}]}$

In addition to binary $\mathrm{Pb}-\mathrm{X}$, introducing other materials to form a composite is another important way to modify TE properties. For example, He et al. ${ }^{[55]}$ reported a new approach, displacement of the layered structure $\left(\mathrm{PbSnS}_{2}\right)$ rather than nanostructures or a solid solution, to enhance phonon scattering in a $\mathrm{PbTe}$ based thermoelectric composite. Extremely low lattice thermal conductivity $(0.8 \mathrm{~W} / \mathrm{m} \cdot \mathrm{K})$ was obtained for the composite, which is almost $30 \%$ of that of bulk PbTe at room temperature. This is an excellent example of a bulk PbTe thermoelectric material without nanostructures that can still greatly enhance phonon scattering and provide very low thermal conductivity.

(3) Full-scale-length scattering of phonons

Reducing thermal conductivity is a major approach to increase $Z T$ values of conventional thermoelectric materials. As mentioned in connection with the $\mathrm{Bi}-\mathrm{X}$ system, heat carrier phonons have a wide range of vibration frequencies, so carefully controlling the microstructure to form a full-scale scattering center is an effective way to minimize thermal conductivity to enhance $Z T$ values. ${ }^{[12,20 b, 56]}$ For example, a $Z T$ of 2.2 at $915 \mathrm{~K}$ was achieved via a combination of $\mathrm{Na}$ doping and nano-inclusions of SrTe in $\mathrm{PbTe}$. As presented in Figure 12, in contrast to the concept of decreasing the thermal conductivity by conventional nanostructure scattering, mesoscale structures with a size range of 100-1000 nm are effective for phonon scattering in the $\mathrm{Pb}-\mathrm{X}$ system. Pei et al. investigated the effective upper limit to the length-scale of microstructures where this effect becomes insignificant. ${ }^{[47 \mathrm{e}]}$

\subsection{Ternary A-B-X system (Group 3)}

Chalcogens can react with metals to form different varieties of complex crystal structures; an example is ternary A-B-X which offers a wealth of thermoelectric properties tuned through the crystal structure engineering. Ternary $\mathrm{I}_{\mathrm{B}}-\mathrm{III}_{\mathrm{A}}-\mathrm{VI}_{\mathrm{A}}$ compounds $\left(\mathrm{I}_{\mathrm{B}}=\mathrm{Cu}, \mathrm{Ag} ; \mathrm{III}_{\mathrm{A}}=\mathrm{Al}, \mathrm{Ga}, \mathrm{In} ; \mathrm{VI}_{\mathrm{A}}=\mathrm{S}, \mathrm{Se}, \mathrm{Te}\right)$ are usually p-type semiconductors with the diamond-like structure (or chalcopyrite structure) derived from the $\mathrm{II}_{\mathrm{B}}-$ 
$\mathrm{VI}_{\mathrm{A}}$ cubic zinc-blende structure. The $\mathrm{Zn}$ atom layers in the cubic $\mathrm{ZnTe}$ structure are cross-substituted by ordered $\mathrm{I}_{\mathrm{B}}-\mathrm{III}_{\mathrm{A}}$ atoms, leading to a tetragonal (chalcopyrite) structure with the space group I-42d, as shown in Figure 13(a). The $\mathrm{I}_{\mathrm{B}}-\mathrm{III}_{\mathrm{A}}-\mathrm{IV}_{\mathrm{A}}$ atoms are connected mainly by mixed covalent and ionic bonds to form a 3D network, with the chalcogen atoms residing in the tetrahedral voids formed by $\mathrm{I}_{\mathrm{B}}$ and $\mathrm{III}_{\mathrm{A}}$ atoms, which means that each anion is coordinated by two $\mathrm{I}_{\mathrm{B}}$ and two $\mathrm{III}_{\mathrm{A}}$ cations, whereas each cation is tetrahedrally coordinated by four anions. The existence of two different cations results in two different bond distances for $\mathrm{A}-\mathrm{X}$ and $\mathrm{B}-\mathrm{X}$, which yields lattice distortion and a smaller band gap than the original ZnTe type structure. ${ }^{[57]}$

There are no vacancies in the diamond like structure, and the $p$-type conductivity is mainly attributed to the close proximity of the top of valence band to the Fermi level. The low lattice thermal conductivity and electrical conductivity originate from the distortion of the unit cell caused by the structure, ${ }^{[57-58]}$ which could be simply characterized by the parameter $\delta$ ( $\delta=c / a$, where $c$ and $a$ are lattice parameters). The closer $\delta$ is to 2, the less distortion of lattice there is, and the higher the lattice thermal conductivity and electrical conductivity. If $\delta$ is around 2, the crystal field splitting energy reaches its minimum state, leading to a cubic-like highly degenerate electronic band-edge state, a large power factor, and a high $Z T$ value. For example, the $\delta$ (lattice distortion) of $\mathrm{CuInTe}_{2}$ was improved to nearly 2 by prolonging the annealing time, and a higher electrical conductivity and a $Z T$ of 1.18 were obtained, which are better than for less annealed counterparts. ${ }^{[58]}$ The maximum $Z T$ of 1.4 was first achieved in polycrystalline $\mathrm{CuGaTe}_{2}$ by Plirdpring et al. ${ }^{[59]}$ and later by Massaya et al. ${ }^{[60]}$ via ball milling and hot pressing. The reason for such a high $Z T$ value is mainly due to a sudden decrease in the thermal conductivity in the high temperature range. According to theoretical calculations, however, the $Z T$ of $\mathrm{CuGaTe}_{2}$ could reach 1.69 at $950 \mathrm{~K}$, with an optimized hole concentration of $3.7 \times 10^{19} \mathrm{~cm}^{-3}$. ${ }^{[61]}$ The thermoelectric performances of $\mathrm{I}_{\mathrm{B}}-\mathrm{III}_{\mathrm{A}}-\mathrm{VI}_{\mathrm{A}}$ compounds are listed in Table 4. To further enhance their performance, doping is a widely used as an effective method. ${ }^{[62]}$ A notable example is $\mathrm{CuInTe}_{2}$ doped with $\mathrm{Mn}$, which modifies its band structure. ${ }^{[57]}$ 
Deficiency of elements, alloying, and the formation of nanocomposites are also effective routes for enhancing their thermoelectric performance. ${ }^{[62 \mathrm{~h}, 63]}$

In addition to the formation of stoichiometric compounds, ternary $\mathrm{I}_{\mathrm{B}}-\mathrm{III}_{\mathrm{A}}-\mathrm{VI}_{\mathrm{A}}\left(\mathrm{I}_{\mathrm{B}}=\mathrm{Cu}, \mathrm{Ag} ; \mathrm{III}_{\mathrm{A}}=\mathrm{Al}\right.$, $\mathrm{Ga}, \mathrm{In} ; \mathrm{VI}_{\mathrm{A}}=\mathrm{S}, \mathrm{Se}, \mathrm{Te}$ ) also can form "non-stoichiometric" compounds with complex crystal structures. "Non-stoichiometry" means that the atomic ratio of $A: B: X$ deviates from 1:1:2. One special nonstoichiometric $n$-type semiconductor is $\mathrm{AgIn}_{5} \mathrm{Se}_{8},{ }^{[64]}$ which is not a typical chalcopyrite structure. This material belongs to the $\mathrm{I}_{\mathrm{B}}-\mathrm{III}_{\mathrm{A} 5}-\mathrm{IV}_{\mathrm{A} 8}$ family and the defective non-cubic ternary analogs of the $\mathrm{III}_{\mathrm{A} 2}-\mathrm{VI}_{\mathrm{A} 3}$ crystal structure. It is a pseudo-alloy of $\mathrm{AgInSe}_{2}$ and $\mathrm{In}_{2} \mathrm{Se}_{3}{ }^{[64]}$ Because of the small difference in bonding energies between Se-Ag and Se-In, Se could form bonds with either Ag or In, or both with moderate heat treatment. Therefore, with different heat treatments, different microstructures are achieved in one bulk sample, which is called microstructure modulation. $\mathrm{Cu}_{2} \mathrm{Ga}_{4} \mathrm{Te}_{7}$ is another pseudo alloy of $\mathrm{Cu}_{2} \mathrm{Te}$ and $\mathrm{Ga}_{2} \mathrm{Te}_{3}$ with a sphalerite structure (F-43m) and a band gap of $1.08 \mathrm{eV}$. In contrast to the chalcopyrite structure, abundant ordered defects exist in this structure. ${ }^{[62 \mathrm{a}]}$ By doping with $\mathrm{Zn}$, the concentration and type of defects were optimized to achieve a $Z T$ of 0.47 at $770 \mathrm{~K} .^{[62 \mathrm{a}]}$

Ternary $\mathrm{I}_{\mathrm{B}}-\mathrm{IV}_{\mathrm{A}}-\mathrm{VI}_{\mathrm{A}}$ compounds (e.g. $\mathrm{Cu}_{2} \mathrm{MSe}_{3}, \mathrm{M}=\mathrm{Sn}, \mathrm{Ge}$ ) also have the diamond-like structure which could be derived from the ZnTe structure by a substitution involving three Zn-Te unit cells (e.g. substituting two $\mathrm{Cu}$ atoms for two $\mathrm{Zn}$ atoms and one $\mathrm{Sn}$ or $\mathrm{Ge}$ atom for one $\mathrm{Zn}$ atom), while maintaining the ratio of the valence to the number of atoms present in the compound [Figure $13(\mathrm{~b})] \cdot{ }^{[65]} \mathrm{Cu}-\mathrm{Se}$ forms a complex charge carrying network, which has a great influence on the electrical conductivity, and the Ge or Sn atom acts like a filler atom, causing a reduction in lattice thermal conductivity. This structure leads to a low lattice thermal conductivity, moderate electrical conductivity, and thus a high ZT value. As Sn or Ge atoms contributes little to electrical conductivity, doping with other elements on this site or Ge substitution for Sn are commonly used to further enhance its thermoelectric performance. For example, maximum $Z T$ values of 0.62 in $\mathrm{Cu}_{2} \mathrm{Sn}_{0.925} \mathrm{In}_{0.075} \mathrm{Se}_{2.1} \mathrm{~S}_{0.9}$, and 1.14 in doped $\mathrm{Cu}_{2} \mathrm{Sn}_{0.9} \mathrm{In}_{0.1} \mathrm{Se}_{3}$ are reported, ${ }^{[66]}$ which are close to $p$-type commercial $\mathrm{Bi}_{2} \mathrm{Te}_{3}$-based materials. ${ }^{[58]} \mathrm{Cu}_{4} \mathrm{Sn}_{7} \mathrm{~S}_{14}$ is an $n$-type A-B- 
$\mathrm{X}$ semiconductor. It features a large Seebeck coefficient (close to $-600 \mu \mathrm{V} / \mathrm{K}$ at room temperature) and a low thermal conductivity, which are benefits of its complex structure. A small $Z T$ of 0.2 , however, was achieved at $600 \mathrm{~K}$ due to its low electrical conductivity. ${ }^{[67]}$

Contrast to diamond-like structure, $\mathrm{I}_{\mathrm{B}}-\mathrm{V}_{\mathrm{A}}-\mathrm{VI}_{\mathrm{A}}$ compounds $\mathrm{AgSbSe} \mathrm{C}_{2}$ and $\mathrm{AgBiS}$ are crystallized in the cubic rock salt structure $(\mathrm{Fm}-3 \mathrm{~m})$ at room temperature with disordered $\mathrm{Ag}$ and $\mathrm{Sb} / \mathrm{Bi}$ positions and ordered $\mathrm{Se} / \mathrm{S}$ atoms. The lone pair electrons on the $\mathrm{V}_{\mathrm{A}}$ elements (such as active $5 s^{2}$ pairs in $\mathrm{Sb}$ ) would distort the crystal lattice and lead to strong anharmonicity in the $\mathrm{V}_{\mathrm{A}^{-}}-\mathrm{VI}_{\mathrm{A}}$ bond and ultimately, low thermal conductivity, such as in $\mathrm{AgBiS}_{2}{ }^{[68]}$ The thermoelectric performance of $\mathrm{AgSbSe}_{2}$ can be significantly improved by the convergence of the valence band valleys through proper carrier engineering by doping. It has been reported that a $\mathrm{ZT}$ of above 1 was achieved in $\mathrm{AgSbSe}_{2}$ when it was doped with $\mathrm{Pb}$ and $\mathrm{Bi}^{[68 \mathrm{a}]}$

$\mathrm{Cu}_{3} \mathrm{SbX}_{4}(\mathrm{X}=\mathrm{S}, \mathrm{Se})$ compounds possess a tetragonal structure (I-42d) and have low thermal conductivity due to their complex structure. Substitution of other elements for Sb, doping, and deficiency of elements, as well as the formation of nanocomposites are used to further decrease its thermal conductivity and enhance the $Z T$ value. ${ }^{[69]} \mathrm{Cu}_{7} \mathrm{PSe}_{6}$, as a member of the argyrodite class, is a ternary ionic conductor with an extremely complex structure, which can be described as a cubic close-packing of $\mathrm{Se}^{2-}$ anions, with additional $\mathrm{Se}^{2-}$ and tetrahedral $\left[\mathrm{PSe}_{4}\right]^{3-}$ units alternately occupying the tetrahedral voids. ${ }^{[70]}$ Despite this complex structure and the presence of a light $\mathrm{V}_{\mathrm{A}}$ element $(\mathrm{P})$, extremely low thermal conductivity $[0.4-0.6 \mathrm{~W} /(\mathrm{m} \cdot \mathrm{K})]$ is achieved between 300 and $600 \mathrm{~K}$. This value is even lower than the glass limit calculated by Cahill's formulation. ${ }^{[70]}$

Compared with well crystallized $\mathrm{I}_{\mathrm{B}}-\mathrm{V}_{\mathrm{A}}-\mathrm{VI}_{\mathrm{A}}$ compounds, amorphous analogues usually have lower thermal conductivity. For example, $\mathrm{Cu}-\mathrm{As}$-Te compounds can be easily made in pure amorphous form by the conventional quenching method and thus do not need ultrafast-quenching techniques such as meltspinning. Vaney et al. ${ }^{[11]}$ first synthesized amorphous $\mathrm{Cu}_{15} \mathrm{As}_{30} \mathrm{Te}_{55}$, which possessed extremely low thermal conductivity. They then varied the conditions of heat treatment or consolidation to carefully 
adjust the degree of crystallinity to modify the thermoelectric properties of the material. The $Z T$ values of this type of material are relative low, however, typically no more than $0.2 .^{[161]}$

Besides the elements from the $\mathrm{III}_{\mathrm{A}}-\mathrm{V}_{\mathrm{A}}$ group, replacing the "B" component in A-B-X system with a transition metal, such as Fe, also can from diamond-like structure. The narrow-band-gap semiconductor $\mathrm{CuFeS}_{2}$ (chalcopyrite ore, band-gap energy, $E_{\mathrm{g}}=0.3-0.5 \mathrm{eV}$ ), composed of the earth-abundant, non-toxic, and inexpensive elements $\mathrm{Cu}, \mathrm{Fe}$, and $\mathrm{S}$, is such a compound with a tetrahedral structure and lattice parameters $a=5.289 \AA$ and $c=10.42 \AA \AA^{[72]}$ The $\delta$ of $\mathrm{CuFeS}_{2}$ is around 1.97, and a low thermal conductivity is expected. The maximum $Z T$ of 0.33 was achieved in $\mathrm{Cu}_{0.97} \mathrm{Fe}_{1.03} \mathrm{~S}_{2}$ at $700 \mathrm{~K}$ due to the increased lattice defects caused by element deficiency and the diminished carrier-magnetic-moment interactions at high temperature. ${ }^{[72 \mathrm{a}]}$ Qiu et al. reported the maximum $Z T$ of 1.2 at $900 \mathrm{~K}$ for a composite of $0.8 \mathrm{Cu}_{8} \mathrm{~S}_{4}+0.2 \mathrm{Cu}_{5} \mathrm{Fe}_{2} \mathrm{~S}_{4}{ }^{[73]}$

In addition to above $\mathrm{I}_{\mathrm{B}}-\mathrm{III}_{\mathrm{A}}-\mathrm{VI}_{\mathrm{A}}, \mathrm{I}_{\mathrm{B}}-\mathrm{IV}_{\mathrm{A}}-\mathrm{VI}_{\mathrm{A}}$ and $\mathrm{I}_{\mathrm{B}}-\mathrm{V}_{\mathrm{A}}-\mathrm{VI}_{\mathrm{A}}$ compounds, there are some other A-BX systems. For example, thallium-M-Te $(\mathrm{M}=\mathrm{Ag}, \mathrm{Bi}, \mathrm{Cr}, \mathrm{Zr}$, etc. $)$ has long been investigated as a family of good thermoelectric materials since the 1960s. ${ }^{[74]}$ Figure 14, as well as Table 4, presents the thermal conductivities and $Z T$ values of some typical compounds in this system, ${ }^{[74 \mathrm{~b}]}$ from which it is found that the $Z T$ of $\mathrm{Tl}_{9} \mathrm{BiTe}_{6}$ and $\mathrm{Ag}_{9} \mathrm{TlTe}_{5}$ reached 1.2 at 500 and $700 \mathrm{~K}$, respectively. ${ }^{[75]}$ The extremely low thermal conductivities of Tl-M-X compounds originate from two aspects. One is that the Tl-M-X system possesses an extremely well crystallized structure, For example, $\mathrm{Tl}_{9} \mathrm{BiTe} \mathrm{T}_{6}$ is a derivative of the isostructural compound $\mathrm{Tl}_{5} \mathrm{Te}_{3}$ and formed by replacing $\mathrm{Tl}^{3+}$ with $\mathrm{Bi}^{3+}$ in $2\left[\mathrm{Tl}_{5} \mathrm{Te}_{3}\right]=\left[\mathrm{Tl}^{+}\left(\mathrm{Tl}^{+} \mathrm{Tl}^{3+}\right) \mathrm{Te}^{2-}\right.$ $\left.{ }_{3}\right],{ }^{[74 a]}$ while $\mathrm{Ag}_{9} \mathrm{TlTe}_{5}$ has a unit cell including 120 atoms. ${ }^{[74 \mathrm{~b}]}$ The second reason is that the heavy atoms in this system greatly contribute to the low thermal conductivity by reducing phonon energies and the speed of sound. If the number of atoms per unit cell is $N$, the ratio of acoustic modes (vibrational modes that effectively transport heat) to the total number of modes will be $1 / N$. A large $N$ means a low proportion of acoustic modes, and low lattice thermal conductivity is expected. ${ }^{[74 \mathrm{~b}]}$ 
Mo-Sb-Te based compounds are another type of A-B-X, and their structures originate from metallic $\mathrm{Mo}_{3} \mathrm{Sb}_{7}$ (Im3m, 40 atoms per unit cell). By replacing two $\mathrm{Sb}$ atoms with Te, the system changes into a semiconductor with a big cubic void in its crystal structure. ${ }^{[76]}$ Thus in a similar way to the filled skutterudites, introducing other atoms into the big cubic void creates a rattling effect, and a significant decrease in the thermal conductivity could be achieved. ${ }^{[76-77]}$ For example, the maximum $Z T$ of 0.93 was achieved in Ni-filled Mo-Sb-Te. ${ }^{[76 a]}$ Chevrel phases with a general formula $\mathrm{M}_{x} \mathrm{Mo}_{6} \mathrm{X}_{8}(\mathrm{M}=$ metal; $\mathrm{X}=\mathrm{S}$, $\mathrm{Se}, \mathrm{Te})$ are another group of Mo-containing compounds with high potential as thermoelectric materials due to their complex structure. The host structure of a Chevrel phase consists of stacked $\mathrm{Mo}_{6} \mathrm{X}_{8}$ clusters with metallic cations (M) filling in the spaces between the $\mathrm{Mo}_{6} \mathrm{X}_{8}$ clusters, which act as rattling centers. In general, Chevrel phases crystallize in a trigonal structure (R3), and filling in metal ions would distort the hexagonal structure to a triclinic symmetry (P1). In addition to their low thermal conductivity, another important advantage of Chevrel phases is that their electrical properties appear to be dependent on the number of valence electrons per Mo atom; this number is referred to as the cluster-valence-electron count (cluster-VEC). ${ }^{[78]}$ The cluster-VEC is calculated by adding the valence electrons of the $\mathrm{M}$ atoms (VM) to the valence electrons of the Mo atoms $\left(V_{M 0}\right)$, subtracting the number of electrons required to fill the octets of the $\mathrm{X}$ atoms $\left(V_{X}\right)$ from the resultant valence electrons, and then dividing the resultant value by the number of Mo atoms $\left(N_{M \circ}\right)$, e.g. $V E C=\frac{N_{M \infty}}{V_{M}+V_{M o}-V_{\lambda}}$. Chevrel phases can have cluster-VECs in the range of 3.3 to 4.0, and the Seebeck coefficient and electrical conductivity could be easily optimized by modifying the cluster-VEC. ${ }^{[78]}$ The TE property of this group is also presented in Table 4.

Derived from A-B-X system, the quaternary $\mathrm{Cu}-\mathrm{C}-\mathrm{B}-\mathrm{X}$ system also exists, in which " $\mathrm{C}$ " is another metal element from either the transition metal or the main groups, such as $\mathrm{Ag}, \mathrm{Zn}, \mathrm{Fe}, \mathrm{Hg}$, In, $\mathrm{Ga}$, etc., ${ }^{[79]}$ while "B" is mainly Sn or Ge. These materials are usually used in solar cells due to their wide band gaps. Due to their low thermal conductivity, originating from their extremely complex crystal structures, they have also been widely investigated as thermoelectric materials; such as $\mathrm{Cu}_{2} \mathrm{ZnSnSe}_{4}$, the structure of which can be derived as an analogue of $\mathrm{ZnSe}$, with cross-substitution of other atoms so as to maintain an 
electron-to-atom ratio of 4 . Every Se atom resides in the tetrahedral voids formed by the cationic elements. The diverse interatomic distances (mainly Se with other atoms) and the electronegativity between the cations result in a natural superlattice structure of the tetragonal type (I-42d; $a=5.449 \AA ; c=10.757$ $\AA$ A). ${ }^{[79 b]}$ The complex crystal structure could be divided into conducting units and insulating units, such as the tetrahedral $\left[\mathrm{Cu}_{2} \mathrm{X}_{4}\right]$ slabs and tetrahedral $\left[\mathrm{SnZnX}_{4}\right]$ in $\mathrm{Cu}_{2} \mathrm{ZnSnX}_{4}[\mathrm{X}=\mathrm{S}, \mathrm{Se}] .{ }^{[79 a}$ Although a wide band gap is detrimental for electrical conductivity, it can effectively suppress the bipolar effect at high temperature, which occurs very often in the narrow-band-gap materials. The bipolar effect is explained in Figure 15. At high temperature, the main charge carriers, such as holes, in narrow-band-gap materials will hop from the valence band (VB) to the conduction band (CB) due to the strengthened random thermal motion and small band gap, which leads to compensation of carriers and changes in the DOS; no such phenomena occur, however, in wide-gap semiconductors. Usually the bipolar effect leads to a decreased Seebeck coefficient and enhanced thermal conductivity. It should be noted that in the presence of the bipolar effect, Equation (5) cannot be used to estimate lattice thermal conductivity. ${ }^{[80]}$ Due to the combination of these two advantages, high $Z T$ values can be expected in the quaternary materials. Typically, $Z T$ values of 0.95 and 0.90 are reported in $\mathrm{Cu}_{2} \mathrm{ZnSn}_{0.90} \mathrm{In}_{0.10} \mathrm{Se}_{4}$ and $\mathrm{Cu}_{2.1} \mathrm{Zn}_{0.9} \mathrm{SnSe}_{4}$, respectively. ${ }^{[79 a, 79 b]}$

\subsection{Sn-X and In-X systems (Groups 4 and 5)}

Despite the simple composition and crystal structure of the Sn-X and In-X systems, they are typical thermoelectric materials (Table 5) with good performance and low cost. As shown in Figure 16(a), SnSe adopts a layered orthorhombic crystal structure at room temperature. Each layer is made up of two-atomthick SnSe slabs (along the $b-c$ plane), with strong Sn-Se bonding within the plane of the slabs, which are then linked with weaker $\mathrm{Sn}-\mathrm{Se}$ bonding along the direction of the $a$ axis. The two-atom-thick SnSe slabs are corrugated and create a zig-zag accordion-like projection along the $b$ axis. ${ }^{[11]}$ Similarly, the crystal structure of $\operatorname{In}_{4} \mathrm{Se}_{3}$ is formed by a layered structure of $\left(\operatorname{In}_{3}\right)^{5+}$ clusters covalently bonded to Se ions 
in the $b-c$ plane, which are held together by van der Waals interactions along the $a$ axis, as shown in Figure 16(b). ${ }^{[15]}$ In contrast to conventional $\mathrm{Bi}_{2} \mathrm{Te}_{3}$, the layered structure of $\mathrm{SnSe}$ and $\mathrm{In}_{4} \mathrm{Se}_{3}$ is a distorted quasi-one-dimensional chain-like structure. Along this chain-like structure, the charge transport is inherently low dimensional with strong electron-phonon coupling (a structure called the Peierls distortion), leading to a decrease in the thermal conductivity. The occurrence of this phenomenon distorts the chain to form a two-dimensional superlattice structure and charge density wave (CDW) states. ${ }^{[11,15]}$

To explain the effects of the Peierls distortion, models with simple arrangements of metallic atoms are used, as shown in Figure 17, with distortion of the lattice and electron states of the system also appearing, due to the effects on the periodic arrangement of atoms of additional states [new band B in Figure 17(b)] and a small gap near the Fermi level. These are accompanied by decreased electrical conductivity and an increased Seebeck coefficient, so that the metallic material is transformed to a semiconductor or insulator. Therefore, the zigzag arrangement of different atoms (Peierls distortion structure) leads to a tunable band structure. For example, in the off-stoichiometric $\operatorname{In}_{4} \mathrm{Se}_{3-\mathrm{x}}$, the periodical Peierls distortion of the In-Se chains is disturbed by Se vacancies, leading to a big difference in the band structure, as shown in Figure 18. ${ }^{[81]}$ The semiconductor type band structure changes into a semi-metallic band with a deficiency of Se, and there is a flat band along the $\mathrm{X}-\Gamma$ and $\mathrm{Y}-\mathrm{S}$ symmetry lines, indicating that the holes in the $b$-direction are highly localized. ${ }^{[81]}$ The Peierls distortion and charge density wave could also lead to decreased thermal conductivity. ${ }^{[82]}$ In the $\mathrm{SnX}$ and $\mathrm{In}_{4} \mathrm{Se}_{3}$ systems, due to the off-stoichiometric valence of elements, an excess amount of charge carriers usually exists, for example, the hole concentration of SnTe is over $10^{21} \mathrm{~cm}^{-3} \cdot{ }^{[83]}$ Thus, the Se vacancies or element doping could simultaneously adjust the band structure and the carrier concentrations.

The thermoelectric performance of Sn-X and In-X can be further enhanced by the off-stoichiometric element ratio or doping effects, such as excess amount of Sn and deficiency of Se. ${ }^{[15,82-84]}$ Simultaneously, the weak van der Waals bonding between the adjacent layers (along the $a$-axis) is helpful for reducing the thermal conductivity. Due to the combination of these factors, single crystals of $\mathrm{SnSe}$ and $\mathrm{In}_{4} \mathrm{Se}_{3-x}$ showed 
excellent thermoelectric performance, with a $Z T$ of 2.6 at $923 \mathrm{~K}$ (p-type) and 1.48 at $705 \mathrm{~K}$ ( $n$-type), respectively. ${ }^{[1,15]} \mathrm{A}$ theoretical $Z T$ of 3.1 was reported for single-crystal $n$-type SnSe. ${ }^{[85]}$ Despite the effects of the original structure, element doping plays a significant role in the thermoelectric performance of SnTe because it possesses a similar band structure to PbTe, e.g., light and heavy hole bands located close to each other and just below the Fermi level. ${ }^{[83]}$ Thus, it is easy to adjust the band gap via element doping (such as resonant doping with In) and by modifying the band structure with Cd doping. ${ }^{\text {[32a, }}$ 83] Reports from Kanatzidis's group demonstrated that compared with single element doping, multi doping can lead to more efficient enhance on $Z T$ of SnTe. ${ }^{[83,86]}$ Very recently, Zhang et al ${ }^{[87]}$ improved the thermoelectric performance of SnTe by rational doping of Gd and Ag together. Doping Gd into SnTe effectively reduced the lattice thermal conductivity close to the theoretical minimum due to the introduction of nanoprecipitates. Further doping Ag into optimized $\mathrm{Gd}_{0.06} \mathrm{Sn}_{0.94} \mathrm{Te}$ significantly improved the Seebeck coefficient and power factor by tuning its composition to reduce the carrier density. It is very interesting that $\mathrm{Ag}$ doping led to the homogenous distribution of $\mathrm{Gd}$ in SnTe. The low thermal conductivity and large Seebeck coefficient in optimized sample (e.g. $\operatorname{Ag}_{0.11} \mathrm{Gd}_{0.06} \mathrm{Sn}_{0.94} \mathrm{Te}$ ) resulted in the maximum $Z T$ of $\sim 1.1$ at $873 \mathrm{~K}$.

\subsection{Layered structure materials (Group 6)}

Layered structure materials have long been recognized as good thermoelectric materials due to their special crystal structure and the possibility of manipulating charge carrier transport and phonon transport by modulation of different crystal planes. In addition to the aforementioned Bi-Te and Bi-Se systems, recent progress on the thermoelectric performance of layered $\mathrm{ACrX}_{2}(\mathrm{~A}=\mathrm{Ni}, \mathrm{Cu}$, or $\mathrm{Ag} ; \mathrm{X}=\mathrm{S}, \mathrm{Se})$, transition metal dichalcogenides (TMD), as well as the Bi-O-X system, is listed in Table 6. A good comprehensive review on layered structure metal chalcogenides materials by Jood et al. was published in 2015. ${ }^{[7]}$ Here, we mainly focus on the following materials, which are not described in detail.

\subsubsection{Ternary $\mathrm{ACr} \mathrm{X}_{2}$ layered structure}


As a group of magnetic materials, $\mathrm{ACrX}_{2}(\mathrm{~A}=\mathrm{Ni}, \mathrm{Cu}$, or $\mathrm{Ag} ; \mathrm{X}=\mathrm{S}, \mathrm{Se})$ compounds possess a trigonal layered structure $(\mathrm{R} 3 \mathrm{~m})$, which can be described as $\mathrm{CdI}_{2}$-type layers of $\mathrm{CrX}_{2}^{-}$in which the $\mathrm{Cr}^{3+}$ cations are in a distorted octahedral coordination to $\mathrm{X}^{2-}$ anions, with the interlayer spaces being filled by the copper or silver ions occupying tetrahedral sites, such as in the structure shown in Figure 19(a). The atoms inside the triple layers of $\mathrm{CrX}_{2}$ are bound to each other by strong ionic bonds, while the neighboring triple layers are bound to each other by weak van der Waals forces. Thus, $\mathrm{CuCrX}_{2}$ and $\mathrm{AgCrX}_{2}$, which show an order-disorder transition of $\mathrm{Cu}$ or $\mathrm{Ag}$ atoms around $400^{\circ} \mathrm{C}$, are also PLEC materials. ${ }^{[88]}$ Thus, they show excellent thermoelectric performance. Tewari et al. and Gascoin et al. reported the maximum $Z T$ of 2 at $300 \mathrm{~K}$ and 1 at $848 \mathrm{~K}$ for $\mathrm{CuCrS}_{2}$ and $\mathrm{AgCrS}_{2}$, respectively. ${ }^{[88]} \mathrm{A} Z T$ of 1.4 was achieved in sandwich-like $\left(\mathrm{AgCrSe}_{2}\right)_{0.5}\left(\mathrm{CuCrSe}_{2}\right)_{0.5}$ at $773 \mathrm{~K} .^{[89]}$ The thermoelectric performance of this group of materials strongly depends on their synthesis, however. For example Tewari et al. ${ }^{\text {[88a] }}$ obtained highly textured $\mathrm{CuCrS}_{2}$ via a specific heat treatment process, which finally led to high electrical conductivity in the sample, but the $\mathrm{CuCrS}_{2}$ sample fabricated by ball-milling and SPS methods exhibited poor thermoelectric performance with a $Z T$ of $0.11 .^{[90]}$

\subsubsection{Layered transition metal dichalcogenides}

As one kind of transition metal dichalcogenide (TMD), $\mathrm{TiS}_{2}$ also has a layered structure with a trigonal space group (P3m1). As shown in Figure 19(b), the most stable form of $\mathrm{TiS}_{2}\left(1 \mathrm{~T}-\mathrm{TiS}_{2}\right.$, crystallizing in a layered $\mathrm{CdI}_{2}$-like structure) consists of sheets of face-sharing $\mathrm{TiS}_{6}$ octahedra forming S-Ti-S sandwich layers, where a $\mathrm{Ti}$ sheet is sandwiched between two sulfur sheets. Atoms within the S-Ti-S sheets are bound by strong covalent interactions, whereas the bonding between the layers is only due to the weak van der Waals forces. Therefore, as a layer-structured compound with a van der Waals gap, $\mathrm{TiS}_{2}$ is well known for its capability of intercalation by a wide range of both organic and inorganic materials to adjust its performance. ${ }^{[91]}$ Detailed performances of $\mathrm{TiS}_{2}$ related materials have been reported by Jood et al. ${ }^{[7]}$

Because of the wide van der Waals gap, excess Ti atoms can also be inserted into the layers, leading to the formation of $\mathrm{Ti}_{1+x} \mathrm{~S}_{2}$. The Seebeck coefficient and electrical resistivity of $\mathrm{Ti}_{1+x} \mathrm{~S}_{2}$ decrease with 
increasing titanium content because the carrier concentration increases with $x$. A high power factor was found for a near-stoichiometric composition. ${ }^{\left[{ }^{92]}\right.}$ Hence, despite the merits of its low cost, low toxicity, low density, and simple composition, the main difficulty for the wide application of this material is the synthesis of stoichiometric $\mathrm{TiS}_{2}$, which is usually prepared by sulfurization of $\mathrm{TiO}_{2}$ by $\mathrm{CS}_{2} .^{[7,92-93]}$ The atmosphere, pressure, temperature, and synthesis conditions can seriously affect sulfurization. Besides $\mathrm{TiS}_{2}$, other transition metal disulfides (TMD) have also been investigated, such as $\mathrm{MoS}_{2}, \mathrm{WSe}_{2}, \mathrm{TiS}_{3}$, etc. ${ }^{[94]}$

\subsubsection{Bi-O-X system}

The Bi-O-X system features another new type of layered structure with complex crystal structure. As an example, the crystal structure (I4/mmm) of $\mathrm{Bi}_{2} \mathrm{O}_{2} \mathrm{Se}$ is illustrated in Figure 19(c), which consists of tetragonal $(\mathrm{BiO})_{\mathrm{n}}$ layers with Se occupying interlayer positions. ${ }^{[95]}$ This system has a moderate negative Seebeck coefficient but rather low electrical conductivity due to the strong electronegativity of O atoms. As an important route towards tuning electrical conductivity, deficiency of $\mathrm{Bi}$ is reported to be an effective approach for increasing the thermoelectric performance of the Bi-O-Se system. ${ }^{[96]}$

\subsection{AST, LAST, TAGS and GeTe based systems (Group 7)}

Binary GeTe, ternary Ag-Sb-Te (AST), and quaternary Ag-Sb-Pb-Te (LAST) and Ag-Sb-Ge-Te (TAGS) based materials are grouped together because their thermoelectric properties can be enhanced through the formation of endotaxial nanoprecipitates via self-formed inhomogeneities due to spinodal decomposition. Spinodal decomposition is an atomic level mechanism in which a metastable single phase (i.e., a solid solution) generates a bi-phase nanoscale structure by phase segregation. It can occur when the phase diagram exhibits a miscibility gap. Moreover, the spinodal decomposition does not result in a nucleation-growth process; instead, coherent nanodomains are uniformly created throughout the whole matrix via a diffusion-segregation procedure. Therefore, both the composition and temperature play significant roles in the spinodal decomposition. 
The thermoelectric performance of these materials is very sensitive to their compositions and syntheses. Even for the same composition, the $Z T$ values always vary with different synthesis routes. Therefore, their application has long been hindered by the issues of the reproducibility, stability, and complex composition. Table 7 summarizes the thermoelectric properties of materials from group 7.

\subsubsection{Ag-Sb-Te (AST) system}

$\mathrm{AgSbTe}_{2}$ features the cubic rock salt structure (Fm-3m), with disordered $\mathrm{Ag}$ and $\mathrm{Sb}$ atoms randomly occupying the $\mathrm{Na}$ sites. With a certain degree of $\mathrm{Ag}$ and $\mathrm{Sb}$ atomic ordering and different ratios, however, the symmetry can be broken, and the tetragonal $\mathrm{P} 4 \mathrm{mmm}$ or the primary cubic Pm-3m structure can be formed. ${ }^{[97]}$ The disordered lattice structure makes the dominant contribution to low lattice thermal conductivity through Umklapp and intrinsic phonon-phonon scattering processes, without a substantial reduction in its electrical conductivity. ${ }^{[98]}$ This special structure makes this material extremely attractive for thermoelectric application. Moreover, $\mathrm{AgSbTe}_{2}$ can be recognized as a solid solution between $\mathrm{Ag}_{2} \mathrm{Te}$ and $\mathrm{Sb}_{2} \mathrm{Te}_{3}$. Spinodal decomposition could also occur in it with changes in composition. Single-phase $\mathrm{AgSbTe}_{2}$ can only be fabricated in a certain composition range with a ratio of $\mathrm{Ag}_{2} \mathrm{Te} / \mathrm{Sb}_{2} \mathrm{Te}_{3}$ smaller than 1. ${ }^{[97]}$ Accordingly, Zhang et al. ${ }^{[97]}$ synthesized composites in situ with $\mathrm{Ag}_{2} \mathrm{Te}$ or $\mathrm{Sb}_{2} \mathrm{Te}_{3}$ embedded in the $\mathrm{AgSbTe}_{2}$ matrix, by utilizing the change in solid solubility near the single-phase region boundaries. The nanodomain boundaries led to a further decrease in the thermal conductivity and a $Z T$ of 1.53 was obtained in this material.

\subsubsection{Ag-Pb-Sb-Te (LAST) system}

The LAST system refers to the solid solutions of PbTe and $\mathrm{AgSbTe}_{2}$ (both $\mathrm{NaCl}$ type crystals, Fm-3m) because their lattice parameters follow the Vegard law. The nanoscale inclusions of minor phase in LAST-m exhibit coherent or semi-coherent interfaces with the matrix. This seems to be a consequence of the unique properties of spinodal decomposition as well as their similar crystal structures. Therefore, these nanodomains are only minimally detrimental to the charge carriers. The nanodomains in LAST show a preferential orientation along the (001) planes, with a high degree of lattice strain at the interface, which 
is still not fully understood. ${ }^{[4]}$ Although these materials possess complicated compositions, their crystal structures can be derived from simple cubic phase $\mathrm{PbTe}$ or $\mathrm{AgSbTe}_{2}$. Hence, with a less distorted lattice or intrinsic defects, this material offers moderate to high electrical conductivity. The symmetry of the crystal structure and the special band structure are responsible for the high Seebeck coefficient. Thus, it is reasonable to expect high $Z T$ values in these materials, e.g. Hsu et al. ${ }^{[99]}$ reported a high $Z T$ value $(Z T=$ 2.20 at $800 \mathrm{~K}, n$-type) for $\mathrm{AgPb}_{18} \mathrm{SbTe}_{20}$ alloys (LAST-18). As an example of the effects of material processing, Li et al. ${ }^{[100]}$ synthesized $\mathrm{AgPb}_{21} \mathrm{SbTe}_{20}$ by combining mechanical alloying and the spark plasma sintering process. With the advantages of the refined grains and nanostructures produced by repeating milling and SPS processes, simultaneous enhancement of the electrical conductivity and the Seebeck coefficient could be achieved, leading to a 50\% increase in $Z T$ value.

\subsubsection{Ag-Ge-SbTe (TAGS) system}

$(\mathrm{GeTe})_{\mathrm{m}}\left(\mathrm{AgSbTe}_{2}\right)_{100-\mathrm{m}}$ compounds, commonly referred to as 'TAGS-m', can be considered as pseudo-binary compounds of $\mathrm{AgSbTe}_{2}$ and $\mathrm{GeTe}$, and they represent some of the best traditional thermoelectric materials. ${ }^{[101]}$ This material system possesses high electrical conductivity, a high Seebeck coefficient, and relatively low thermal conductivity on the GeTe-rich side, especially for TAGS with 80 and $85 \mathrm{~mol} \%$ GeTe (denoted as TAGS-80 and TAGS-85). The high power factor originates from the coexistence of the high carrier concentration and the high Seebeck coefficient. Both theoretical and experimental investigations indicate that TAGS are highly degenerate semiconductors similar to PbTe ${ }^{[102]}$ and their valence bands consist of two sub-bands with different effective masses. This suggests that the presence of a second, heavy valence band causes the dependence of the Seebeck coefficient on the hole density, also known as the Pisarenko relation [Equation (4)], to undergo a deviation when the carrier concentration increases and the Fermi level moves further into the heavy band. Above about $500 \mathrm{~K}$, TAGS are in a face-centered-cubic Fm-3m phase; below that temperature, they are in a rhombohedral R3m phase. ${ }^{[101]}$ Thus, with increasing temperature, band degeneracy appears due to the improved symmetry of the crystal structure. Based on LAST and TAGS materials, several similar systems with 
spinodal decomposition have been developed, such as $\mathrm{AgPb}_{\mathrm{m}} \mathrm{Sn}_{\mathrm{n}} \mathrm{SbTe}_{2+\mathrm{m}+\mathrm{n}}$ (LASTT-m), $\mathrm{NaPb}_{\mathrm{m}} \mathrm{SbTe}_{2+\mathrm{m}}$ (SALT-m), $\mathrm{NaPb}_{\mathrm{m}} \mathrm{Sn}_{\mathrm{n}} \mathrm{SbTe}_{\mathrm{m}+2+\mathrm{n}}$ (SALTT-m), $\mathrm{KPb}_{\mathrm{m}} \mathrm{SbTe}_{2+\mathrm{m}}$ (PLAT-m), etc., which possess a similar crystal structure and exhibit spinodal decomposition at moderate temperatures and compositions, as described in a comprehensive review by the Kanatzidis group. ${ }^{[4]}$ The progress on this type of material from 2010 is also summarized in Table 7.

\subsubsection{GeTe system}

GeTe features a large deviation from stoichiometry towards tellurium and a high density of defects that exist as doubly ionized metal vacancies. As a result, GeTe always exhibits $p$-type conductivity with a high carrier concentration $\left(10^{20} \mathrm{~cm}^{-3}\right.$ to $\left.10^{21} \mathrm{~cm}^{-3}\right),{ }^{[103]}$ which leads to high electrical conductivity and thermal conductivity. Element doping is an effective way to improve the thermoelectric properties of GeTe by reducing its hole concentration and/or introducing a secondary phase into the matrix to reduce its thermal conductivity, e.g. Mn, Yb doped GeTe. ${ }^{[104]}$ At ambient temperature, the thermodynamically stable pseudo-binary compounds of the homologous series $\mathrm{Ge}_{n} \mathrm{Sb}_{2} \mathrm{Te}_{\mathrm{n}+3}$ consist of tetradymite-type $\mathrm{Sb}_{2} \mathrm{Te}_{3}$ slabs that are formally enlarged by $n$ layers of additional GeTe. The crystal structure of these compounds consists of layer-like distorted rock-salt-type building blocks separated by van der Waals gaps between the Te atomic layers terminating the individual slabs. ${ }^{[105]}$ These distorted octahedral voids are surrounded by Te atoms, so that the van der Waals gaps can be viewed as layer-like ordered cationic defects, which become randomly disordered in a cubic phase, where $\mathrm{Ge}, \mathrm{Sb}$, and vacancies occupy the cation positions, and Te atoms occupy the anion positions. Moreover, for GeTe rich samples with $n \geq 3$, quenching their high temperature cubic phase yields a metastable pseudo-cubic phase, which easily undergoes spinodal decomposition. ${ }^{[105-106]}$

Another big issue for utilizing GeTe based materials lies in their narrow optimum operating temperature, ranging from $680 \mathrm{~K}$ to $780 \mathrm{~K}$, because a phase transition between the rhombohedral lattice (R3m) and the cubic phase (Fm-3m) occurs at about $700 \mathrm{~K}$. The instability of the cubic phase is probably due to their high concentration of vacancies, which involves "incomplete" coordination spheres and a 
large energy gain when ordered structures are formed. ${ }^{[107]}$ Therefore, decreasing the vacancies, such as by replacing $\mathrm{Ge}^{2+}$ with double monovalent cations, gives a cation/anion ratio closer to 1 and increases the temperature range in which the materials can be applied, as demonstrated by $(\mathrm{GeTe})_{11}\left(\mathrm{LiSbTe}_{2}\right)_{2} \cdot{ }^{[107]}$ The maximum ZT of 1.90 at $773 \mathrm{~K}$ for a $p$-type heterostructure consisting of a Ge-Sb-Te matrix and $\mathrm{CoGe}_{2}$ precipitates was achieved with good reproducibility. ${ }^{[108]}$ The pseudo-binary PbTe-GeTe phase diagram shows unlimited mutual solubility of its end members in both liquid and solid states at high temperature, but phase separation driven by spinodal decomposition (miscibility gap) exists below $860 \mathrm{~K} .{ }^{[103,109]}$

\subsection{Binary and ternary PLEC chalcogenides (Group 8)}

The concept of the phonon liquid electron crystal (PLEC) ${ }^{[16]}$ is very similar to that of the phonon glass electron crystal (PGEC), which can simultaneously exhibit high electrical conductivity and low thermal conductivity. This is mainly composed by binary or ternary chalcogenides of $\mathrm{Cu}$ or Ag. Although this concept was proposed in 2012, investigations of this type of materials have a long history. ${ }^{[110]}$ The TE properties of PLEC crystals are summarized in Table 8; and several PLEC materials (such as $\mathrm{AgBiSe}_{2}$ and $\mathrm{Cu}_{7} \mathrm{PSe}_{6}$ ) have already been described in other series. ${ }^{[70,111]} \mathrm{Cu}_{2} \mathrm{Se}$ is chosen as an example to describe the mobility of cations at high temperature. The crystal structure of high temperature cubic $\mathrm{Cu}_{2} \mathrm{Se}$ is presented in Figure 20, in which the Se atoms are stacked in a close-packed arrangement, with the layers in the sequence of $\mathrm{ABC}$. The $\mathrm{Cu} 1$ position is located exactly at the center of the tetrahedral interstice, whereas the $\mathrm{Cu} 2$ and $\mathrm{Cu} 3$ atoms are located close to a triangular face of the tetrahedron. Each tetrahedron is always occupied by a copper atom, although the copper atom can be disordered in a static or dynamic manner, which means that the $\mathrm{Cu}^{+}$ions can easily drift among the $\mathrm{Cu} 1, \mathrm{Cu} 2$, and $\mathrm{Cu} 3$ positions inside the tetrahedron. ${ }^{[112]}$ The PLEC compounds show outstanding thermoelectric performance, as demonstrated by the $Z T$ of $\mathrm{Cu}_{2} \mathrm{Se}$ and $\mathrm{Cu}_{2} \mathrm{~S}$. Liu et al. ${ }^{[17]}$ reported a $Z T$ value of 2.3 at $400 \mathrm{~K}$ for an Idoped $\mathrm{Cu}_{2} \mathrm{Se}$ sample due to the critical scattering of electrons and phonons, which means the simultaneous achievement of the minimum thermal conductivity and the maximum electrical conductivity. 
Due to the liquid behavior of $\mathrm{Cu}^{+}$, even for polycrystalline bulk $\mathrm{Cu}_{1.97} \mathrm{~S}$ fabricated by a simple meltsolidification method, a maximum $Z T$ of 1.9 at $970 \mathrm{~K}$ was achieved. ${ }^{[13]}$ Nevertheless, the thermoelectric performance of their analogue, $\mathrm{Cu}_{2-x} \mathrm{Te}$, is rather low, ${ }^{[114]}$ which is attributed to its thermal instability arising from the loss of Te element, which leads to changes in the composition and crystal structure.

In addition to binary $I_{B}-V I_{A}$ chalcogenides, some ternary $I_{B}-V_{A}-V I_{A}$ materials are also good PLEC crystals. For example, as shown in Figure $10(\mathrm{c}), \mathrm{AgBiSe}_{2}$ is a $p$-type semiconductor and crystallizes in the hexagonal phase with parameters $a=4.18 \AA$ and $c=19.67 \AA$ (space group $\mathrm{P} 3 \mathrm{~m} 1$ ) at room temperature. This material undergoes a reversible hexagonal-rhombohedral-cubic phase transition, ${ }^{[11]}$ and in the cubic structure, the Se atoms form a rigid crystal lattice, while the $\mathrm{Ag}$ and $\mathrm{Bi}$ ions can change places with each other or move. This order-disorder phase transition leads to drastic changes in the electrical and/or thermal properties. For example, the thermal conductivity of the material was decreased due to the enhanced phonon scattering by highly moveable cations, and a maximum $Z T$ of 1.5 was reported at 700 $\mathrm{K} .{ }^{[111]} \mathrm{Nb}$ doping could transform $\mathrm{AgBiSe}_{2}$ into an $n$-type semiconductor and enhance the thermal power by increasing the carrier concentration. A maximum $Z T$ of 1 was obtained at $773 \mathrm{~K}$ for $\mathrm{Nb}$ doped $\mathrm{AgBiSe}_{2} \cdot{ }^{[115]}$

\subsubsection{Anomalous TE properties during phase transition of PLEC materials}

There is a notable effect of the phase transition on the thermoelectric properties of these PLEC materials. ${ }^{[17,111,116]}$ As phase transitions usually involve changes in the atomic configuration, big transformations of the electronic or the thermal transport properties could take place and give rise to unexpected physical properties of solids. PLEC materials usually undergo an order (low temperature rigid phase)-disorder (high temperature PLEC phase) phase change. In the rigid ordered structure, the rigid crystal lattice yields relatively high electrical conductivity and thermal conductivity, while the highly movable ions in the disordered phase strongly suppress the thermal conductivity and slow the transport of charge carriers. There have been some reports that the maximum $Z T$ point appeared near the phase transition temperature because of the simultaneously optimized power factor and thermal conductivity, ${ }^{[17}$, 
${ }^{116 a]}$ although the phase transition temperature window is rather narrow and there are difficulties in the accurate measurement of thermal conductivity during the phase change. The thermoelectric performance at the phase transition temperature has rarely been investigated.

Another typical phenomenon is a transition of the conduction type arising from the change in the crystal structure. ${ }^{[111,116 \mathrm{~b}, 116 \mathrm{c}]}$ As a typical example, Han et al. ${ }^{[116 \mathrm{~b}]}$ prepared CuAgSe nanoparticles using a low-cost, effective wet chemical method and found that this material underwent a sudden conductivity transition from $n$-type to $p$-type because the crystal structure was transformed from a mixture of orthorhombic and tetragonal to a pure high temperature cubic PLEC phase, as shown in Figure 21(a). This transition was further explained by band structure calculations [Figure 21(b-c)]. Figure 21(b) illustrates the calculated band structure of the tetragonal phase at the $\Gamma$ point near the Fermi level. It clearly shows that one of conduction bands crosses the Fermi level along the $Z-\Gamma$ and $\Gamma-X$ lines, while the top of the valence band is located just below the Fermi level. Therefore, the low-temperature tetragonal $\mathrm{CuAgSe}$ should possess two kinds of charge carriers. The main charge carriers are electrons, however, and the conductivity is $n$-type. For the high temperature cubic phase [Figure 21(c)], however, the band gap has disappeared, and two valence bands with positive charge carrier effective mass and one conduction band with negative charge carrier effective mass have appeared near the Fermi level. The estimated total effective mass is positive because of the presence of both valence bands and the bigger curvature, resulting in a positive Seebeck coefficient.

\subsubsection{Effects of element deficiency on PLEC materials}

The effects on thermoelectric performance of defects formed due to non-stoichiometric elemental ratio are also notable. ${ }^{[116 \mathrm{~d}, 117]}$ Typically, in the binary $\mathrm{Cu}_{2} \mathrm{X}$ system, it is easy to form $\mathrm{Cu}$ vacancies, and the composition changes from stoichiometric $\mathrm{Cu}_{2} \mathrm{X}$ to non-stoichiometric $\mathrm{Cu}_{2-x} \mathrm{X}$. The vacancies caused by $\mathrm{Cu}$ deficiency play several significant roles in the thermoelectric properties: (i) the vacancies as point defects directly tune the carrier concentration and conduction type of a PLEC; ${ }^{[116 d, 117 b]}$ (ii) the orderdisorder phase transition temperature could also vary with $x$, because the vacancies may offer diffusion 
paths and accelerate the diffusion process, ${ }^{[118]}$ (iii) the existence of these vacancies leads to a percolation effect on electrical conductivity, as charge carriers could also pass through them, ${ }^{[17 \mathrm{a}]}$ which is very similar to the concept of the energy filtering effect (EFE, Figure 6). The vacancies can be regarded as a conductive medium with an energy barrier, and the conductivity of the vacancies could be described by the percolation law presented in the literature. ${ }^{[117 a]}$ Thereby element deficiency is an efficient way to adjust thermoelectric performance of PLEC materials.

\subsubsection{Mosaic crystals of PLEC materials}

Besides the conventional routes (e.g. nanostructuring, ${ }^{[119]}$ alloying, ${ }^{[120]}$ forming nanocomposites ${ }^{[121]}$ and full-scale scattering ${ }^{[122]}$ ) used to further enhance thermoelectric performance, He et al. ${ }^{[123]}$ proposed the concept of a "mosaic crystal" to explain the enhanced thermoelectric performance of $\mathrm{Cu}_{2} \mathrm{~S}_{0.5} \mathrm{Te}_{0.5}$ bulk materials with a $Z T$ of 2.2 at $1000 \mathrm{~K}$. As presented in Figure 22, in most cases, bulk thermoelectric crystals are composed of many crystallites with various sizes and random orientations, which are referred to as polycrystalline specimens. Especially in the case of polycrystalline nanobulks, the presence of a huge amount of grain boundaries leads to a simultaneous decrease in thermal conductivity and electrical conductivity. On the contrary, in a large bulk single-crystal material, the electrical conductivity and thermal conductivity are both relatively high due to the lack of grain boundaries. In contrast to the random orientations in polycrystalline or nanocrystal materials, the blocks in a mosaic crystal exhibit a nearly identical orientation, and the bulk appears to be a single crystal from the macroscale point of view, but it contains a number of small-angle grain boundaries. Therefore, the mosaic crystal is much like a single crystal with grain boundaries, and an effect similar to critical scattering is achieved, ${ }^{[17]}$ e.g. phonons could be scattered by the presence of the grain boundaries, while charge carriers are seldom affected by small angle grain boundaries.

The formation of mosaic crystals is not easy, however. To form a mosaic crystal, a fast cooling speed is usually necessary to suppress the diffusion and accumulation of structural defects at the surface. In the meantime, possible compositional variation is more important, because it results in large internal stress to 
further underscore the imperfection of the crystals, such as in the case of $\mathrm{Cu}_{2} \mathrm{~S}_{0.5} \mathrm{Te}_{0.5}$. Although the cooling speed is not high, the big size difference between $S(1.04 \AA)$ and Te $(1.70 \AA)$ ions causes large internal stress in the crystal, which needs to be released by the formation of sub-grain boundaries. ${ }^{[123]}$

\subsubsection{Stability of PLEC materials}

Despite the high thermoelectric performance of $\mathrm{Cu} / \mathrm{Ag}$ based PLECs, a big obstacle hindering their wide application is their poor stability at high temperature. In virtue of the high mobility of $\mathrm{Cu}^{+}$, degradation of the composition and performance appear after several cycles of heating and cooling, even in a protective atmosphere. ${ }^{[124]}$ One efficient way to increase thermal stability is to take advantage of the pinning effect of $\mathrm{Fe}$ atoms on the $\mathrm{Cu}$ sites, which can greatly suppress the migration of copper ions. ${ }^{[73]}$ Because $\mathrm{Fe}$ atoms are more reactive than $\mathrm{Cu}$ atoms and are randomly located at the same crystallographic sites as the mobile $\mathrm{Cu}$ ions, the migration of $\mathrm{Cu}$ ions can be blocked or interrupted. ${ }^{[73]}$ However, it is very interesting that $\mathrm{CuAgSe}$ shows intrinsically good cycling stability. ${ }^{[16 \mathrm{~b}]}$

\subsection{Other metal chalcogenides (Group 9)}

\subsubsection{Ga-Te system}

$\mathrm{Ga}_{2} \mathrm{Te}_{3}$ is one of the typical defective semiconductors containing atoms from the $\mathrm{III}_{\mathrm{A} 2}$ and $\mathrm{VI}_{\mathrm{A} 3}$ groups, with a band gap of $1.65 \mathrm{eV}$. It has the same crystal structure as a defective zinc-blende cubic crystal [F43m, Figure 23(a)]. Due to the valence mismatch between the cations and anions, two thirds of the ordered Ga atoms occupy the $4 \mathrm{c}$ Wyckoff positions $(1 / 4,1 / 4,1 / 4)$, and the remaining one third of $4 \mathrm{c}$ positions are vacancies, ${ }^{[125]}$ so that the chemical formula of $\mathrm{Ga}_{2} \mathrm{Te}_{3}$ can be described as $\mathrm{Ga}_{2} \mathrm{~V}_{\mathrm{A1}} \mathrm{Te}_{3}$, where $\mathrm{V}_{\mathrm{A}}$ means vacancy. Moreover, there are periodical self-assembled 2D vacancy planes [(111) planes] that wrap the nanostructured domains, as shown in Figure 23. Thus, $\mathrm{Ga}_{2} \mathrm{Te}_{3}$ shows low thermal conductivity. ${ }^{[126]}$ The engineering of the vacancy planes via doping or alloying has been found to be an effective way to control the thermoelectric performance of this kind of material. ${ }^{[125-127]}$ For example, because the difference in electronegativity (0.09) between $\mathrm{Cu}$ and $\mathrm{Ga}$ is much smaller than that between 
$\mathrm{Cu}$ and $\mathrm{Te}(0.2), \mathrm{Cu}$ tends to occupy the Ga lattice sites or vacancies rather than Te sites to form covalent bonds with Te. As a consequence, the periodicity of the self-assembled 2D vacancy planes is disturbed, releasing the wrapped nanostructured domains, which can scatter phonons on a large scale. ${ }^{[126 \mathrm{~b}]}$

\subsubsection{Non-layered transition metal chalcogenides}

Besides the aforementioned layered metal chalcogenides, other non-layered metal chalcogenides, such as $\mathrm{MnTe}, \mathrm{Ce}_{3} \mathrm{Te}_{4}, \mathrm{CeSe}_{2}, \mathrm{FeS}_{2}, \mathrm{Re}-\mathrm{Gd}-\mathrm{S}(\mathrm{Re}=$ rare earth element), etc. have also proved to be promising thermoelectric materials because of either their complex crystal structures or their special band structures originating from the unique properties of transition metals. ${ }^{[128]}$ The relevant thermoelectric performances of these materials are summarized in Table 9. $\operatorname{ReGd}_{1+x} \mathrm{~S}_{3}$ compounds feature quite high performance as $n$ type thermoelectric materials because of their special properties such as their self-doping ability, which originates from the formation of their cubic structures with abundant metal vacancies. These compounds can be written as $\operatorname{Re}_{2} \mathrm{~V}_{\mathrm{A} 0.25} \mathrm{~S}_{3}$ (or $\operatorname{Re}_{2.67} \mathrm{~V}_{\mathrm{A} 0.33} \mathrm{~S}_{4}$, where Re is a rare-earth metal and $\mathrm{V}_{\mathrm{A}}$ is a metal vacancy). These vacancies can be filled with Re atoms. The carrier concentration increases with the Re content. These materials also have low thermal conductivity due to their complex crystal structure. ${ }^{[128 a, 128 g]}$

\subsection{Others}

\subsubsection{Modulation doping}

Modulation doping (MD), another important way to enhance thermoelectric performance, is a welldeveloped technique that is widely used in thin-film devices in order to improve the electrical conductivity. A typical thin film device utilizing the concept of modulation doping consists of three active layers, i.e. a doped layer which provides charge carriers, an undoped layer, which serves as a charge transport channel without interruptions from impurity atoms, and a thin spacer layer which spatially separates the above two layers. ${ }^{[128 r]}$ Extending this concept to $3 \mathrm{D}$ bulk materials, Wu et al. ${ }^{[128 r]}$ mixed dopant particles $\left(\mathrm{BiAgSeS}_{0.97} \mathrm{Cl}_{0.03}\right)$ with undoped matrix material (BiAgSeS) and consolidated the powder into bulks, which showed increased electrical conductivity and decreased thermal conductivity 
due to the modulation doping effect. A schematic illustration of $3 \mathrm{D}$ modulation doping is shown in Figure 24. Compared with traditional uniform doping, the dopants offer extra charge carriers to the whole bulk, while the scattering between the charge carriers and the ionized dopants is greatly reduced, as the dopants are localized in the doped grains. Hence, this method provides a new approach to increasing the concentration of charge carriers while reducing the loss of carrier mobility. Moreover, it is a general method to enhance the thermoelectric performance of other kinds of materials, such as in the $\mathrm{SiGe}$ and $\mathrm{Pb}-\mathrm{X}$ systems. ${ }^{[54 \mathrm{~b}, 129]}$

\subsubsection{Surface engineering of thermoelectric nanomaterials prepared by the wet chemical method}

Although nanostructuring has long been identified as the most widely used and effective method to enhance thermoelectric performance, its application is strongly hindered by the lack of a large-scale fabrication method with both low cost and high controllability of the nanostructures. As one of most important bottom-up routes used to fabricate nanobulk materials, the wet chemical method has been used to fabricate nanostructured thermoelectric materials. ${ }^{[130]}$ The merits of this method are obvious: (i) the morphology, composition, and crystallinity of nanostructured metal chalcogenides can be well controlled via the reaction parameters; ${ }^{[9 a]}$ (ii) it is a facile and low-cost method compared with other methods, such as solid-state reaction and melt-spinning; ${ }^{[20 \mathrm{~b}, 131]}$ (iii) the product has relatively high purity compared with ball milling. Due to their large surface area, the nanostructures may be covered, however, by nonconductive solvents or ligands, which are hard to remove and very fatal for the electrical conductivity of the sintered bulk. ${ }^{[24,132]}$ The yield of the wet chemical method is also relatively low. ${ }^{[9 a]}$ In addition, sometimes the cost of wet chemical method is high if expensive solvents or ligands are used. ${ }^{[9 a, 133]}$

Although the wet chemical method has advantages in tuning the size and morphology of nanostructures, ${ }^{[130]}$ the resultant nanostructures may be covered by non-conductive solvents or ligands due to their large surface area, which are hard to remove and fatal for the electrical conductivity of the sintered bulk. An alternative is the development of surfactant-free chemical synthesis routes. Recently, Han et al. ${ }^{[16 \mathrm{~b}, 131]}$ developed a low-cost wet chemical method to synthesize different kinds of surfactant- 
free binary and ternary metal chalcogenide nanostructures. As presented in Figure 25, the method is based on the extremely low solubility of metal chalcogenides in aqueous solution, and includes a reduction of the chalcogen source by $\mathrm{NaBH}_{4}$ and a precipitation of the obtained chalcogen ions with metal ions. The whole synthesis is conducted under ambient conditions, no surfactants are used, and it is easy to scale up. The thermoelectric performance of consolidated nanobulks from the obtained nanostructures is comparable to those of the corresponding bulk analogues. ${ }^{[116 \mathrm{~b}, 131]}$

Another important method to enhance the thermoelectric performance of nanostructures obtained by wet chemical methods is the surface engineering of nanocrystals by using other inorganic materials to replace the capping ligands and absorbed organic solvents. ${ }^{[45 a, 52 b, 134]}$ As the simplest agent for surface modification, hydrazine is already widely used to remove residual ligands in the wet chemical method. ${ }^{\text {[24a, }}$ ${ }^{130 a]}$ Simply replacing surface oleic acid of $\mathrm{PbS}$ nanocrystals with $\mathrm{NH}_{4} \mathrm{SCN}$ led to a strong increase in the electrical conductivity in the low temperature range compared with the original oleic acid covered $\mathrm{PbS}$ nanocrystals. ${ }^{[52 \mathrm{~b}]}$ Stirring oleic acid covered $\mathrm{PbS}$ with $\mathrm{HCl}$ can simultaneously replace the non-conductive oleic acid and promote doping with $\mathrm{Cl}$ ions, leading to a significant increase in the electrical conductivity over the whole temperature range. ${ }^{[52 \mathrm{~b}]}$ Talapin et al. simply replaced non-conductive organics with inorganic materials and proposed the concept of "nanocrystal glue" or "semiconductor solder" for mesoscale particles of thermoelectric materials. ${ }^{[45 \mathrm{a}, 134]}$ The nanocrystal glue can form a semiconducting material after heat treatment, which is structurally and compositionally matched to the bonded semiconductors. Because the electronic properties of semiconductor interfaces are much more sensitive to impurities and structural defects than those of metals, the misalignment of the Fermi energy levels or the trapping of charge carriers at the interface creates a Schottky barrier. ${ }^{[134 b]}$ Details of fabrication of nanocrystal glues can be found in their report. ${ }^{[134 b]}$ The benefits of using nanocrystal glue are: (i) there is a depressed melting point for nanocrystals, which permits the consolidation of grains at lower temperature; (ii) the usage of glue can improve the quality of the sintered body and lead to higher density at lower temperature, as shown in Figure 26; (iii) selective modification of the grain boundaries can be by tuning 
the chemistry of the nanocrystal glue, offering an additional degree of control over charge and heat transport in thermoelectric materials. For example, due to the structurally and compositionally matched interfaces, the decrease in charge carrier mobility was minimized with an extremely small amount of the solder (1-3 wt.\%). ${ }^{[45 a, 134]}$ CdSe nanocrystals capped with $\mathrm{Na}_{2} \mathrm{Cd}_{2} \mathrm{Se}_{3}$ solder were used as a soluble precursor for CdSe films, with electron mobility exceeding $300 \mathrm{~cm}^{2} /(\mathrm{V} \cdot \mathrm{s}) .{ }^{[134 \mathrm{~b}]}$

\subsubsection{Other approaches used for defect engineering}

As mentioned previously, ${ }^{[20 a, 35 a]}$ defect engineering has been an important route to tuning the properties of thermoelectric materials in the Bi-Te system. Actually, it is a general method that can be used for other metal chalcogenides, as the defects can affect carrier concentrations and lower thermal conductivity. Besides hot deformation, the defects engineering can be achieved in several different ways; such as by hydraulic pressure together with ion beams, ${ }^{[135]}$ bombardment by ion beams or high energy electromagnetic radiation, such as with $\mathrm{He}^{2+}, \mathrm{Ar}^{+}$, neutrons, $\gamma$-rays, $\mathrm{X}$-rays, etc., which are widely used for improving the thermoelectric performance of films, etc. ${ }^{[135 b, 136]}$ Joonki et al. ${ }^{[135 b]}$ used $\mathrm{He}^{2+}$ ion beam to induce native defects that dramatically enhanced the thermoelectric properties in $\mathrm{Bi}_{2} \mathrm{Te}_{3}$ film by simultaneously modifying all of them towards the desired direction. This was enabled by the multiple functions of native defects, which act beneficially as electron donors, energy-dependent charge scattering centers, and phonon blockers.

Hydrogenation is another approach to improve the performance of thermoelectric materials. The introduction of hydrogen atoms onto the surface or into the lattice of the target materials can be performed in several ways, such as hydrogenation at high temperature in the presence of an $\mathrm{H}$ source; bombardment with a high energy $\mathrm{H}^{+}$ion beam, direct hydrogenation using $\mathrm{HCl}$, etc. ${ }^{[135 \mathrm{a}]}$ Besides the introduction of point defects, the injected electrons from the doped hydrogen atoms greatly influence the density of states (DOS), which leads to increased charge density across the Fermi surface to improve the electrical conductivity. Meanwhile, due to their very small ionic radius, the incorporation of protons can avoid large-scale structural distortion and maintain the lattice thermal conductivity. For example, in the 
case of $\mathrm{VO}_{2}$, after hydrogen incorporation, electrons from the hydrogen atoms were injected into the $\mathrm{V}-\mathrm{V}$ chains, resulting in obviously enhanced electron-electron correlation effects. The hydrogenated $\mathrm{VO}_{2}$ with the highest hydrogen concentration had a $Z T$ value of about 0.12 at $210 \mathrm{~K}$, which was much higher than for the other two samples with less or no hydrogen incorporation. ${ }^{[137]}$

\section{Summary and outlook}

Metal chalcogenides, which possess many different structures with different compositions (e.g. layered structures, diamond-like structures, complex cage structures, etc.), and relatively low fabrication costs, offer a good platform for either searching for new thermoelectric materials or discovering new theories that can lead to high thermoelectric performance. Significant advances in improving the thermoelectric performance of metal-chalcogenide-based materials have been made in the last few decades.

\subsection{Summary}

In the field of materials, besides the conventional thermoelectric materials, such as $\mathrm{Bi}-\mathrm{X}, \mathrm{Pb}-\mathrm{X}$, etc., many new kinds of metal chalcogenides have been proved to be effective thermoelectric materials, such as PLEC materials with an order-disorder transition $(\mathrm{Cu}, \mathrm{Ag}$ chalcogenides), layered structures with quasi-one-dimensional structures (In-X, Sn-X system), structures with extremely complex lattices (Tl-MTe system, Chevrel phase), structures with vacancy planes $\left(\mathrm{Ga}_{2} \mathrm{Te}_{3}\right)$, etc. The development of metalchalcogenide-based thermoelectric materials mainly shows the following features: (i) The materials with simple compositions but complex structures have attracted ever increasing attention, such as $\mathrm{SnSe},{ }^{[1]}$ $\mathrm{In}_{4} \mathrm{Se}_{3},{ }^{[15]} \mathrm{CsBi}_{4} \mathrm{Te}_{6},{ }^{[29 \mathrm{a}]}$ etc. (ii) The formation of nanocomposites has been a widely used method to

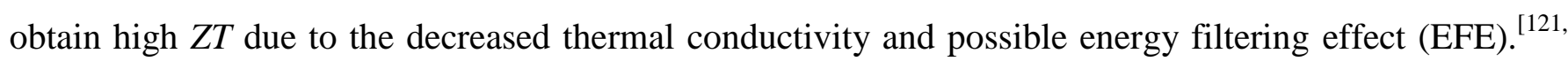
138] (iii) Composition fluctuations from using solid solutions, substitution of atoms, self-doping, or deficiency of elements can introduce defects and decrease thermal conductivity, and lead to high performance thermoelectric materials. ${ }^{[128 \mathrm{f}, 128 \mathrm{~g}, 128 \mathrm{k}]}$ (iv) Formation of heterostructures has been another way to produce new thermoelectric materials. ${ }^{[45 a, 130 a, 130 b, 139]}$ (v) Precise intercalation into the gaps 
between adjacent layers of layered materials is an important route to producing new types of thermoelectric materials. ${ }^{[89,91 \mathrm{e}, 91 \mathrm{~g}]}$ (vi) Phase separation and the formation of nanostructured precipitates, induced by composition control; representing another important direction in the search for new thermoelectric materials. ${ }^{[27 \mathrm{j}, 97,140]}$

For the strategies and methodologies used to enhance the thermoelectric performance of metal chalcogenides, they also exhibit several new trends including: (i) tuning of distorted structure, unit cells, and mobility of atoms; ${ }^{[141]}$ (ii) band engineering through resonant doping ${ }^{[32 b]}$ and band degeneracy, ${ }^{[46]}$ which can increase the DOS near the Fermi level to optimize the power factor; (iii) engineering intrinsic defects, which can act as both charge carrier donors and phonon scattering centres; ${ }^{[20 a]}$ (iv) full-scale scattering originating from composition engineering, ${ }^{[12,122]}(\mathrm{v})$ dislocation arrays formed by the pressureassisted liquid phase sintering technique ${ }^{[20 b]}$ (vi) phonon liquid electron crystals, showing both high electrical conductivity and low thermal conductivity; ${ }^{[16]}$ (vii) formation of mosaic crystals, which possess well oriented grains and grain boundaries; ${ }^{[123]}$ (viii) 3D modulation doping, which can localize ionized impurities to increase charge carrier mobility; ${ }^{[54 b, 128 r]}$ (ix) surface engineering, such as utilizing nanocrystal glues to improve connections between nanocrystals and decrease the sintering temperature of nanobulks; ${ }^{[45 a, 52 b, 134]}$ (x) deformation as an important way to enhance thermoelectric performance, because it can both refine crystal grains and introduce defects, as well as improving mechanical properties; ${ }^{[34 \mathrm{e}, 38 \mathrm{~b}, 142]}$ and (xi) enhancement of orientation for materials with anisotropic thermoelectric performance along different crystal directions, as an effective way to improve their thermoelectric performance, such as in the Bi-Te system and SnSe. ${ }^{[11,33,37]}$ Among these strategies, methods involving nanoscience and nanotechnology ${ }^{[4,74 a, 110,143]}$ represent the most significant and most widely used strategy.

\subsection{Outlook}

Although metal chalcogenide based thermoelectric materials shows relatively higher $Z T$ values than other materials and significant progress has been achieved in recent years, several problems still need to be resolved. (i) Many high-ZT metal chalcogenides such as bulk SnSe single crystal, ${ }^{[11]}$ full scale 
structured PbTe bulk, ${ }^{[12]}$ bulk CuSTe system, ${ }^{[123]}$ etc. are produced in the laboratory, they face many difficulties for making commercialization. For instance, it is more difficult and expensive to grow a single crystal or a Mosaic crystal than fabrication of a polycrystalline SnSe. (ii) Most metal chalcogenides (e.g. $\mathrm{Pb}-\mathrm{X}$ based materials) with high thermoelectric performance show poor mechanical properties, ${ }^{[144]}$ which limits their real application. (iii) Due to the intrinsic volatility of chalcogen elements ( $\mathrm{S}, \mathrm{Se}, \mathrm{Te})$, some metal chalcogenides possess poor thermal stability, especially for those nanoscale metal chalcogenides fabricated from bottom up processes. ${ }^{[131]}$ For PLEC materials, the fast movement of liquid like metal ions could also lead to their instability. The chalcogenide nanostructures originated from spinodal decomposition are also not stable during operation because spinodal decomposition is sensitive to temperature. (iv) Most high thermoelectric performance metal chalcogenides have the environmental issue or fabrication cost due to the use of toxic elements (e.g. $\mathrm{Pb}$ ) or expensive precursors (e.g. $\mathrm{Ag}$ and Te). ${ }^{[145]}$ To fully develop the potential of thermoelectric materials for wide commercial applications in the near future, parallel development on both materials and thermoelectric devices are needed.

From the viewpoint of materials, traditional $\mathrm{Bi}-\mathrm{Te}$ and $\mathrm{Pb}$-Te systems would continue dominate the commercial market because of their better performance than other metal chalcogenides and mature processing technologies. However, more and more efforts would be devoted to enhancing their mechanical strength, reducing fabricating cost and optimizing thermoelectric generators. In addition, low dimensional metal sulphides and selenides would attract considerable attention due to the possibility of simultaneous optimization of the thermal and electrical conductivity via separating the transfer of charge carriers from that of phonons, and their lower cost, environmental friendliness, as well as simple composition. Moreover, the stable PLEC materials with high performance would be a focus for future research.

Meanwhile careful tailoring of nanostructures including shape, size, and interface would be still an important and efficient way to further enhance thermoelectric properties in near future. Partially introducing rationally designed nanostructures into bulk matrix would be a major development because of 
its distinct advantages. It can improve the thermal stability of metal chalcogenides, and the scattering of charge carriers can be supressed. The hybrid of nanostrcutures and bulk may lead to full scale phonon scattering compared with single size of nanostructure. The introduced nanostructures could also lead to energy filtering effect. Chen et al. ${ }^{[146]}$ designed a core-shell structure to simultaneously achieve total nonscattering of charge carriers and enhance the Seebeck coefficient. This effect is called "anti-resonant doping" or "invisible dopants" effect.

Besides nanostructure engineering, defect engineering is another new highlight in the near future to further enhance thermoelectric performance of metal chalcogenides, because defects could effectively decrease their thermal conductivity and tune their carrier concentrations. Compared with traditional hot deformation method, irradiation could be a better way to introduce defects in thermoelectric materials because defects can be well controlled with different beams and their dosage. The effects of induced defects on thermoelectric properties of bulk materials have been rarely reported.

For practical applications, more efforts should be devoted to fabricate efficient thermoelectric devices. An important development on thermoelectric devices is fabrication of flexible thin film thermoelectric generators (TEGs), which has several merits in comparison with rigid bulk modules. ${ }^{[147]}$ It can be easily integrated into unusual topologies and maximize the heat absorbing area, leading to an enhanced practical efficiency compared to rigid TE devices. More importantly, the cost of thin film TEGs is low because the screen printing, inkjet printing or the roll to roll manufacturing have been widely used. The thin film TEGs can be used to supply power for small electronics due to their high power density. Their weight is also low. These supreme features of thin film TEGs have attracted considerable attentions ${ }^{[147]}$ and remarkable progress has been achieved. However, most of thin film TEGs are fabricated from Bi-Te system and polymers, and used at room temperature. ${ }^{[148]}$ A major problem of thin films TEGs is their much lower ZT compared with that of bulk materials, due to the less density of film and low sintering temperature. 
To further opens up new market for metal chalcogenides based thermoelectric materials, one of the important developments of their application forms is combine the thermoelectric devices with other energy harvest devices such as solar cells. Many metal chalcogenide based thermoelectric materials can also be used in solar cells, such as the $\mathrm{Pb}-\mathrm{X}$ system, $\mathrm{Cu}-\mathrm{X}$ system, $\mathrm{Cu}-\mathrm{In}-\mathrm{Ga}-\mathrm{Se}$ system, etc. ${ }^{\text {[9b, 9c, 149] }}$ Recently, Kraemer et al. ${ }^{[150]}$ reported a flat-panel solar thermoelectric generator (STEG) with a system efficiency of $4.6 \%-5.2 \%$ generated from a temperature difference of $180{ }^{\circ} \mathrm{C}\left(T_{\mathrm{c}}=20{ }^{\circ} \mathrm{C}, T_{\mathrm{h}}=200{ }^{\circ} \mathrm{C}\right)$. The thermoelectric legs are made from $p$-type and $n$-type $\mathrm{ZnSb}$ compound. The efficiency is $7-8$ times higher than the best value previously reported. ${ }^{[150]}$

With the development of nanotechnology and fabrication technology, with the discovery of new metal chalcogenide structures, as well as new theories leading to high thermoelectric performance, the $Z T$ values of metal chalcogenides could be further enhanced to yield a comparable efficiency to conventional heat engines, and thus make greater contributions to energy saving and environmental protection.

\section{Acknowledgements}

C. Han gratefully acknowledges the Chinese Scholarship Council (CSC) for his scholarship. Z. Li acknowledges support from the Australian Research Council (ARC) through the Discovery Projects DP130102699 and DP130102274, and support from the National Natural Science Foundation of China (81471657, 81527901), the 1000 Talents Plan, and Jiangsu Specially Appointed Professorship. S. Dou is grateful for support from the Baosteel-Australia Research Centre (BARC) through the project BA110011 and from the ARC through the Linkage Project LP120200289. The authors are grateful for the support from ISEM at UOW, Jiangsu Provincial Key Laboratory of Radiation Medicine and Protection, and the Priority Academic Program Development of Jiangsu Higher Education Institutions (PAPD). The authors would like to thank Dr. Tania Silver for polishing the manuscript.

Received: ((will be filled in by the editorial staff))

Revised: ((will be filled in by the editorial staff))

Published online: ((will be filled in by the editorial staff))

[1] A. P. Gonçalves, C. Godart, Eur. Phys. J. B 2014, 87, 42.

[2] T. Kuroki, K. Kabeya, K. Makino, T. Kajihara, H. Kaibe, H. Hachiuma, H. Matsuno, A. Fujibayashi, J. Electron. Mater. 2014, 43, 2405.

[3] C. Han, Z. Li, S. Dou, Chin. Sci. Bull. 2014, 59, 2073.

[4] M. G. Kanatzidis, Chem. Mater. 2010, 22, 648.

[5] A. D. LaLonde, Y. Pei, H. Wang, G. Jeffrey Snyder, Mater. Today 2011, 14, 526. 
[6] J. He, Y. Liu, R. Funahashi, J. Mater. Res. 2011, 26, 1762.

[7] P. Jood, M. Ohta, Mater. Today 2015, 8, 1124.

[8] a) K. Nielsch, J. Bachmann, J. Kimling, H. Böttner, Adv. Energy Mater. 2011, 1, 713; b) Z. Li, Q. Sun, X. D. Yao, Z. H. Zhu, G. Q. Lu, J. Mater. Chem. 2012, 22, 22821.

[9] a) C. Han, Z. Li, W.-j. Li, S.-1. Chou, S.-x. Dou, J. Mater. Chem. A 2014, 2, 11683; b) Y. Bai, C. Han, X. Chen, H. Yu, X. Zong, Z. Li, L. Wang, Nano Energy 2015, 13, 609; c) M.-R. Gao, Y.-F. Xu, J. Jiang, S.-H. Yu, Chem. Soc. Rev. 2013, 42, 2986; d) J. Xiong, C. Han, Z. Li, S. Dou, Chi. Sci. Bull. 2015, 60, 2083; e) J. Xiong, C. Han, W. Li, Q. Sun, J. Chen, S. Chou, Z. Li, S. Dou, CrystEngComm 2016, 18, 930; f) Y. B. Chao Han, Qiao Sun, Shaohua Zhang, Zhen Li, Lianzhou Wang, Shixue Dou, Adv. Sci. 2016, DOI: DOI: 10.1002/advs.201500350; g) X. Q. Chen, Y. Bai, Z. Li, L. Z. Wang, S. X. Dou, ChemPlusChem 2016, 81, 414; h) X. Q. Chen, Z. Li, Y. Bai, Q. Sun, L. Z. Wang, S. X. Dou, Chem. A. Europ. J. 2015, 21, 1055; i) W.-J. Li, C. Han, S.-L. Chou, J.-Z. Wang, Z. Li, Y.-M. Kang, H.-K. Liu, S.-X. Dou, Chem. A. Europ. J. 2016, 22, 590.

[10] T. C. Harman, P. J. Taylor, M. P. Walsh, B. E. LaForge, Science 2002, 297, 2229.

[11] L.-D. Zhao, S.-H. Lo, Y. Zhang, H. Sun, G. Tan, C. Uher, C. Wolverton, V. P. Dravid, M. G. Kanatzidis, Nature 2014, 508, 373.

[12] K. Biswas, J. He, I. D. Blum, C.-I. Wu, T. P. Hogan, D. N. Seidman, V. P. Dravid, M. G. Kanatzidis, Nature 2012, 489, 414.

[13] G. G. Yadav, J. A. Susoreny, G. Zhang, H. Yang, Y. Wu, Nanoscale 2011, 3, 3555.

[14] S. LeBlanc, S. K. Yee, M. L. Scullin, C. Dames, K. E. Goodson, Renew. Sustain. Energy Rev. 2014, 32, 313.

[15] J.-S. Rhyee, K. H. Lee, S. M. Lee, E. Cho, S. I. Kim, E. Lee, Y. S. Kwon, J. H. Shim, G. Kotliar, Nature 2009, 459, 965.

[16] H. Liu, X. Shi, F. Xu, L. Zhang, W. Zhang, L. Chen, Q. Li, C. Uher, T. Day, G. J. Snyder, Nat Mater 2012, 11, 422.

[17] H. Liu, X. Yuan, P. Lu, X. Shi, F. Xu, Y. He, Y. Tang, S. Bai, W. Zhang, L. Chen, Y. Lin, L. Shi, H. Lin, X. Gao, X. Zhang, H. Chi, C. Uher, Adv. Mater. 2013, 25, 6607.

[18] R. Venkatasubramanian, E. Siivola, T. Colpitts, B. O'Quinn, Nature 2001, 413, 597.

[19] C. B. Satterthwaite, R. W. Ure, Phys. Rev. 1957, 108, 1164.

[20] a) L. Hu, T. Zhu, X. Liu, X. Zhao, Adv. Funct. Mater. 2014, 24, 5211; b) K. H. L. Sang Il Kim, Hyeon A. Mun, Hyun Sik Kim, Sung Woo Hwang, Jong Wook Roh, Dae Jin Yang, Weon Ho Shin, Xiang Shu Li, Young Hee Lee, G. Jeffrey Snyder, Sung Wng Kim, Science 2015, 348, 109.

[21] P. Puneet, R. Podila, M. Karakaya, S. Zhu, J. He, T. M. Tritt, M. S. Dresselhaus, A. M. Rao, Sci. Rept. 2013, 3, 3212.

[22] W. Xie, X. Tang, Y. Yan, Q. Zhang, T. M. Tritt, J. Appl. Phys. 2009, 105, 113713.

[23] F. Wu, H. Song, F. Gao, W. Shi, J. Jia, X. Hu, J. Electron. Mater. 2013, 42, 1140.

[24] a) R. J. Mehta, Y. Zhang, C. Karthik, B. Singh, R. W. Siegel, T. Borca-Tasciuc, G. Ramanath, Nat Mater 2012, 11, 233; b) A. Soni, Z. Yanyuan, Y. Ligen, M. K. K. Aik, M. S. Dresselhaus, Q. Xiong, Nano Lett. 2012, 12, 1203.

[25] H. Li, H. Jing, Y. Han, G.-Q. Lu, L. Xu, Intermetallics 2013, 43, 16.

[26] D.-W. Liu, J.-F. Li, C. Chen, B.-P. Zhang, J. Electron. Mater. 2011, 40, 992.

[27] a) N. Gothard, J. E. Spowart, T. M. Tritt, Phys. Status Solidi (a) 2010, 207, 157; b) J. H. Sun, X. Y. Qin, H. X. Xin, D. Li, L. Pan, C. J. Song, J. Zhang, R. R. Sun, Q. Q. Wang, Y. F. Liu, J. Alloys Compd. 2010, 500, 215; c) Y. H. Zhang, G. Y. Xu, F. Han, Z. Wang, C. C. Ge, J. Electron. Mater. 2010, 39, 1741; d) F. Li, X. Huang, Z. Sun, J. Ding, J. Jiang, W. Jiang, L. Chen, J. Alloys Compd. 2011, 509, 4769; e) D.-H. Park, M.-Y. Kim, T.-S. Oh, Curr. Appl. Phys. 2011, 11, S41; f) K.-C. Je, B. Ko, C. Kim, H. Kim, D.-H. Kim, J. Alloys Compd. 2012, 517, 75; g) H. Fang, T. Feng, H. Yang, X. Ruan, Y. Wu, Nano Lett. 2013, 13, 2058; h) L. P. Tan, T. Sun, S. Fan, L. Y. Ng, A. Suwardi, Q. Yan, H. H. Hng, Nano Energy 2013, 2, 4; i) J.-H. Yim, S.-H. Baek, H.-Y. Shin, D. Hyun, J.-S. Kim, J. Electron. Mater. 2013, 42, 2178; j) Y. Zhai, T. Zhang, Y. Xiao, J. Jiang, S. 
Yang, G. Xu, J. Alloys Compd. 2013, 563, 285; k) T. Zhang, J. Jiang, Y. Xiao, Y. Zhai, S. Yang, G. Xu, Appl. Mater. Interface 2013, 5, 3071; 1) M. Keshavarz, D. Vasilevskiy, R. Masut, S. Turenne, J. Electron. Mater. 2014, 43, 2239; m) Y. Xiao, G. Chen, H. Qin, M. Wu, Z. Xiao, J. Jiang, J. Xu, H. Jiang, G. Xu, J. Mater. Chem. A 2014, 2, 8512; n) Q. Zhang, X. Ai, W. Wang, L. Wang, W. Jiang, Acta Mater. 2014, 73, 37; o) Y. Li, D. Li, X. Qin, X. Yang, Y. Liu, J. Zhang, Y. Dou, C. Song, H. Xin, J. Mater. Chem. C 2015, 3, 7045; p) Z. Li, S. Zheng, Y. Zhang, H. Chen, T. Huang, G. Lu, J. Electron. Mater. 2015, 44, 2061; q) Q. Lognoné, F. Gascoin, J. Alloys Compd. 2015, 635, 107; r) S. Hwang, S.-I. Kim, K. Ahn, J. Roh, D.-J. Yang, S.-M. Lee, K.-H. Lee, J. Electron. Mater. 2013, 42, 1411; s) C.-L. Hsin, Y.-Y. Tsai, Nano Energy 2015, 11, 647; t) D. K. Misra, S. Sumithra, N. S. Chauhan, W. M. Notling, P. F. P. Poudeu, K. L. Stokes, Mater. Sci. Semicond. Process. 2015, 40, 453.

[28] M. Scheele, N. Oeschler, I. Veremchuk, S.-O. Peters, A. Littig, A. Kornowski, C. Klinke, H. Weller, ACS Nano 2011, 5, 8541.

[29] a) D.-Y. Chung, T. Hogan, P. Brazis, M. Rocci-Lane, C. Kannewurf, M. Bastea, C. Uher, M. G. Kanatzidis, Science 2000, 287, 1024; b) V. A. Kulbachinskii, V. G. Kytin, P. M. Tarasov, N. A. Yuzeeva, Phys. Solid State 2010, 52, 1830; c) X. Zhang, X.-y. Ma, Q.-m. Lu, F.-p. Zhang, Y.-q. Liu, J.-x. Zhang, L. Wang, J. Electron. Mater. 2011, 40, 773; d) V. A. Kulbachinskii, V. G. Kytin, A. A. Kudryashov, R. A. Lunin, J. Solid State Chem. 2012, 193, 83; e) M. K. Fuccillo, S. Jia, M. E. Charles, R. J. Cava, J. Electron. Mater. 2013, 42, 1246; f) M.-K. Han, H. Ryu, S.-J. Kim, J. Electron. Mater. 2013, 42, 2758; g) K.-H. Lee, S. Hwang, B. Ryu, K. Ahn, J. Roh, D. Yang, S.-M. Lee, H. Kim, S.-I. Kim, J. Electron. Mater. 2013, 42, 1617; h) H. Kitagawa, T. Matsuura, T. Kato, K.-y. Kamata, J. Electron. Mater. 2015, 44, 1870; i) H. Mun, K. Lee, S. Kim, J.-Y. Kim, J. Lee, J.-H. Lim, H. Park, J. Roh, S. Kim, Mater. Today 2015, 8, 959.

[30] V. A. Kulbachinskii, H. Negishi, M. Sasaki, Y. Giman, M. Inoue, P. Losták, J. Horák, Phys. Status Solidi (b) 1997, 199, 505.

[31] C. M. Jaworski, B. Wiendlocha, V. Jovovic, J. P. Heremans, Energy Environ. Sci. 2011, 4, 4155.

[32] a) Q. Zhang, B. Liao, Y. Lan, K. Lukas, W. Liu, K. Esfarjani, C. Opeil, D. Broido, G. Chen, Z. Ren, Proceed. Nation, Academy Sci. U. S. A. 2013, 110, 13261; b) J. P. Heremans, V. Jovovic, E. S. Toberer, A. Saramat, K. Kurosaki, A. Charoenphakdee, S. Yamanaka, G. J. Snyder, Science 2008, 321, 554; c) H. S. Dow, M. W. Oh, B. S. Kim, S. D. Park, B. K. Min, H. W. Lee, D. M. Wee, J. Appl. Phys. 2010, 108, 113709.

[33] Y. Luo, J. Yang, Q. Jiang, L. Fu, Y. Xiao, W. Li, D. Zhang, Z. Zhou, Y. Cheng, Nano Energy 2015, 15, 709 .

[34] a) H. Kitagawa, A. Kurata, H. Araki, S. Morito, E. Tanabe, J. Electron. Mater. 2010, 39, 1692; b) R. Srinivasan, N. Gothard, J. Spowart, Mater. Lett. 2010, 64, 1772; c) X. Yan, B. Poudel, Y. Ma, W. S. Liu, G. Joshi, H. Wang, Y. Lan, D. Wang, G. Chen, Z. F. Ren, Nano Lett. 2010, 10, 3373; d) A. M. Dehkordi, D. Vashaee, Phys. Status Solidi (a) 2012, 209, 2131; e) Y. Nagami, K. Matsuoka, T. Akao, T. Onda, T. Hayashi, Z.-C. Chen, J. Electron. Mater. 2014, 43, 2262.

[35] a) T. Zhu, Z. Xu, J. He, J. Shen, S. Zhu, L. Hu, T. M. Tritt, X. Zhao, J. Mater. Chem. A 2013, 1, 11589; b) Q. Jiang, H. Yan, J. Khaliq, H. Ning, S. Grasso, K. Simpson, M. J. Reece, J. Mater. Chem. A 2014, 2, 5785.

[36] a) D. H. Kim, C. Kim, K.-C. Je, G. H. Ha, H. Kim, Acta Mater. 2011, 59, 4957; b) H. Kim, D. H. Kim, C. Kim, S. Park, AIP Confer. Proceeds. 2012, 1449, 139.

[37] W.-T. Zhu, W.-Y. Zhao, H.-Y. Zhou, J. Yu, D.-G. Tang, Z.-Y. Liu, Q.-J. Zhang, J. Electron. Mater. 2014, 43, 1768.

[38] a) G. Rogl, A. Grytsiv, P. Rogl, E. Royanian, E. Bauer, J. Horky, D. Setman, E. Schafler, M. Zehetbauer, Acta Mater. 2013, 61, 6778; b) J.-J. Shen, T.-J. Zhu, X.-B. Zhao, S.-N. Zhang, S.-H. Yang, Z.-Z. Yin, Energy Environ. Sci. 2010, 3, 1519; c) X. Guo, X. Jia, T. Su, K. Jie, H. Sun, H. Ma, Chem. Phys. Lett. 2012, 550, 170; d) D. I. Bogomolov, V. T. Bublik, S. Y. Skipidarov, N. Y. Tabachkova, Inorg. Mater. 2013, 49, 758; e) S.-J. Jung, J.-H. Kim, D.-I. Kim, S. K. Kim, H.-H. 
Park, J.-S. Kim, D.-B. Hyun, S.-H. Baek, Phys. Chem. Chem. Phys. 2014, 16, 3529; f) Z. J. Xu, L. P. Hu, P. J. Ying, X. B. Zhao, T. J. Zhu, Acta Mater. 2015, 84, 385.

[39] R. Amatya, R. J. Ram, J. Electron. Mater. 2012, 41, 1011.

[40] a) Z. Ali, S. Butt, C. Cao, F. K. Butt, M. Tahir, M. Tanveer, I. Aslam, M. Rizwan, F. Idrees, S. Khalid, AIP Advances 2014, 4, 117129; b) S. Gupta, N. Vijayan, A. Krishna, K. Thukral, K. K. Maurya, S. Muthiah, A. Dhar, B. Singh, G. Bhagavannarayana, J. Appl. Crystallogr. 2015, 48, 533.

[41] W. Liu, C. F. Guo, M. Yao, Y. Lan, H. Zhang, Q. Zhang, S. Chen, C. P. Opeil, Z. Ren, Nano Energy 2014, 4, 113.

[42] a) Y.-Q. Yu, B.-P. Zhang, Z.-H. Ge, P.-P. Shang, Y.-X. Chen, Mater. Chem. Phys. 2011, 131, 216; b) K. Biswas, L.-D. Zhao, M. G. Kanatzidis, Adv. Energy Mater. 2012, 2, 634; c) Z.-H. Ge, B.-P. Zhang, Y.-Q. Yu, P.-P. Shang, J. Alloys Compd. 2012, 514, 205; d) X. Du, F. Cai, X. Wang, J. Alloys Compd. 2014, 587, 6; e) L. Li, Y. Liu, J. Y. Dai, H. X. Zhu, A. J. Hong, X. H. Zhou, Z. F. Ren, J. M. Liu, Nano Energy 2015, 12, 447; f) Z. Liu, Y. Pei, H. Geng, J. Zhou, X. Meng, W. Cai, W. Liu, J. Sui, Nano Energy 2015, 13, 554; g) G. Sun, X. Qin, D. Li, J. Zhang, B. Ren, T. Zou, H. Xin, S. B. Paschen, X. Yan, J. Alloys Compd. 2015, 639, 9.

[43] X. Du, R. Shi, Y. Ma, F. Cai, X. Wang, Z. Yuan, RSC Advances 2015, 5, 31004.

[44] H. Iwasaki, I. Kimura, T. Murakami, H. Kim, Physica B: Condensed Matter 2015, 472, 91.

[45] a) M.-K. Han, S. Kim, H.-Y. Kim, S.-J. Kim, RSC Advances 2013, 3, 4673; b) W. Liu, K. C. Lukas, K. McEnaney, S. Lee, Q. Zhang, C. P. Opeil, G. Chen, Z. Ren, Energy Environ. Sci. 2013, 6, 552; c) L.-J. Zhang, B.-P. Zhang, Z.-H. Ge, C.-G. Han, Solid State Commun. 2013, 162, 48.

[46] Y. Pei, X. Shi, A. LaLonde, H. Wang, L. Chen, G. J. Snyder, Nature 2011, 473, 66.

[47] a) J. Androulakis, I. Todorov, D.-Y. Chung, S. Ballikaya, G. Wang, C. Uher, M. Kanatzidis, Phys. Rev. B 2010, 82, 115209; b) S. N. Girard, J. He, X. Zhou, D. Shoemaker, C. M. Jaworski, C. Uher, V. P. Dravid, J. P. Heremans, M. G. Kanatzidis, J. Am. Chem. Soc. 2011, 133, 16588; c) Y. Pei, N. A. Heinz, A. LaLonde, G. J. Snyder, Energy Environ. Sci. 2011, 4, 3640; d) M. Guch, C. Raj Sankar, J. R. Salvador, G. P. Meisner, H. Kleinke, J. Appl. Phys. 2012, 111, 063706; e) Y. Pei, A. D. LaLonde, N. A. Heinz, G. J. Snyder, Adv. Energy Mater. 2012, 2, 670; f) F. F. Aliev, H. A. Hasanov, Indian J. Phys. 2013, 87, 345; g) H. Wang, J. Hwang, M. L. Snedaker, I.-h. Kim, C. Kang, J. Kim, G. D. Stucky, J. Bowers, W. Kim, Chem. Mater. 2015, 27, 944.

[48] J. He, L.-D. Zhao, J.-C. Zheng, J. W. Doak, H. Wu, H.-Q. Wang, Y. Lee, C. Wolverton, M. G. Kanatzidis, V. P. Dravid, J. Am. Chem. Soc. 2013, 135, 4624.

[49] J. He, I. D. Blum, H.-Q. Wang, S. N. Girard, J. Doak, L.-D. Zhao, J.-C. Zheng, G. Casillas, C. Wolverton, M. Jose-Yacaman, D. N. Seidman, M. G. Kanatzidis, V. P. Dravid, Nano Lett. 2012, 12, 5979.

[50] S. Ahmad, S. D. Mahanti, K. Hoang, M. G. Kanatzidis, Phys. Rev. B 2006, 74, 155205.

[51] a) Q. Zhang, H. Wang, W. Liu, H. Wang, B. Yu, Q. Zhang, Z. Tian, G. Ni, S. Lee, K. Esfarjani, G. Chen, Z. Ren, Energy Environ. Sci. 2012, 5, 5246; b) A. D. LaLonde, Y. Pei, G. J. Snyder, Energy Environ. Sci. 2011, 4, 2090.

[52] a) R. J. Korkosz, T. C. Chasapis, S.-h. Lo, J. W. Doak, Y. J. Kim, C.-I. Wu, E. Hatzikraniotis, T. P. Hogan, D. N. Seidman, C. Wolverton, V. P. Dravid, M. G. Kanatzidis, J. Am. Chem. Soc. 2014, 136, 3225; b) M. Ibáñez, R. J. Korkosz, Z. Luo, P. Riba, D. Cadavid, S. Ortega, A. Cabot, M. G. Kanatzidis, J. Am. Chem. Soc. 2015, 137, 4046; c) J. Androulakis, I. Todorov, J. He, D.-Y. Chung, V. Dravid, M. Kanatzidis, J. Am. Chem. Soc. 2011, 133, 10920.

[53] D. Wu, L.-D. Zhao, X. Tong, W. Li, L. Wu, Q. Tan, Y. Pei, L. Huang, J.-F. Li, Y. Zhu, M. G. Kanatzidis, J. He, Energy Environ. Sci. 2015, 8, 2056.

[54] a) S. Aminorroaya Yamini, H. Wang, Z. M. Gibbs, Y. Pei, D. R. G. Mitchell, S. X. Dou, G. J. Snyder, Acta Mater. 2014, 80, 365; b) S. A. Yamini, D. R. G. Mitchell, Z. M. Gibbs, R. Santos, V. Patterson, S. Li, Y. Z. Pei, S. X. Dou, G. Jeffrey Snyder, Adv. Energy Mater. 2015, DOI: 10.1002/aenm.201501047, n/a. 
[55] J. He, S. N. Girard, J.-C. Zheng, L. Zhao, M. G. Kanatzidis, V. P. Dravid, Adv. Mater. 2012, 24, 4440.

[56] Y. Lee, S.-H. Lo, J. Androulakis, C.-I. Wu, L.-D. Zhao, D.-Y. Chung, T. P. Hogan, V. P. Dravid, M. G. Kanatzidis, J. Am. Chem. Soc. 2013, 135, 5152.

[57] J. Yao, N. J. Takas, M. L. Schliefert, D. S. Paprocki, P. E. R. Blanchard, H. Gou, A. Mar, C. L. Exstrom, S. A. Darveau, P. F. P. Poudeu, J. A. Aitken, Phys. Rev. B 2011, 84, 075203.

[58] R. Liu, L. Xi, H. Liu, X. Shi, W. Zhang, L. Chen, Chem. Commun. 2012, 48, 3818.

[59] T. Plirdpring, K. Kurosaki, A. Kosuga, T. Day, S. Firdosy, V. Ravi, G. J. Snyder, A. Harnwunggmoung, T. Sugahara, Y. Ohishi, H. Muta, S. Yamanaka, Adv. Mater. 2012, 24, 3622.

[60] K. K. Masaya Kumagai, Yuji Ohishi,, S. Y. Hiroaki Muta, Mater. Trans. 2014, 55, 1215.

[61] V. Kumar Gudelli, V. Kanchana, G. Vaitheeswaran, A. Svane, N. E. Christensen, J. Appl. Phys. 2013, 114, 223707.

[62] a) S. Chen, W. Ren, Q. Meng, X. Liu, J. Yang, J. Cui, Phys. Status Solidi (a) 2014, 211, 618; b) N. Cheng, R. Liu, S. Bai, X. Shi, L. Chen, J. Appl. Phys. 2014, 115, 163705; c) R. L. N. Cheng, S. Bai, Xun Shi, Lidong Chen, J. Appl. Phys. 2014, 115, 163705(1; d) L. Wang, P. Ying, Y. Deng, H. Zhou, Z. Du, J. Cui, RSC Advances 2014, 4, 33897; e) J. Zhang, X. Qin, D. Li, H. Xin, C. Song, L. Li, Z. Wang, G. Guo, L. Wang, J. Alloys Compd. 2014, 586, 285; f) W. D. Carr, D. T. Morelli, J. Alloys Compd. 2015, 630, 277; g) V. Kucek, C. Drasar, J. Navratil, T. Plechacek, L. Benes, J. Phys. Chem. Solids 2015, 83, 18; h) J. Zhang, X. Qin, D. Li, C. Song, X. Zhu, Y. Liu, H. Xin, L. Chen, T. Zou, Intermetallics 2015, 60, 45.

[63] a) K. K. Aikebaier Yusufu, Atsuko Kosuga, Tohru Sugahara, Yuji Ohishi, Hiroaki Muta, Shinsuke Yamanaka, Appl. Phys. Lett. 2011, 99, 061902(1; b) J. Zhang, X. Qin, D. Li, H. Xin, C. Song, L. Li, X. Zhu, Z. Wang, G. Guo, L. Wang, J. Mater. Chem. A 2014, 2, 2891; c) A. H. Reshak, J. Phys. Chem. Solids 2015, 78, 46.

[64] J. L. Cui, Y. Y. Li, Y. Deng, Q. S. Meng, Y. L. Gao, H. Zhou, Y. P. Li, Intermetallics 2012, 31, 217.

[65] C. H. L. Goodman, J. Phys. Chem. Solids 1958, 6, 305.

[66] a) X. Shi, L. Xi, J. Fan, W. Zhang, L. Chen, Chem. Mater. 2010, 22, 6029; b) E. Skoug, J. Cain, D. Morelli, J. Electron. Mater. 2012, 41, 1232.

[67] C. Bourgès, P. Lemoine, O. I. Lebedev, R. Daou, V. Hardy, B. Malaman, E. Guilmeau, Acta Mater. 2015, 97, 180.

[68] a) S. N. Guin, A. Chatterjee, D. S. Negi, R. Datta, K. Biswas, Energy Environ. Sci. 2013, 6, 2603; b) S. N. Guin, K. Biswas, Chem. Mater. 2013, 25, 3225.

[69] a) A. Suzumura, M. Watanabe, N. Nagasako, R. Asahi, J. Electron. Mater. 2014, 43, 2356; b) T.R. Wei, F. Li, J.-F. Li, J. Electron. Mater. 2014, 43, 2229; c) T. H. Zou, X. Y. Qin, D. Li, G. L. Sun, Y. C. Dou, Q. Q. Wang, B. J. Ren, J. Zhang, H. X. Xin, Y. Y. Li, Appl. Phys. Lett. 2014, 104, 013904.

[70] K. S. Weldert, W. G. Zeier, T. W. Day, M. Panthöfer, G. J. Snyder, W. Tremel, J. Am. Chem. Soc. 2014, 136, 12035.

[71] a) J. B. Vaney, G. Delaizir, E. Alleno, O. Rouleau, A. Piarristeguy, J. Monnier, C. Godart, M. Ribes, R. Escalier, A. Pradel, A. P. Goncalves, E. B. Lopes, G. J. Cuello, P. Ziolkowski, E. Muller, C. Candolfi, A. Dauscher, B. Lenoir, J. Mater. Chem. A 2013, 1, 8190; b) J. B. Vaney, A. Piarristeguy, A. Pradel, E. Alleno, B. Lenoir, C. Candolfi, A. Dauscher, A. P. Gonçalves, E. B. Lopes, G. Delaizir, J. Monnier, M. Ribes, C. Godart, J. Solid State Chem. 2013, 203, 212.

[72] a) Y. Li, T. Zhang, Y. Qin, T. Day, G. Jeffrey Snyder, X. Shi, L. Chen, J. Appl. Phys. 2014, 116, 203705; b) N. Tsujii, T. Mori, Y. Isoda, J. Electron. Mater. 2014, 43, 2371.

[73] P. Qiu, T. Zhang, Y. Qiu, X. Shi, L. Chen, Energy Environ. Sci. 2014, 7, 4000.

[74] a) J. R. Sootsman, D. Y. Chung, M. G. Kanatzidis, Angew. Chem. Int. Ed. 2009, 48, 8616; b) K. Kurosaki, S. Yamanaka, Phys. Status Solidi (a) 2013, 210, 82. 
[75] a) B. Wölfing, C. Kloc, J. Teubner, E. Bucher, Phys. Rev. Lett. 2001, 86, 4350; b) K. Kurosaki, A. Kosuga, H. Muta, S. Yamanaka, Mater. Trans. 2005, 46, 1502.

[76] a) H. Zhang, J. He, B. Zhang, Z. Su, T. Tritt, N. Soheilnia, H. Kleinke, J. Electron. Mater. 2007, 36, 727; b) C. Candolfi, B. Lenoir, C. Chubilleau, A. Dauscher, E. Guilmeau, J. Phys.: Condens. Matter 2010, 22, 025801.

[77] H. Xu, K. M. Kleinke, T. Holgate, D. Rossouw, G. Botton, T. M. Tritt, H. Kleinke, J. Alloys Compd. 2010, 504, 314.

[78] a) M. Ohta, A. Yamamoto, H. Obara, J. Electron. Mater. 2010, 39, 2117; b) T. Zhou, B. Lenoir, C. Christophe, A. Dauscher, P. Gall, P. Gougeon, M. Potel, E. Guilmeau, J. Electron. Mater. 2011, 40, 508; c) R. Al Rahal Al Orabi, P. Gougeon, P. Gall, B. Fontaine, R. Gautier, M. Colin, C. Candolfi, A. Dauscher, J. Hejtmanek, B. Malaman, B. Lenoir, Inorg. Chem. 2014, 53, 11699.

[79] a) M.-L. Liu, F.-Q. Huang, L.-D. Chen, I.-W. Chen, Appl. Phys. Lett. 2009, 94, 202103; b) X. Y. Shi, F. Q. Huang, M. L. Liu, L. D. Chen, Appl. Phys. Lett. 2009, 94, 122103; c) F.-J. Fan, Y.-X. Wang, X.-J. Liu, L. Wu, S.-H. Yu, Adv. Mater. 2012, 24, 6158; d) K. Suekuni, M. Kunii, H. Nishiate, M. Ohta, A. Yamamoto, M. Koyano, J. Electron. Mater. 2012, 41, 1130; e) H. Yang, L. A. Jauregui, G. Zhang, Y. P. Chen, Y. Wu, Nano Lett. 2012, 12, 540; f) K. Suekuni, K. Tsuruta, H. Fukuoka, M. Koyano, J. Alloys Compd. 2013, 564, 91; g) J. Navrátil, V. Kucek, T. Plecháček, E. Černošková, F. Laufek, Č. Drašar, P. Knotek, J. Electron. Mater. 2014, 43, 3719.

[80] J.-S. Rhyee, E. Cho, K. H. Lee, S. I. Kim, E. S. Lee, S. M. Lee, Y. S. Kwon, J. Appl. Phys. 2009, $105,053712$.

[81] J.-S. Rhyee, E. Cho, K. H. Lee, S. M. Lee, S. I. Kim, H.-S. Kim, Y. S. Kwon, S. J. Kim, Appl. Phys. Lett. 2009, 95, 212106.

[82] J.-S. Rhyee, J. Kim, Mater. Today 2015, 8, 1283.

[83] G. Tan, L.-D. Zhao, F. Shi, J. W. Doak, S.-H. Lo, H. Sun, C. Wolverton, V. P. Dravid, C. Uher, M. G. Kanatzidis, J. Am. Chem. Soc. 2014, 136, 7006.

[84] a) K. Ahn, E. Cho, J.-S. Rhyee, S. Il Kim, S. Mock Lee, K. Hyoung Lee, Appl. Phys. Lett. 2011, 99, 102110; b) J.-S. Rhyee, K. Ahn, K. H. Lee, H. S. Ji, J.-H. Shim, Adv. Mater. 2011, 23, 2191; c) G. H. Zhu, Y. C. Lan, H. Wang, G. Joshi, Q. Hao, G. Chen, Z. F. Ren, Phys. Rev. B 2011, 83, 115201; d) J.-Y. Yang, J. Wu, G. Li, J.-S. Zhang, J. Peng, J. Electron. Mater. 2012, 41, 1077; e) Y. Zhai, Q. Zhang, J. Jiang, T. Zhang, Y. Xiao, S. Yang, G. Xu, J. Alloys Compd. 2013, 553, 270; f) J. H. Kim, M. J. Kim, S. Oh, J.-S. Rhyee, J. Alloys Compd. 2014, 615, 933.

[85] J. Yang, G. Zhang, G. Yang, C. Wang, Y. X. Wang, J. Alloys Compd. 2015, 644, 615.

[86] G. Tan, F. Shi, J. W. Doak, H. Sun, L.-D. Zhao, P. Wang, C. Uher, C. Wolverton, V. P. Dravid, M. G. Kanatzidis, Energy Environ. Sci. 2015, 8, 267.

[87] Z. Li, L. Zhenag, J. Wang, Z. X. Cheng, Q. Sun, S. Dou, J. Mater. Chem. A 2016, DOI: 10.1039/C6TA01994C.

[88] a) G. Tewari, T. S. Tripathi, A. K. Rastogi, J. Electron. Mater. 2010, 39, 1133; b) F. Gascoin, A. Maignan, Chem. Mater. 2011, 23, 2510.

[89] S. Bhattacharya, A. Bohra, R. Basu, R. Bhatt, S. Ahmad, K. N. Meshram, A. K. Debnath, A. Singh, S. K. Sarkar, M. Navneethan, Y. Hayakawa, D. K. Aswal, S. K. Gupta, J. Mater. Chem. A 2014, 2, 17122.

[90] Y.-X. Chen, B.-P. Zhang, Z.-H. Ge, P.-P. Shang, J. Solid State Chem. 2012, 186, 109.

[91] a) E. Guilmeau, Y. Bréard, A. Maignan, Appl. Phys. Lett. 2011, 99, 052107; b) J. Zhang, X. Y. Qin, H. X. Xin, D. Li, C. J. Song, J. Electron. Mater. 2011, 40, 980; c) R. Nunna, F. Gascoin, E. Guilmeau, J. Alloys Compd. 2015, 634, 32; d) C. Wan, X. Gu, F. Dang, T. Itoh, Y. Wang, H. Sasaki, M. Kondo, K. Koga, K. Yabuki, G. J. Snyder, R. Yang, K. Koumoto, Nat Mater 2015, 14, 622; e) C. Wan, Y. Wang, N. Wang, K. Koumoto, Mater. Today 2010, 3, 2606; f) T. Holgate, Y. Liu, D. Hitchcock, T. Tritt, J. He, J. Electron. Mater. 2013, 42, 1751; g) P. Jood, M. Ohta, H. Nishiate, A. Yamamoto, O. I. Lebedev, D. Berthebaud, K. Suekuni, M. Kunii, Chem. Mater. 2014, 26, 2684. 
[92] M. Ohta, S. Satoh, T. Kuzuya, S. Hirai, M. Kunii, A. Yamamoto, Acta Mater. 2012, 60, 7232.

[93] M. Beaumale, T. Barbier, Y. Bréard, G. Guelou, A. V. Powell, P. Vaqueiro, E. Guilmeau, Acta Mater. 2014, 78, 86.

[94] a) T. P. Swastibrata Bhattacharyya, Abhishek K Singh, Nanotechnology 2014, 25, 465701(1; b) S. Kumar, U. Schwingenschlögl, Chem. Mater. 2015, 27, 1278; c) P. R. N. Misse, D. Berthebaud, O. I. Lebedev, A. Maignan, E. Guilmeau, Materials (1996-1944) 2015, 8, 2514.

[95] P. Ruleova, C. Drasar, P. Lostak, C. P. Li, S. Ballikaya, C. Uher, Mater. Chem. Phys. 2010, 119, 299.

[96] B. Zhan, Y. Liu, X. Tan, J.-1. Lan, Y.-h. Lin, C.-W. Nan, J. Am. Ceram. Soc. 2015, 98, 2465.

[97] S. N. Zhang, T. J. Zhu, S. H. Yang, C. Yu, X. B. Zhao, J. Alloys Compd. 2010, 499, 215.

[98] R. Mohanraman, R. Sankar, F. C. Chou, C. H. Lee, Y.-Y. Chen, J. Appl. Phys. 2013, 114, 163712.

[99] K. F. Hsu, S. Loo, F. Guo, W. Chen, J. S. Dyck, C. Uher, T. Hogan, E. K. Polychroniadis, M. G. Kanatzidis, Science 2004, 303, 818.

[100] Z.-Y. Li, J.-F. Li, Adv. Energy Mater. 2014, 4, n/a.

[101] C. M. J. Y Chen, Y B Gao, H Wang, T J Zhu, G J Snyder, J P Heremans, X B Zhao, New J. Phys. 2014, 16, 013057(1.

[102] S. K. Plachkovka, T. I. Georgiev, J. Phys.: Condens. Matter 1993, 5, 67.

[103] J. Q. Li, J. F. Deng, S. K. Li, Y. Li, F. S. Liu, W. Q. Ao, Intermetallics 2015, 56, 63.

[104] a) J. F. Deng, J. Q. Li, R. F. Ye, X. Y. Liu, F. S. Liu, W. Q. Ao, J. Alloys Compd. 2014, 585, 173; b) J. K. Lee, M. W. Oh, B. S. Kim, B. K. Min, H. W. Lee, S. D. Park, Electron. Mater. Letters 2014, 10, 813; c) Z. W. Lu, J. Q. Li, C. Y. Wang, Y. Li, F. S. Liu, W. Q. Ao, J. Alloys Compd. 2015, 621, 345 .

[105] T. Rosenthal, P. Urban, K. Nimmrich, L. Schenk, J. de Boor, C. Stiewe, O. Oeckler, Chem. Mater. 2014, 26, 2567.

[106] a) T. Rosenthal, S. Welzmiller, O. Oeckler, Solid State Sci. 2013, 25, 118; b) R. Sankar, D. P. Wong, C.-S. Chi, W.-L. Chien, J.-S. Hwang, F.-C. Chou, L.-C. Chen, K.-H. Chen, CrystEngComm 2015, 17, 3440.

[107] T. Schröder, S. Schwarzmüller, C. Stiewe, J. de Boor, M. Hölzel, O. Oeckler, Inorg. Chem. 2013, $52,11288$.

[108] F. Fahrnbauer, D. Souchay, G. Wagner, O. Oeckler, J. Am. Chem. Soc. 2015, 137, 12633.

[109] J. Q. Li, Z. W. Lu, H. J. Wu, H. T. Li, F. S. Liu, W. Q. Ao, J. Luo, J. Q. He, Acta Mater. 2014, 74, 215.

[110] C. J. Vineis, A. Shakouri, A. Majumdar, M. G. Kanatzidis, Adv. Mater. 2010, 22, 3970.

[111] C. Xiao, X. Qin, J. Zhang, R. An, J. Xu, K. Li, B. Cao, J. Yang, B. Ye, Y. Xie, J. Am. Chem. Soc. 2012, 134, 18460 .

[112] M. D. Lubomir GULAY, Oksana STROK, Adam PIETRASZKO, Chem. Metal Alloys 2011, 4, 200.

[113] L. Zhao, X. Wang, F. Y. Fei, J. Wang, Z. Cheng, S. Dou, J. Wang, G. J. Snyder, J. Mater. Chem. A 2015, 3, 9432 .

[114] C. Nethravathi, C. R. Rajamathi, M. Rajamathi, R. Maki, T. Mori, D. Golberg, Y. Bando, J. Mater. Chem. A 2014, 2, 985.

[115] L. Pan, D. Bérardan, N. Dragoe, J. Am. Chem. Soc. 2013, 135, 4914.

[116] a) D. R. Brown, T. Day, K. A. Borup, S. Christensen, B. B. Iversen, G. J. Snyder, APL Materials 2013, 1, 052107; b) C. Han, Q. Sun, Z. X. Cheng, J. L. Wang, Z. Li, G. Q. Lu, S. X. Dou, J. Am. Chem. Soc. 2014, 136, 17626; c) A. J. Hong, L. Li, H. X. Zhu, X. H. Zhou, Q. Y. He, W. S. Liu, Z. B. Yan, J. M. Liu, Z. F. Ren, Solid State Ionics 2014, 261, 21; d) W. Mi, P. Qiu, T. Zhang, Y. Lv, X. Shi, L. Chen, Appl. Phys. Lett. 2014, 104, 133903.

[117] a) Q. Jiang, H. Yan, J. Khaliq, Y. Shen, K. Simpson, M. J. Reece, J. Mater. Chem. A 2014, 2 , 9486; b) P. Q. Xiaobei Wang, Tiansong Zhang, Dudi Ren, Lihua Wu, Xun Shi, Jihui Yang, Lidong Chen, J. Mater. Chem. A 2015, 3, 13662. 
[118] X.-X. Xiao, W.-J. Xie, X.-F. Tang, Q.-J. Zhang, Chin. Phys. B 2011, 20, 087201.

[119] a) H. Wang, W. Chu, D. Wang, W. Mao, W. Pan, Y. Guo, Y. Xiong, H. Jin, J. Electron. Mater. 2011, 40, 624; b) D. Li, X. Y. Qin, Y. F. Liu, C. J. Song, L. Wang, J. Zhang, H. X. Xin, G. L. Guo, T. H. Zou, G. L. Sun, B. J. Ren, X. G. Zhu, RSC Advances 2014, 4, 8638; c) X. Q. Chen, Z. Li, S. X. Dou, Appl. Mater. Interface 2015, 7, 13295; d) K. Tyagi, B. Gahtori, S. Bathula, M. Jayasimhadri, N. K. Singh, S. Sharma, D. Haranath, A. K. Srivastava, A. Dhar, J. Phys. Chem. Solids 2015, 81, 100.

[120] a) F. Drymiotis, T. W. Day, D. R. Brown, N. A. Heinz, G. Jeffrey Snyder, Appl. Phys. Lett. 2013, 103, 143906; b) L. Zhao, X. Wang, F. F. Yun, J. Wang, Z. Cheng, S. Dou, J. Wang, G. J. Snyder, Adv. Electron. Mater. 2015, 1 , n/a.

[121] L. Zou, B.-P. Zhang, Z.-H. Ge, C. Gao, D.-B. Zhang, Y.-C. Liu, Phys. Status Solidi (a) 2013, 210, 2550.

[122] B. Gahtori, S. Bathula, K. Tyagi, M. Jayasimhadri, A. K. Srivastava, S. Singh, R. C. Budhani, A. Dhar, Nano Energy 2015, 13, 36.

[123] P. L. Ying He, Xun Shi, Fangfang Xu, Tiansong Zhang, Gerald Geffrey Snyder, Ctirad Uher, Lidong Chen, Adv. Mater. 2015, 27, 3639.

[124] G. Dennler, R. Chmielowski, S. Jacob, F. Capet, P. Roussel, S. Zastrow, K. Nielsch, I. Opahle, G. K. H. Madsen, Adv. Energy Mater. 2014, 4, n/a.

[125] D. Tian, H. Liu, Y. Deng, Z. Du, J. Cui, RSC Advances 2014, 4, 34104.

[126] a) S. Yamanaka, M. Ishimaru, A. Charoenphakdee, H. Matsumoto, K. Kurosaki, J. Electron. Mater. 2009, 38, 1392; b) J. Cui, Y. Gao, H. Zhou, Y. Li, Q. Meng, J. Yang, Appl. Phys. Lett. 2012, 101, 081908.

[127] Y. Gao, P. Ying, J. Cui, S. Chen, Y. Li, Procedia Engin. 2012, 27, 156.

[128] a) M. Ohta, S. Hirai, J. Electron. Mater. 2009, 38, 1287; b) A. Charoenphakdee, K. Kurosaki, A. Harnwunggmoung, H. Muta, S. Yamanaka, J. Alloys Compd. 2010, 496, 53; c) J.-S. Rhyee, E. Cho, K. H. Lee, S. M. Lee, H.-s. Kim, Y. S. Kwon, J. Appl. Phys. 2010, 107, 053705; d) J. V. Zaikina, T. Mori, K. Kovnir, D. Teschner, A. Senyshyn, U. Schwarz, Y. Grin, A. V. Shevelkov, Chem. A. Europ. J. 2010, 16, 12582; e) O. Mayasree, C. R. Sankar, Y. Cui, A. Assoud, H. Kleinke, Eur. J. Inorg. Chem. 2011, 2011, 4037; f) C.-Y. Meng, H. Chen, P. Wang, L. Chen, Chem. Mater. 2011, 23, 4910; g) M. Ohta, S. Hirai, T. Kuzuya, J. Electron. Mater. 2011, 40, 537; h) X. Wang, R. Yang, Y. Zhang, P. Zhang, Y. Xue, Appl. Phys. Lett. 2011, 98, 222110; i) B. Kim, I. Kim, B.-k. Min, M. Oh, S. Park, H. Lee, Electron. Mater. Letters 2013, 9, 477; j) T. Kyratsi, M. Ioannou, J. Electron. Mater. 2013, 42, 1604; k) H. Lin, H. Chen, J.-N. Shen, L. Chen, L.-M. Wu, Chem. A. Europ. J. 2014, 20, 15401; 1) M. Wu, Y. Xiao, Z. Fu, Z. Li, J. Xu, J. Jiang, H. Jiang, G. Xu, J. Electron. Mater. 2014, 43, 3087; m) W. Xie, S. Populoh, K. Gałązka, X. Xiao, L. Sagarna, Y. Liu, M. Trottmann, J. He, A. Weidenkaff, J. Appl. Phys. 2014, 115, 103707; n) H. Zhang, S. Li, D. Li, S. Jin, S. Shen, T. Ying, Z. Lin, K. Li, D. Yuan, H. Zhao, Mater. Lett. 2015, 152, 117; o) D. Parker, A. F. May, H. Wang, M. A. McGuire, B. C. Sales, D. J. Singh, Phys. Rev. B 2013, 87, 045205; p) J. Heo, G. Laurita, S. Muir, M. A. Subramanian, D. A. Keszler, Chem. Mater. 2014, 26, 2047; q) C. Uhlig, E. Guenes, A. Schulze, M. Elm, P. Klar, S. Schlecht, J. Electron. Mater. 2014, 43, 2362; r) D. Wu, Y. Pei, Z. Wang, H. Wu, L. Huang, L.-D. Zhao, J. He, Adv. Funct. Mater. 2014, 24, 7763; s) J. Corps, P. Vaqueiro, A. Aziz, R. Grau-Crespo, W.

Kockelmann, J.-C. Jumas, A. V. Powell, Chem. Mater. 2015, 27, 3946.

[129] B. Yu, M. Zebarjadi, H. Wang, K. Lukas, H. Wang, D. Wang, C. Opeil, M. Dresselhaus, G. Chen, Z. Ren, Nano Lett. 2012, 12, 2077.

[130] a) M. Ibáñez, R. Zamani, S. Gorsse, J. Fan, S. Ortega, D. Cadavid, J. R. Morante, J. Arbiol, A. Cabot, ACS Nano 2013, 7, 2573; b) M. Ibáñez, R. Zamani, W. Li, D. Cadavid, S. Gorsse, N. A. Katcho, A. Shavel, A. M. López, J. R. Morante, J. Arbiol, A. Cabot, Chem. Mater. 2012, 24, 4615; c) F. Wu, W. Shi, X. Hu, Electron. Mater. Letters 2015, 11, 127.

[131] C. Han, Z. Li, G. Q. Lu, S. Xue Dou, Nano Energy 2015, 15, 193. 
[132] C. Kim, D. H. Kim, Y. S. Han, J. S. Chung, S. Park, H. Kim, Powder Technol. 2011, 214, 463.

[133] K. Ding, H. Lu, Y. Zhang, M. L. Snedaker, D. Liu, J. A. Maciá-Agulló, G. D. Stucky, J. Am. Chem. Soc. 2014, 136, 15465.

[134] a) J. S. Son, H. Zhang, J. Jang, B. Poudel, A. Waring, L. Nally, D. V. Talapin, Angew. Chem. Int. Ed. 2014, 53, 7466; b) H. Z. Dmitriy S. Dolzhnikov, Jaeyoung Jang, Jae Sung Son, Mattew G. Panthani, Tomohiro Shibata, Soma Chattopadhyay, Dmitri V. Talapin, Science 2015, 347, 425.

[135] a) Y. G. Xu Sun, Changzheng Wu, Yi Xie, Adv. Mater. 2015, 27, 3850; b) K. M. Y. Joonki Suh, Deyi Fu, Xinyu Liu, Fan Yang, Jin Fan, David J. Smith, Yong-Hang Zhang, Jacek K. Furdyna, Chris Dames, Wladyslaw Walukiewicz, Junqiao Wu, Adv. Mater. 2015, 27, 3681.

[136] A. M. Ibrahim, D. A. Thompson, Nuclear Instruments and Methods in Physics Research Section B: Beam Interactions with Materials and Atoms 1985, 7-8, Part 2, 566.

[137] C. Wu, F. Feng, J. Feng, J. Dai, L. Peng, J. Zhao, J. Yang, C. Si, Z. Wu, Y. Xie, J. Am. Chem. Soc. 2011, 133, 13798.

[138] M. H. Lee, J.-S. Rhyee, M. Vaseem, Y.-B. Hahn, S.-D. Park, H. Jin Kim, S.-J. Kim, H. J. Lee, C. Kim, Appl. Phys. Lett. 2013, 102, 223901.

[139] Y. Min, G. Park, B. Kim, A. Giri, J. Zeng, J. W. Roh, S. I. Kim, K. H. Lee, U. Jeong, ACS Nano 2015, 9, 6843.

[140] Z.-Y. Li, M. Zou, J.-F. Li, J. Alloys Compd. 2013, 549, 319.

[141] Y. Pei, H. Wang, G. J. Snyder, Adv. Mater. 2012, 24, 6125.

[142] D. Vasilevskiy, R. A. Masut, S. Turenne, J. Electron. Mater. 2012, 41, 1057.

[143] B. Poudel, Q. Hao, Y. Ma, Y. Lan, A. Minnich, B. Yu, X. Yan, D. Wang, A. Muto, D. Vashaee, X. Chen, J. Liu, M. S. Dresselhaus, G. Chen, Z. Ren, Science 2008, 320, 634.

[144] a) S.-J. Jung, S. Kim, H.-H. Park, D.-B. Hyun, S.-H. Baek, J.-S. Kim, J. Electron. Mater. 2014, 43, 1726; b) V. Ponnambalam, D. Morelli, J. Electron. Mater. 2015, 44, 2089.

[145] A. Patyk, J. Electron. Mater. 2010, 39, 2023.

[146] M. Zebarjadi, B. Liao, K. Esfarjani, M. Dresselhaus, G. Chen, Adv. Mater. 2013, 25, 1577.

[147] a) Z. Lu, M. Layani, X. Zhao, L. P. Tan, T. Sun, S. Fan, Q. Yan, S. Magdassi, H. H. Hng, Small 2014, 10, 3551; b) D. Madan, Z. Wang, P. K. Wright, J. W. Evans, Applied Energy 2015, 156, 587; c) B. T. McGrail, A. Sehirlioglu, E. Pentzer, Angewandte Chemie International Edition 2015, 54, 1710; d) J. Y. Oh, J. H. Lee, S. W. Han, S. S. Chae, E. J. Bae, Y. H. Kang, W. J. Choi, S. Y. Cho, J.-O. Lee, H. K. Baik, T. I. Lee, Energy Environ. Sci. 2016, DOI: 10.1039/C5EE03813H; e) K. V. Selvan, M. S. Mohamed Ali, Renewable and Sustainable Energy Reviews 2016, 54, 1035; f) Y. Sun, J. A. Rogers, Adv. Mater. 2007, 19, 1897; g) T. Wada, Y. Matsuo, S. Nomura, Y. Nakamura, A. Miyamura, Y. Chiba, A. Yamada, M. Konagai, Phys. Status Solidi (a) 2006, 203, 2593; h) C. Yan, P. S. Lee, Small 2014, 10, 3443; i) C. Yu, A. Murali, K. Choi, Y. Ryu, Energy Environ. Sci. 2012, 5, 9481; j) B. Zhang, J. Sun, H. E. Katz, F. Fang, R. L. Opila, ACS Appl. Mater. Interface 2010, 2, 3170; k) W. Zhao, H. T. Tan, L. P. Tan, S. Fan, H. H. Hng, Y. C. F. Boey, I. Beloborodov, Q. Yan, ACS Appl. Mater. Interface 2014, 6, 4940; 1) C. Zhou, C. Dun, Q. Wang, K. Wang, Z. Shi, D. L. Carroll, G. Liu, G. Qiao, ACS Appl. Mater. Interface 2015, 7, 21015.

[148] a) A. Besganz, V. Zöllmer, R. Kun, E. Pál, L. Walder, M. Busse, Procedia Technology 2014, 15, 99; b) C. Cho, B. Stevens, J.-H. Hsu, R. Bureau, D. A. Hagen, O. Regev, C. Yu, J. C. Grunlan, Adv. Mater. 2015, 27, 2996; c) G. Delaizir, J. Monnier, M. Soulier, R. Grodzki, B. Villeroy, J. Testard, J. Simon, C. Navone, C. Godart, Sensors and Actuators A: Physical 2012, 174, 115; d) C. Dun, C. A. Hewitt, H. Huang, D. S. Montgomery, J. Xu, D. L. Carroll, Physical Chemistry Chemical Physics 2015, 17, 8591; e) S. Kim, J. H. Son, S. H. Lee, B. K. You, K.-I. Park, H. K. Lee, M. Byun, K. J. Lee, Adv. Mater. 2014, 26, 7480; f) S. J. Kim, J. H. We, B. J. Cho, Energy Environ. Sci. 2014, 7, 1959; g) K. Kusagaya, M. Takashiri, J. Alloys Compounds 2015, 653, 480; h) L.-X. Liang, Y. Deng, Y. Wang, H.-L. Gao, J. Cui, J Nanopart Res 2014, 16, 1. 
[149] P. Jackson, D. Hariskos, E. Lotter, S. Paetel, R. Wuerz, R. Menner, W. Wischmann, M. Powalla, Prog. Photovoltaics: Res. Appl. 2011, 19, 894.

[150] D. Kraemer, B. Poudel, H.-P. Feng, J. C. Caylor, B. Yu, X. Yan, Y. Ma, X. Wang, D. Wang, A. Muto, K. McEnaney, M. Chiesa, Z. Ren, G. Chen, Nat Mater 2011, 10, 532.

[151] K. Kurosaki, H. Matsumoto, A. Charoenphakdee, S. Yamanaka, M. Ishimaru, Y. Hirotsu, Appl. Phys. Lett. 2008, 93, 012101.

[152] L. P. Bulat, V. T. Bublik, I. A. Drabkin, V. V. Karataev, V. B. Osvenskii, Y. N. Parkhomenko, G. I. Pivovarov, D. A. Pshenai-Severin, N. Y. Tabachkova, J. Electron. Mater. 2010, 39, 1650.

[153] K. Kim, K. Kim, G. Ha, Electron. Mater. Letters 2010, 6, 177.

[154] N. Keawprak, S. Lao-ubol, C. Eamchotchawalit, Z. M. Sun, J. Alloys Compd. 2011, 509, 9296.

[155] J. J. Shen, Z. Z. Yin, S. H. Yang, C. Yu, T. J. Zhu, X. B. Zhao, J. Electron. Mater. 2011, 40, 1095.

[156] X. Guo, X. Jia, K. Jie, H. Sun, Y. Zhang, B. Sun, H. Ma, Chem. Phys. Lett. 2013, 568-569, 190.

[157] J. Li, Q. Tan, J.-F. Li, D.-W. Liu, F. Li, Z.-Y. Li, M. Zou, K. Wang, Adv. Funct. Mater. 2013, 23, 4317.

[158] G. Lee, G. Ha, J. Electron. Mater. 2014, 43, 1697.

[159] P.-Y. Lee, J. Hao, T.-Y. Chao, J.-Y. Huang, H.-L. Hsieh, H.-C. Hsu, J. Electron. Mater. 2014, 43, 1718.

[160] K. Lee, S.-M. Choi, J. Roh, S. Hwang, S. Kim, W. Shin, H. Park, J. Lee, S. Kim, D. Yang, J. Electron. Mater. 2015, 44, 1531.

[161] F. Yu, J. Zhang, D. Yu, J. He, Z. Liu, B. Xu, Y. Tian, J. Appl. Phys. 2009, 105, 094303.

[162] Y. Zhou, X. Li, S. Bai, L. Chen, J. Cryst. Growth 2010, 312, 775.

[163] C. Kim, D. H. Kim, J. S. Kim, Y. S. Han, J. S. Chung, H. Kim, J. Alloys Compd. 2011, 509, 9472.

[164] C. E. Carlton, C. A. Kuryak, W.-s. Liu, Z. Ren, G. Chen, Y. Shao-Horn, J. Appl. Phys. 2012, 112, 093518.

[165] G.-E. Lee, A. Y. Eum, K.-M. Song, I.-H. Kim, Y. Lim, W.-S. Seo, B.-J. Choi, C.-W. Hwang, J. Electron. Mater. 2015, 44, 1579.

[166] Q. Zhang, X. Ai, L. Wang, Y. Chang, W. Luo, W. Jiang, L. Chen, Adv. Funct. Mater. 2015, 25, 966.

[167] B. Yu, Q. Zhang, H. Wang, X. Wang, H. Wang, D. Wang, H. Wang, G. J. Snyder, G. Chen, Z. F. Ren, J. Appl. Phys. 2010, 108, 016104.

[168] C. Kang, H. Wang, H. Kim, S.-J. Kim, W. Kim, J. Electron. Mater. 2014, 43, 353.

[169] S. N. Girard, J. He, C. Li, S. Moses, G. Wang, C. Uher, V. P. Dravid, M. G. Kanatzidis, Nano Lett. 2010, 10, 2825.

[170] H. Zhang, J. Luo, H.-T. Zhu, J.-K. Liang, L.-M. Ruan, Q.-L. Liu, J.-B. Li, G.-Y. Liu, Acta Mater. 2012, 60, 7241.

[171] J. Q. Li, X. X. Li, F. S. Liu, W. Q. Ao, H. T. Li, J. Electron. Mater. 2013, 42, 366.

[172] X. X. Li, J. Q. Li, F. S. Liu, W. Q. Ao, H. T. Li, L. C. Pan, J. Alloys Compd. 2013, 547, 86.

[173] A. Bali, H. Wang, G. J. Snyder, R. C. Mallik, J. Appl. Phys. 2014, 116, 033707.

[174] O. Falkenbach, D. Hartung, P. Klar, G. Koch, S. Schlecht, J. Electron. Mater. 2014, 43, 1674.

[175] P. K. Rawat, B. Paul, P. Banerji, Appl. Mater. Interface 2014, 6, 3995.

[176] Y. Lee, S.-H. Lo, C. Chen, H. Sun, D.-Y. Chung, T. C. Chasapis, C. Uher, V. P. Dravid, M. G. Kanatzidis, Nat Commun 2014, 5.

[177] H. Fan, T. Su, H. Li, B. Du, B. Liu, H. Sun, Y. Zhang, L. Li, S. Li, M. Hu, H. Ma, X. Jia, J. Alloys Compd. 2015, 639, 106.

[178] Q. Zhang, E. K. Chere, K. McEnaney, M. Yao, F. Cao, Y. Ni, S. Chen, C. Opeil, G. Chen, Z. Ren, Adv. Energy Mater. 2015, 5, n/a.

[179] L.-D. Zhao, S.-H. Lo, J. He, H. Li, K. Biswas, J. Androulakis, C.-I. Wu, T. P. Hogan, D.-Y. Chung, V. P. Dravid, M. G. Kanatzidis, J. Am. Chem. Soc. 2011, 133, 20476.

[180] L.-D. Zhao, J. He, C.-I. Wu, T. P. Hogan, X. Zhou, C. Uher, V. P. Dravid, M. G. Kanatzidis, J. Am. Chem. Soc. 2012, 134, 7902. 
[181] Z. Ye, J. Young Cho, M. M. Tessema, J. R. Salvador, R. A. Waldo, H. Wang, W. Cai, J. Solid State Chem. 2013, 201, 262.

[182] J. Y. Cho, X. Shi, J. R. Salvador, J. Yang, H. Wang, J. Appl. Phys. 2010, 108, 073713.

[183] E. J. Skoug, J. D. Cain, D. T. Morelli, J. Alloys Compd. 2010, 506, 18.

[184] J. Fan, W. Carrillo-Cabrera, L. Akselrud, I. Antonyshyn, L. Chen, Y. Grin, Inorg. Chem. 2013, 52, 11067.

[185] J. Fan, H. Liu, X. Shi, S. Bai, X. Shi, L. Chen, Acta Mater. 2013, 61, 4297.

[186] R. Chetty, D. S. Prem Kumar, M. Falmbigl, P. Rogl, S. W. You, I.-H. Kim, R. C. Mallik, Intermetallics 2014, 54, 1.

[187] C. Raju, M. Falmbigl, P. Rogl, P. Heinrich, E. Royanian, E. Bauer, R. C. Mallik, Mater. Chem. Phys. 2014, 147, 1022.

[188] X. Y. Li, D. Li, H. X. Xin, J. Zhang, C. J. Song, X. Y. Qin, J. Alloys Compd. 2013, 561, 105.

[189] S. N. Guin, D. S. Negi, R. Datta, K. Biswas, J. Mater. Chem. A 2014, 2, 4324.

[190] R. Mohanraman, R. Sankar, K. M. Boopathi, F.-C. Chou, C.-W. Chu, C.-H. Lee, Y.-Y. Chen, J. Mater. Chem. A 2014, 2, 2839.

[191] K. Kurosaki, H. Uneda, H. Muta, S. Yamanaka, J. Alloys Compd. 2004, 376, 43.

[192] C. R. Sankar, S. Bangarigadu-Sanasy, A. Assoud, H. Kleinke, J. Mater. Chem. 2010, $20,7485$.

[193] C. Sankar, S. Bangarigadu-Sanasy, H. Kleinke, J. Electron. Mater. 2012, 41, 1662.

[194] S. Bangarigadu-Sanasy, C. R. Sankar, P. Schlender, H. Kleinke, J. Alloys Compd. 2013, 549, 126.

[195] Q. Guo, M. Chan, B. A. Kuropatwa, H. Kleinke, Chem. Mater. 2013, 25, 4097.

[196] H. Takahashi, N. Raghavendra, F. Gascoin, D. Pelloquin, S. Hébert, E. Guilmeau, Chem. Mater. 2013, 25, 1809.

[197] B. A. Kuropatwa, Q. Guo, A. Assoud, H. Kleinke, Z. Anorg. Allg. Chem. 2014, 640, 774.

[198] H. Fu, P. Ying, J. Cui, Y. Yan, X. Zhang, J. Electron. Mater. 2011, 40, 937.

[199] A. Banik, K. Biswas, J. Mater. Chem. A 2014, 2, 9620.

[200] L. D. Ivanova, V. G. Leontyev, L. I. Petrova, Y. V. Granatkina, E. S. Avilov, Inorg. Mater. 2014, $50,124$.

[201] Q. Tan, J.-F. Li, J. Electron. Mater. 2014, 43, 2435.

[202] Y. Li, X. Shi, D. Ren, J. Chen, L. Chen, Energies 2015, 8, 6275.

[203] B.-Z. Sun, Z. Ma, C. He, K. Wu, RSC Advances 2015, 5, 56382.

[204] X. Shi, J. Y. Cho, J. R. Salvador, J. Yang, H. Wang, Appl. Phys. Lett. 2010, 96, 162108.

[205] J. Cho, Y. Lim, S.-M. Choi, K. Kim, W.-S. Seo, H.-H. Park, J. Electron. Mater. 2011, 40, 1024.

[206] J. Cui, X. Liu, X. Zhang, Y. Li, Y. Deng, J. Appl. Phys. 2011, 110, 023708.

[207] J.-H. Yim, H.-H. Park, H. Jang, M.-J. Yoo, D.-S. Paik, S. Baek, J.-S. Kim, J. Electron. Mater. 2012, 41, 1354.

[208] G. Li, J. Yang, Y. Luo, Y. Xiao, L. Fu, M. Liu, J. Peng, J. Am. Ceram. Soc. 2013, 96, 2703.

[209] G. Li, J. Yang, Y. Xiao, L. Fu, J. Peng, Y. Deng, P. Zhu, H. Yan, J. Electron. Mater. 2013, 42, 675.

[210] J. Kim, J.-S. Rhyee, Electron. Mater. Letters 2014, 10, 801.

[211] G. Tewari, T. S. Tripathi, P. Kumar, A. K. Rastogi, S. K. Pasha, G. Gupta, J. Electron. Mater. 2011, 40, 2368.

[212] A. Kaltzoglou, P. Vaqueiro, T. Barbier, E. Guilmeau, A. Powell, J. Electron. Mater. 2014, 43, 2029.

[213] G. C. Tewari, T. S. Tripathi, H. Yamauchi, M. Karppinen, Mater. Chem. Phys. 2014, 145, 156.

[214] R. Bhatt, R. Basu, S. Bhattacharya, A. Singh, D. K. Aswal, S. K. Gupta, G. S. Okram, V. Ganesan, D. Venkateshwarlu, C. Surgers, M. Navaneethan, Y. Hayakawa, Appl. Phys. A 2013, 111, 465.

[215] S. G. Tan, L. J. Li, Y. Liu, P. Tong, B. C. Zhao, W. J. Lu, Y. P. Sun, Phys. C: Supercond. 2012, 483, 94.

[216] K. Zhang, C. Hu, X. Kang, S. Wang, Y. Xi, H. Liu, Mater. Res. Bull. 2013, 48, 3968. 
[217] F. Drymiotis, T. Drye, D. Rhodes, Q. Zhang, J. C. Lashey, Y. Wang, S. Cawthorne, B. Ma, S. Lindsey, T. Tritt, J. Phys.: Condens. Matter 2010, 22, 035801.

[218] J. Xu, H. Li, B. Du, X. Tang, Q. Zhang, C. Uher, J. Mater. Chem. 2010, 20, 6138.

[219] B. Du, J. Xu, W. Zhang, X. Tang, J. Electron. Mater. 2011, 40, 1249.

[220] H.-j. Wu, S.-w. Chen, T. Ikeda, G. Jeffrey Snyder, Acta Mater. 2012, 60, 6144.

[221] J. Wu, J.-Y. Yang, J.-S. Zhang, G. Li, J.-Y. Peng, Y. Xiao, L.-W. Fu, Q.-Z. Liu, J. Electron. Mater. 2012, 41, 1100.

[222] S. Perlt, T. Höche, J. Dadda, E. Müller, B. Rauschenbach, J. Electron. Mater. 2013, 42, 1422.

[223] H.-j. Wu, T.-W. Lan, S.-w. Chen, Y.-Y. Chen, T. Day, G. J. Snyder, Acta Mater. 2015, 93, 38.

[224] X. Xin, Y. Jiang, D. Kong, H. Zhong, L. Chen, D. Yu, Phys. Status Solidi (a) 2010, 207, 163.

[225] P. F. P. Poudeu, A. Guéguen, C.-I. Wu, T. Hogan, M. G. Kanatzidis, Chem. Mater. 2010, 22, 1046.

[226] M. Zhou, J.-F. Li, H. Wang, T. Kita, L. Li, Z. Chen, J. Electron. Mater. 2011, 40, 862.

[227] H. Li, K. F. Cai, Y. Du, H. F. Wang, S. Z. Shen, X. L. Li, Y. Y. Wang, C. W. Zhou, Curr. Appl. Phys. 2012, 12, 188.

[228] Z.-Y. Li, J.-F. Li, J. Electron. Mater. 2012, 41, 1365.

[229] Z.-x. Yu, J.-F. Li, B.-P. Zhang, Z.-H. Ge, J. Electron. Mater. 2012, 41, 1337.

[230] Q. Zhang, Y. Lan, S. Yang, F. Cao, M. Yao, C. Opeil, D. Broido, G. Chen, Z. Ren, Nano Energy 2013, 2, 1121 .

[231] L. Zhang, W. Wang, B. Ren, J. Guo, J. Electron. Mater. 2013, 42, 1303.

[232] B. Yu, W. Liu, S. Chen, H. Wang, H. Wang, G. Chen, Z. Ren, Nano Energy 2012, 1, 472.

[233] Y. He, T. Day, T. Zhang, H. Liu, X. Shi, L. Chen, G. J. Snyder, Adv. Mater. 2014, 26, 3974.

[234] L. Zou, B.-P. Zhang, Z.-H. Ge, L.-J. Zhang, J. Mater. Res. 2014, 29, 1047.

[235] L.-1. Zhao, X.-1. Wang, J.-y. Wang, Z.-x. Cheng, S.-x. Dou, J. Wang, L.-q. Liu, Sci. Rept. 2015, 5, 7671.

[236] H. Zhu, J. Luo, H. Zhao, J. Liang, J. Mater. Chem. A 2015, 3, 10303.

[237] J. Capps, F. Drymiotis, S. Lindsey, T. M. Tritt, Philos. Mag. Lett. 2010, 90, 677. 


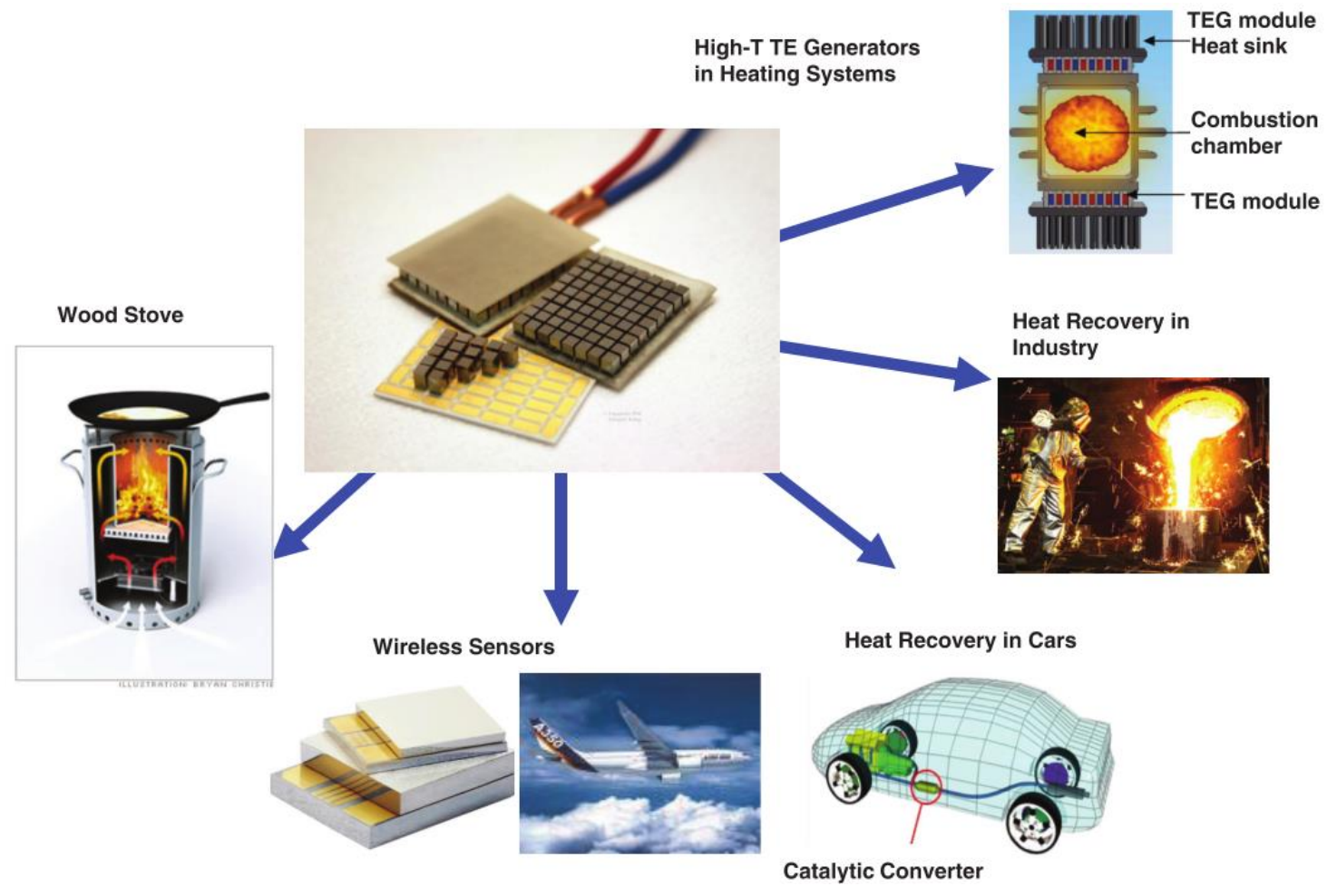

Figure 1. Typical applications of thermoelectric materials. ${ }^{[8 a]}$ Reprint with permission from WILEYVCH Verlag GmbH \& Co. KGaA, Weinheim. 


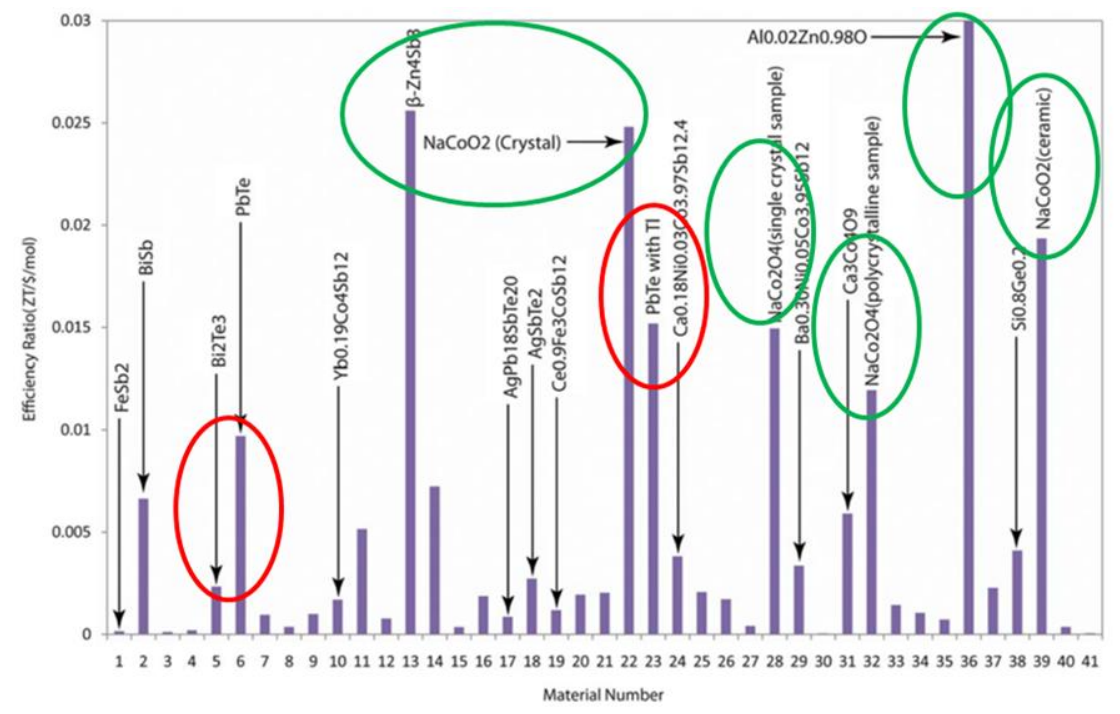

Figure 2. Efficiency ratios for various thermoelectric materials. ${ }^{[13]}$ Reprint with permission from Royal Society of Chemistry. 


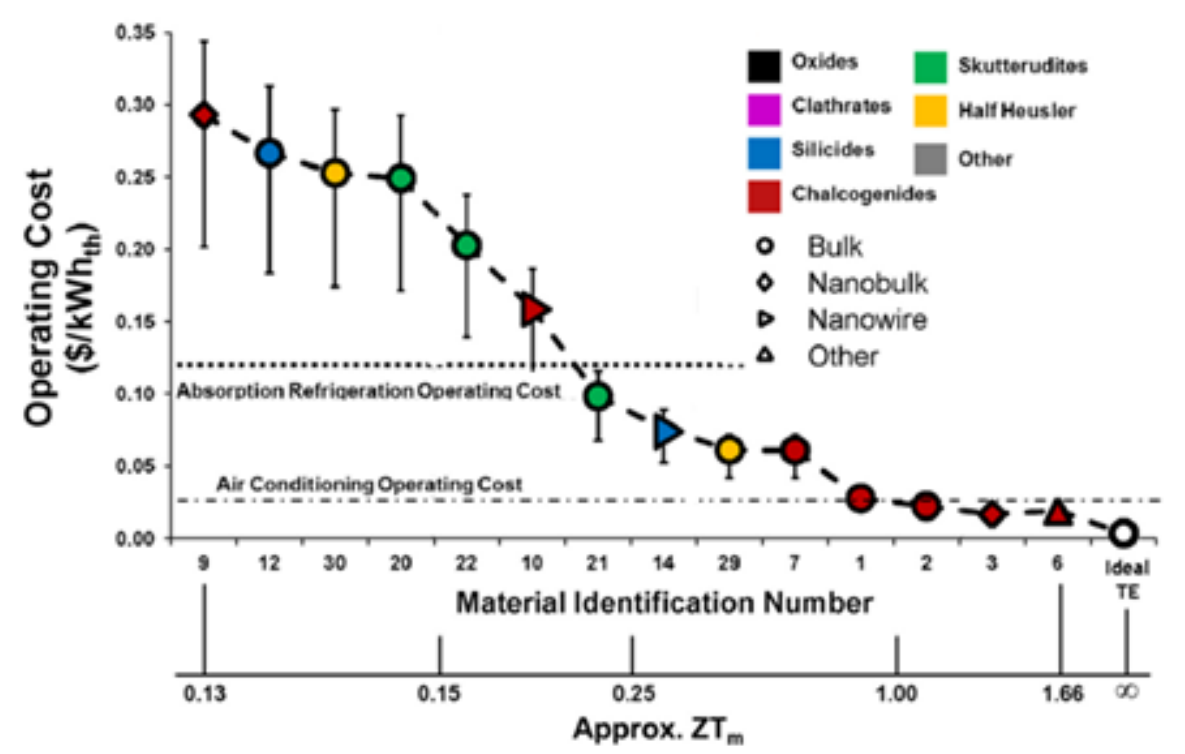

Figure 3. Operating costs of a thermoelectric cooler constructed from various materials. ${ }^{[14]}$ Reprint with permission from Elsevier Ltd. 


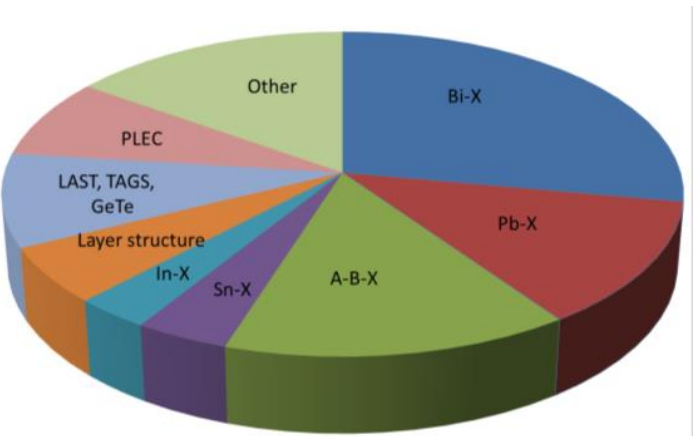

Figure 4. Shares of reports in the literature on different classes of metal chalcogenides. 


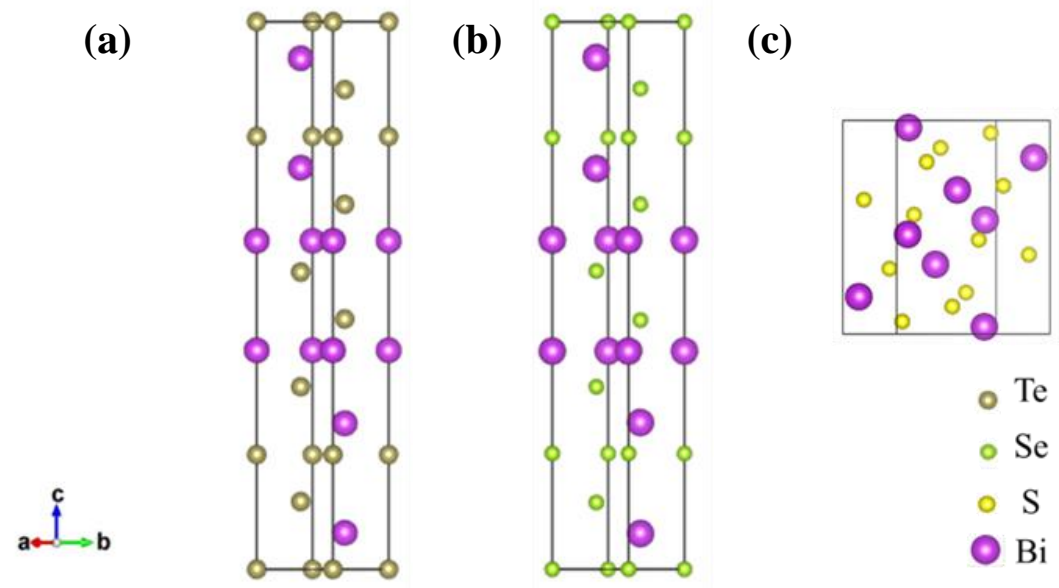

Figure 5. Crystal structures of (a) $\mathrm{Bi}_{2} \mathrm{Te}_{3}$; (b) $\mathrm{Bi}_{2} \mathrm{Se}_{3}$, and (c) $\mathrm{Bi}_{2} \mathrm{~S}_{3}$. 


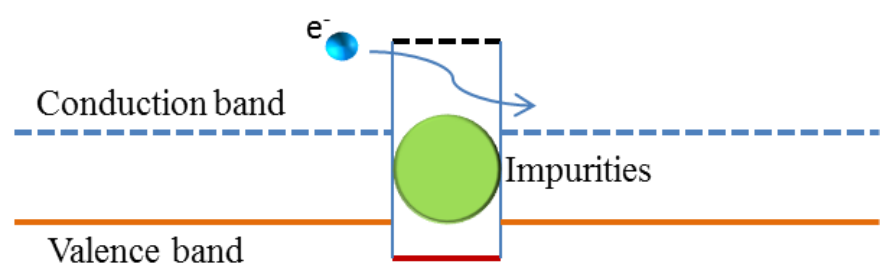

Figure 6. Schematic diagram of energy filtering effect (EFE). 


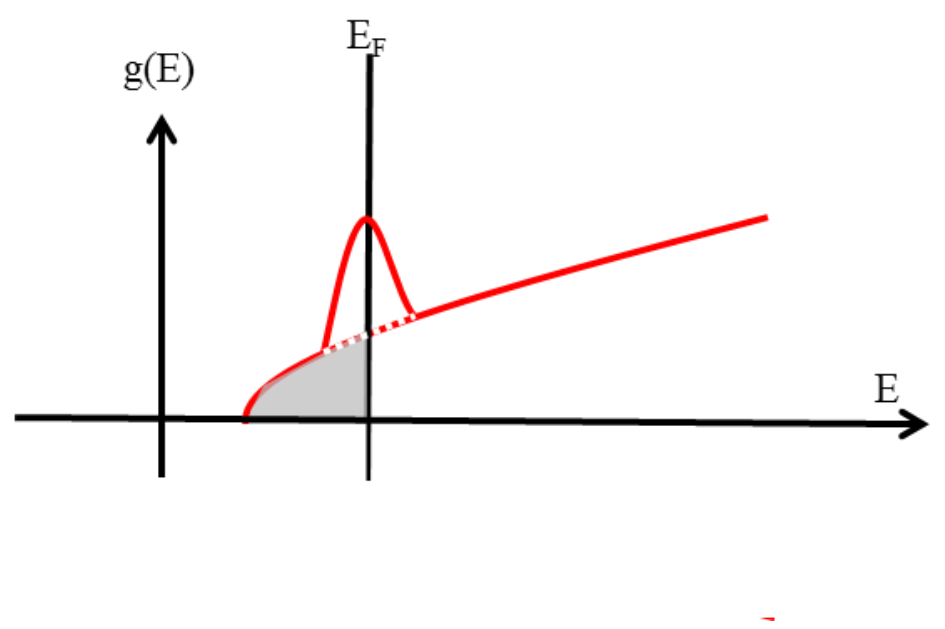

Figure 7. Schematic illustration of the density of states $(\mathrm{g}(\mathrm{E}))$ enhancement that can be achieved from the distortion caused by the resonant energy level. The dashed line corresponds to pure $\mathrm{Bi}_{2} \mathrm{Te}_{3}$, and the solid line corresponds to $\mathrm{Sn}-\mathrm{Bi}_{2} \mathrm{Te}_{3}$ (with resonant energy levels from $\mathrm{Sn}$ ). 

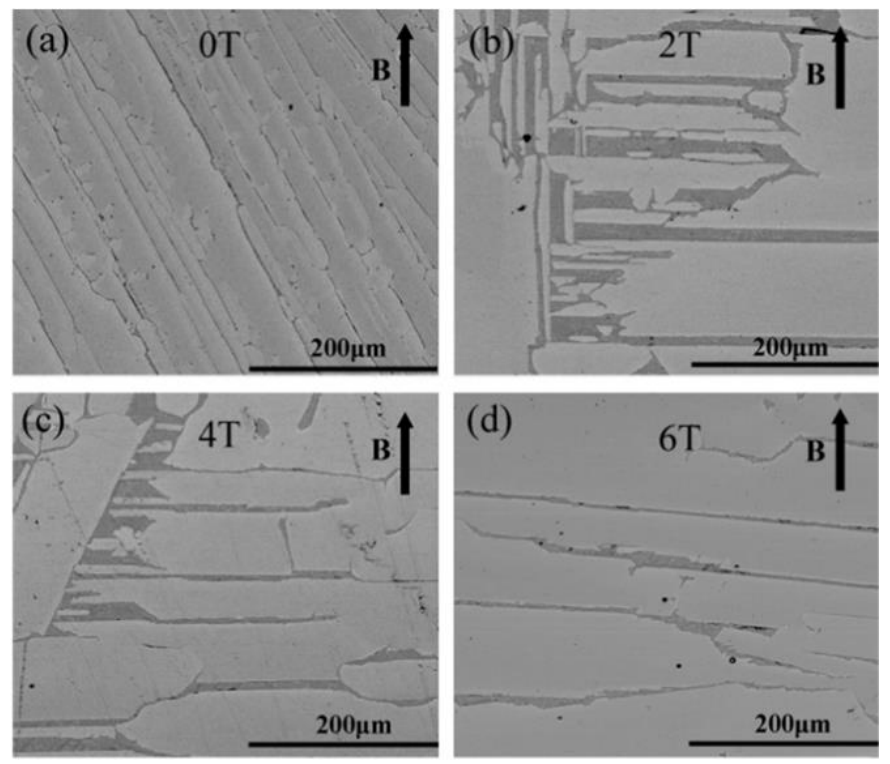

Figure 8. SEM images of a cross-section parallel to the magnetic field direction for $p$-type $\mathrm{Bi}_{0.5} \mathrm{Sb}_{1.5} \mathrm{Te}_{3}$ samples prepared under $0 \mathrm{~T}$ (a), $2 \mathrm{~T}$ (b), $4 \mathrm{~T}$ (c) , and $6 \mathrm{~T}$ (d). ${ }^{[33]}$ Reprint with permission from Elsevier Ltd. 
(a)

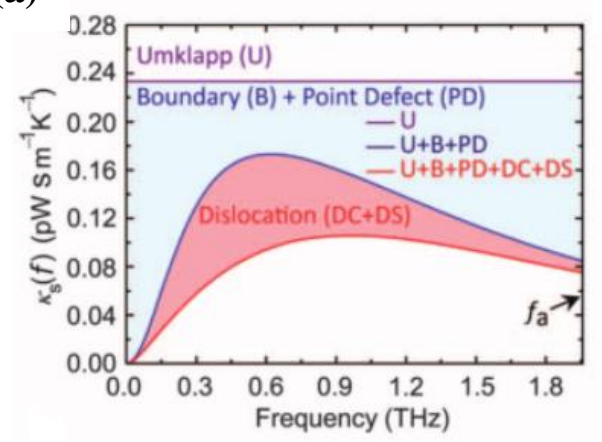

(b)

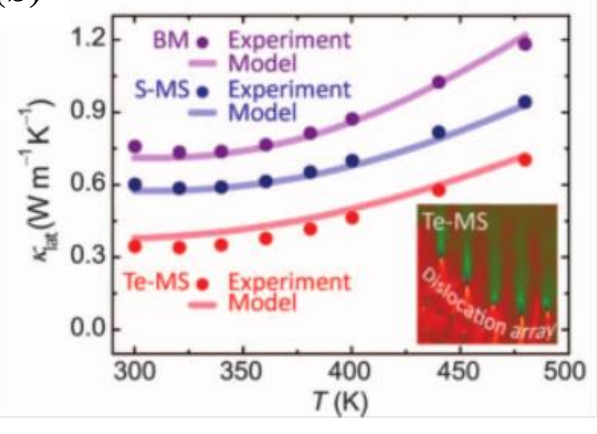

(c)

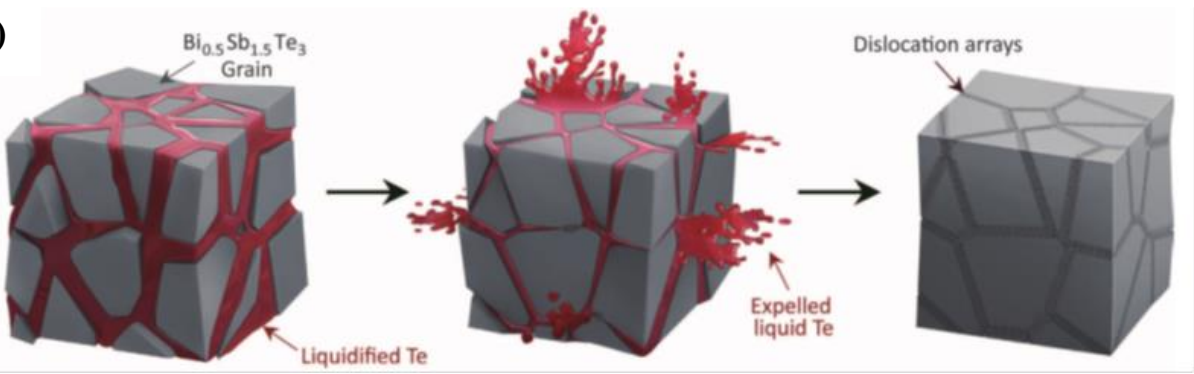

Figure 9. (a) The inclusion of dislocations for scattering is effective across the full frequency spectrum. Boundary and point defects are effective only at low and high frequencies. The acoustic mode Debye frequency is $f_{\mathrm{a}}$. (b) Lattice thermal conductivity for $\mathrm{Bi}_{0.5} \mathrm{Sb}_{1.5} \mathrm{Te}_{3}$ alloys produced by melt-solidification (ingot), solid-phase compaction (BM and S-MS), and liquid-phase compaction (Te-MS). (c) Schematic illustration of liquid-phase compaction using Te at $480^{\circ} \mathrm{C}^{[20 \mathrm{~b}]}$ Reprint with permission from the American Association for the Advancement of Science. 


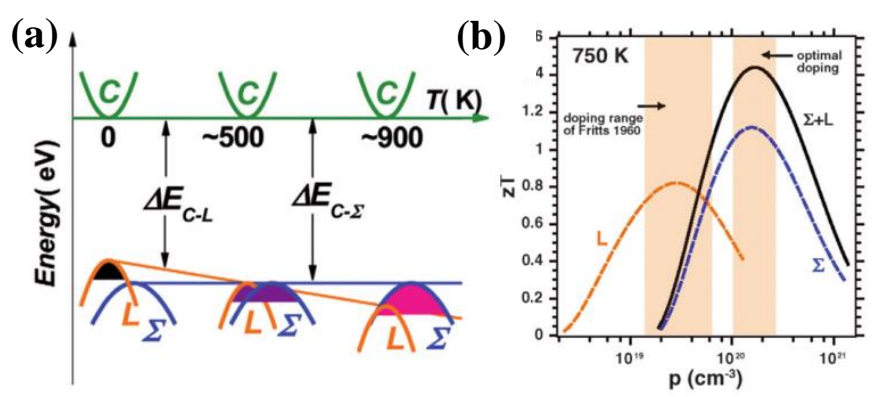

Figure 10. (a) Schematic illustration of two-band model for PbTe, and how the bands move with increasing temperature. The shaded areas schematically represent the hole population of each band. The orange line indicates the movement of the $\mathrm{L}$ band as the temperature increases; the $\Sigma$ band refers to the heavy valence band. (b) The calculated $Z T$ value as a function of carrier concentration for $p$-type PbTe, with a comparison of the results of transport from the $L$ or the $\Sigma$ band alone. The optimal carrier concentrations were proposed in the 1960 s and very recently were also confirmed. ${ }^{[5]}$ Reprint with permission from Elsevier Ltd. 


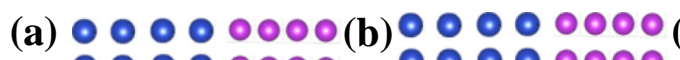

๑ ० ० ०००

$\bullet \bullet \bullet \bullet \bullet ० \bullet \bullet$

๑ ๑ ० ००००

๑ ० ०० ००००

$\bullet \bullet \bullet \bullet \bullet ० ० ०$

$\bullet \bullet \bullet \bullet \bullet ० ० ०$

००००००००

$\bullet \bullet \bullet \bullet ० ० ० \circ$

$\bullet \bullet \bullet \bullet \bullet ० ० ०$

0000

๑ ๑ ० ००००

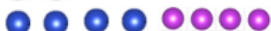

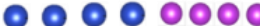

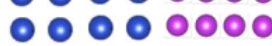

(c) $\odot \circ \circ \odot \circ \circ$

$\because \bullet: \bullet \bullet \bullet \bullet$

$\circ \circ \bullet: \circ: 0 \circ$

$\odot \odot \odot \odot ० ० ० ०$

$\circ \circ \bullet \bullet \circ 000$

$\bullet \odot \bullet \bullet^{\circ}$

Figure 11. Schematic illustration of (a) coherent grain boundaries; (b) semi-coherent boundaries; (c) incoherent boundaries. 


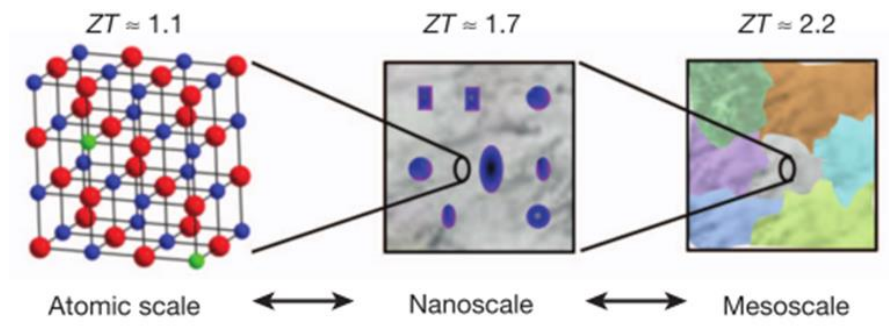

Figure 12. Maximum achievable $Z T$ values for the respective length scales: the atomic scale (alloy scattering: red, Te; blue, $\mathrm{Pb}$; green, dopant), the nanoscale (PbTe matrix, grey; SrTe nanocrystals, blue), and the mesoscale (grain-boundary scattering). ${ }^{[12]}$ Reprint with permission from the Nature Publishing Group. 
(a)

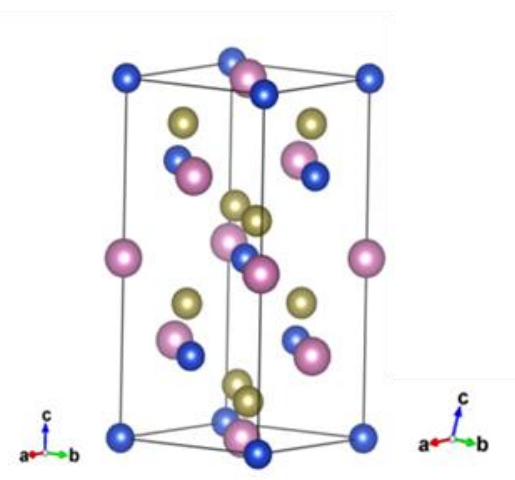

(b)

- $\mathrm{cu}$ in Osn ose

OTe OBi OAg

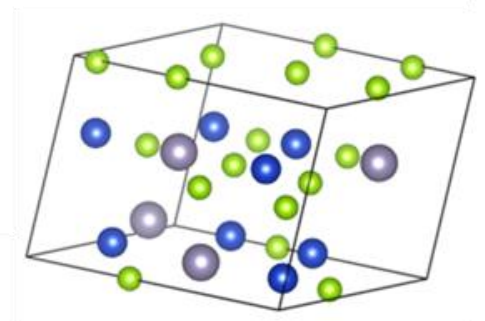

Figure 13. Crystal structures of some typical A-B-X based thermoelectric materials: (a) $\mathrm{CuInTe}_{2}$ type; (b) $\mathrm{Cu}_{2} \mathrm{SnSe}_{3}$ type. 

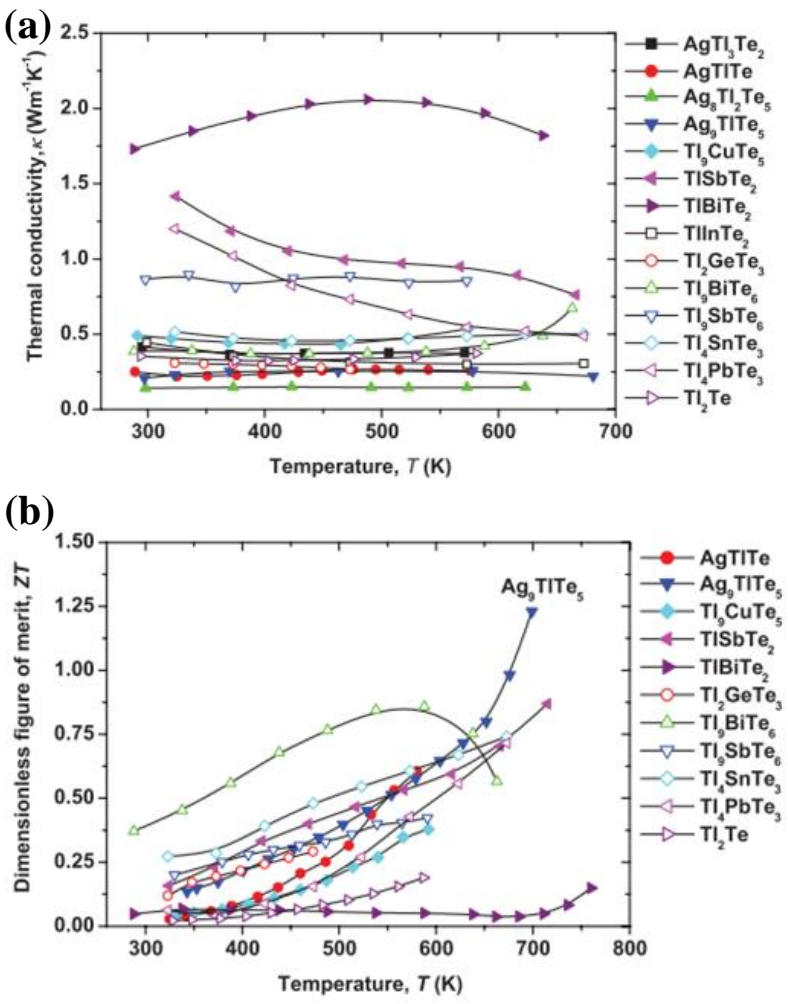

Figure 14. (a) Thermal conductivity and (b) $Z T$ values of some typical compounds in the Tl-M-Te system. ${ }^{[74 b]}$ Reprint with permission from WILEY-VCH Verlag GmbH \& Co. KGaA, Weinheim. 


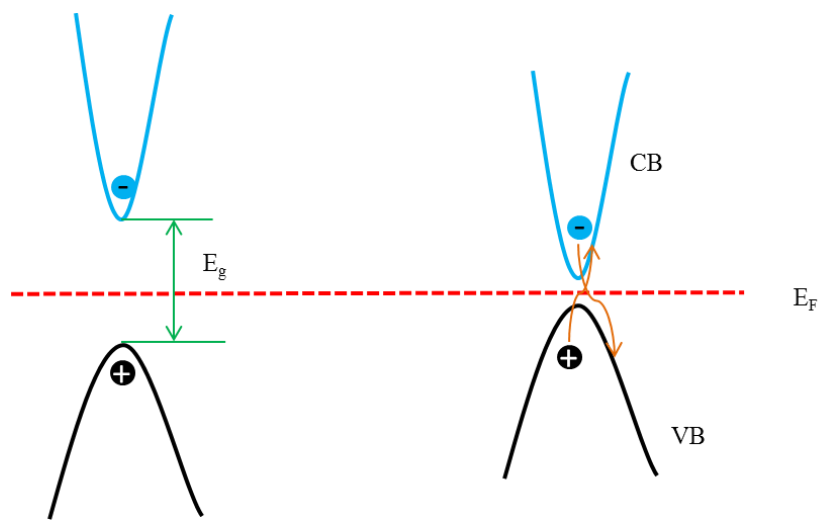

Figure 15. Bipolar effect of narrow-band-gap (right) semiconductor at high temperature. The situation for a large band gap (left) is also presented. 
(a)

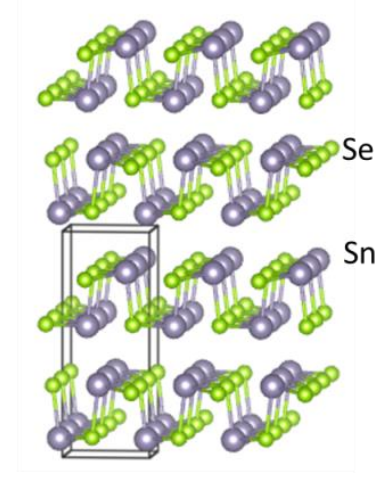

(b)

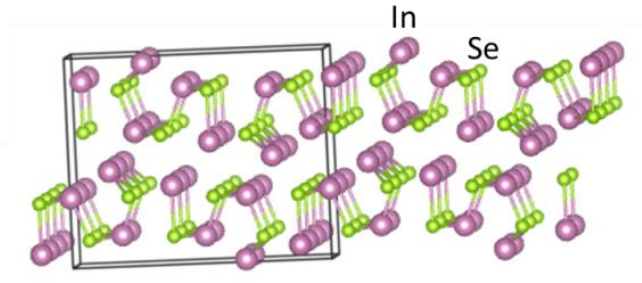

Figure 16. Crystal structure of (a) SnSe and (b) $\mathrm{In}_{4} \mathrm{Se}_{3}$. 
(a)

One-dimensional chain

๑०००००

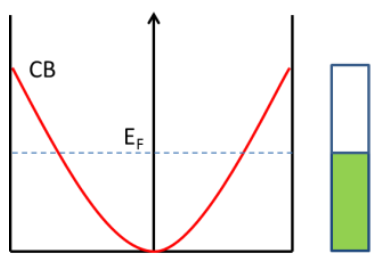

(a) (b)

Peierls distortion

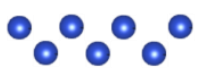

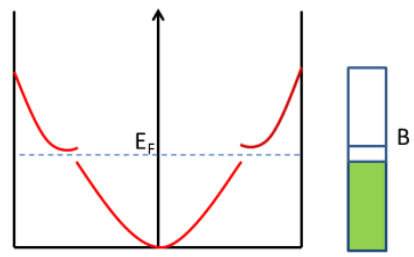

(b)

Figure 17. Effect of Peierls distortion: (a) Original state; (b) Peierls distortion state. 

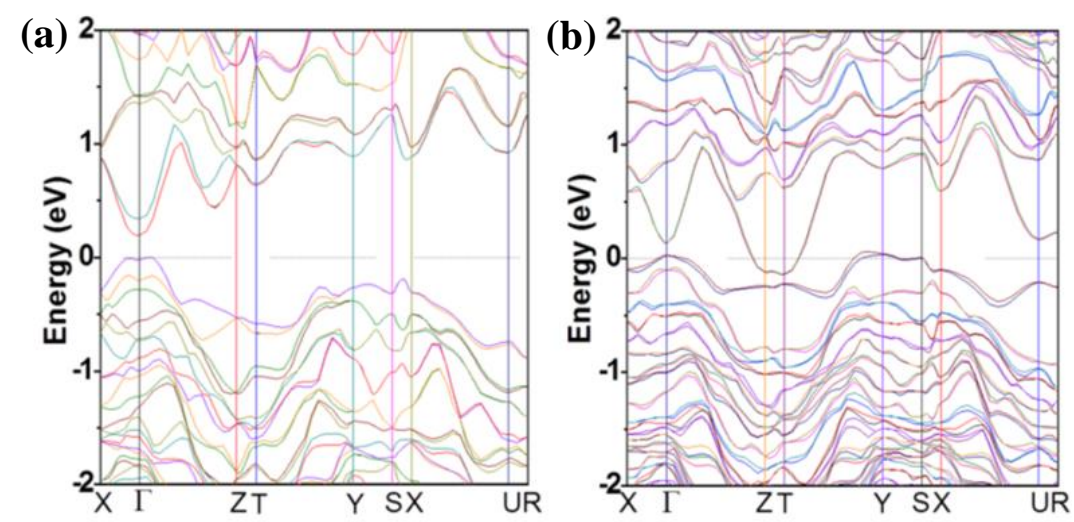

Figure 18. Band structure of $\operatorname{In}_{4} \mathrm{Se}_{3}$ (a) and $\operatorname{In}_{4} \mathrm{Se}_{2.75}$ (b). ${ }^{[81]}$ Reprint with permission from AIP Publishing LLC. 


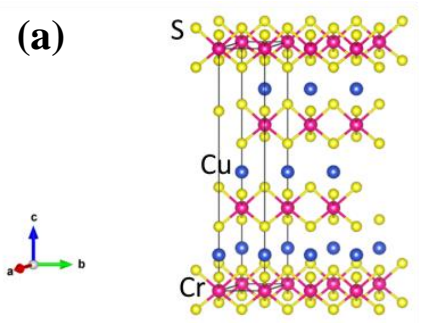

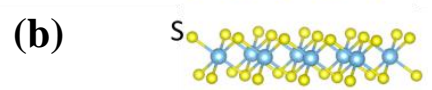

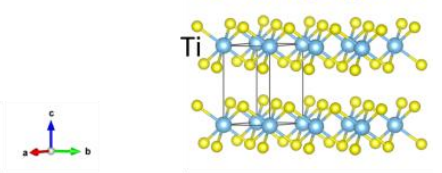

(c) semsigs

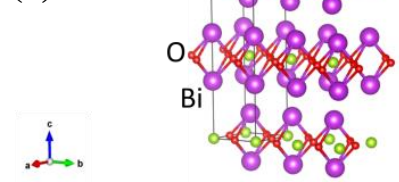

Figure 19. Crystal structures of (a) $\mathrm{CuCrS}_{2}$; (b) $\mathrm{TiS}_{2}$; (c) $\mathrm{Bi}_{2} \mathrm{O}_{2} \mathrm{Se}$. 


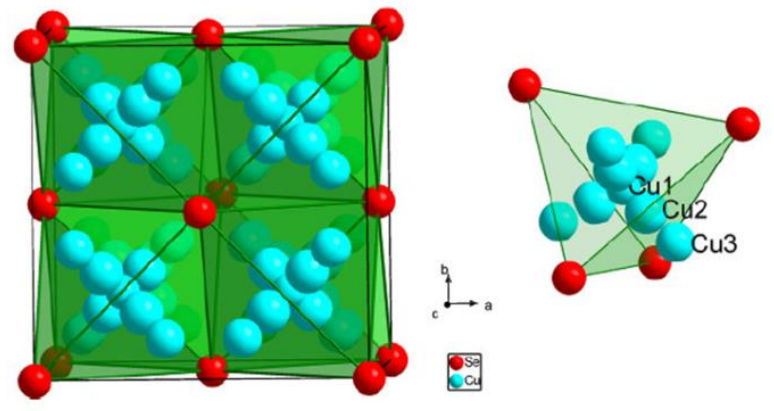

Figure 20. Crystal structure of the high temperature phase of $\mathrm{Cu}_{2} \mathrm{Se}$ (left) and the structure of the $\mathrm{Se}_{4}$ tetrahedron (right). ${ }^{[12]}$ Reprint with permission from Ivan Franko National University of Lviv. 

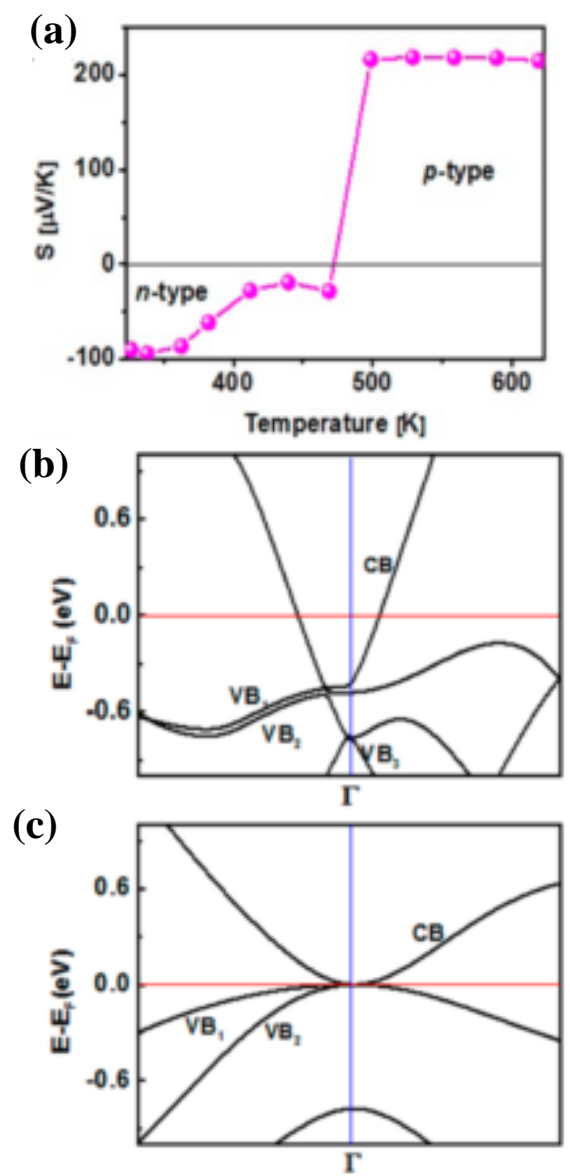

Figure 21. (a) Typical change in conduction type change for $\mathrm{CuAgSe}$ during the phase transition; band structures for the (b) low temperature phase and (c) high temperature PLEC status. ${ }^{[16 b]}$ Copyright 2014 from the American Chemical Society. 


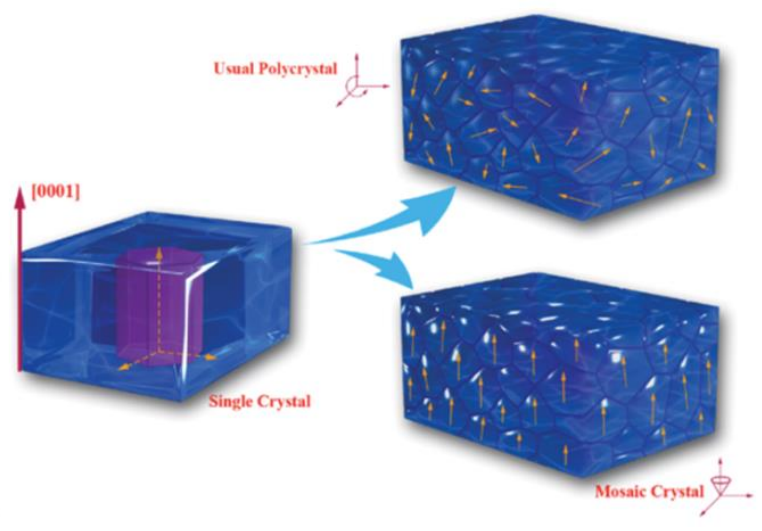

Figure 22. Schematic illustration of single crystal, polycrystal, and mosaic crystal. ${ }^{[123]}$ Reprint with permission from WILEY-VCH Verlag GmbH \& Co. KGaA, Weinheim. 
(a)

(b)
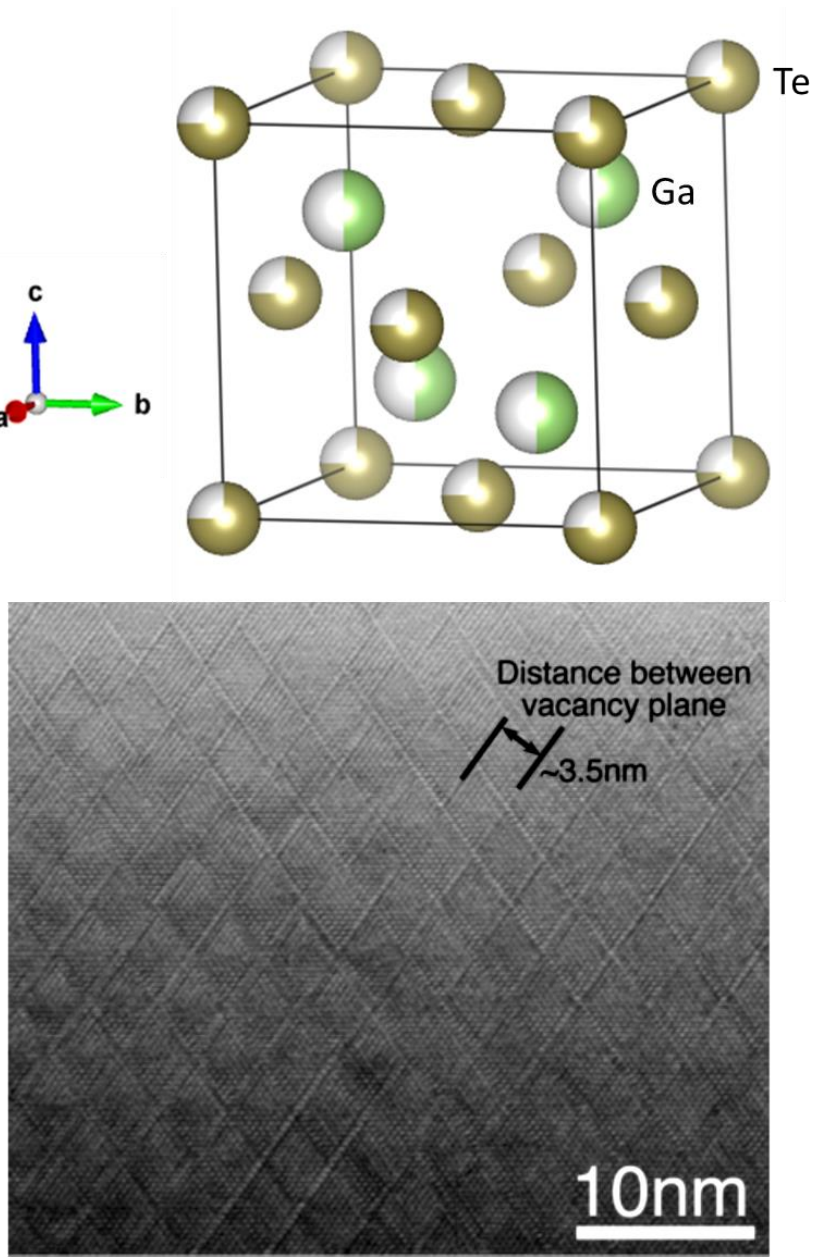

Figure 23. (a) Crystal structure of $\mathrm{Ga}_{2} \mathrm{Te}_{3}$, in which the white part is the vacancy; (b) high resolution transmission electron microscope (TEM) image of $\mathrm{Ga}_{2} \mathrm{Te}_{3}$, with the electron beam aligned along the [110] direction. ${ }^{[151]}$ Reprint with permission from AIP Publishing LLC. 

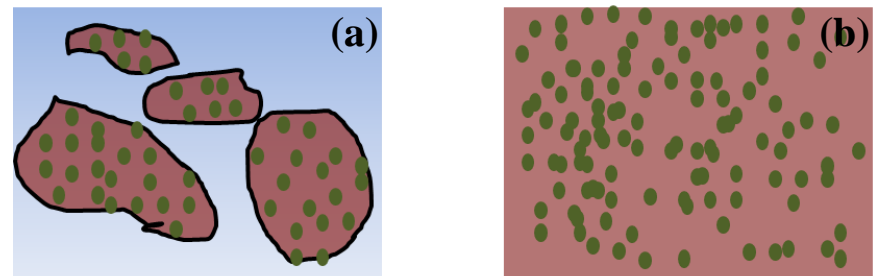

Undoped Matrix

Doped Matrix ${ }^{\bullet}$ Dopants

Figure 24. Schematic illustration of (a) modulation doping and (b) uniform doping. 


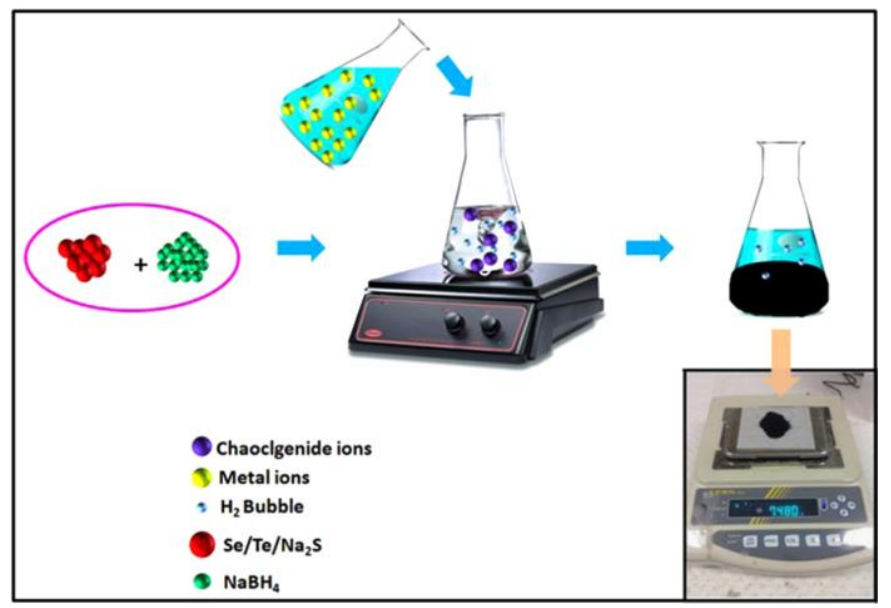

Figure 25. Schematic illustration of wet chemical synthesis route; the inset picture shows the weight of $40 \mathrm{mmol}$ (theoretical yield) for the synthesized $\mathrm{Cu}_{2}$ Se powder. ${ }^{358}$ Reprint with permission from Elsevier Ltd. 

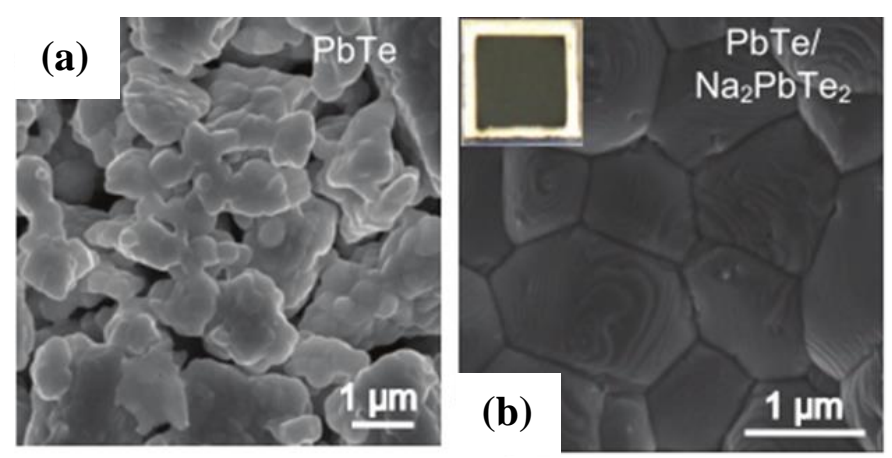

Figure 26. Microstructure of (a) ball-milled PbTe microparticles annealed at $500^{\circ} \mathrm{C}$ for 30 min, and (b) film of similar PbTe microparticles annealed in the presence of 5 wt $\% \mathrm{Na}_{2} \mathrm{PbTe}_{2}$, with the inset showing a photograph of the sample. ${ }^{[134 b]}$ Reprint with permission from the American Association for the Advancement of Science. 
Table 1. Recently reported $Z T$ values of BiSbTe and BiSeTe based materials.

\begin{tabular}{|c|c|c|c|c|c|}
\hline Materials & Type- $Z T_{\max }$ & $\begin{array}{l}\text { Temperature } \\
(\mathrm{K})\end{array}$ & Date & Ref. & Comments \\
\hline $\mathrm{Bi}_{0.5} \mathrm{Sb}_{1.5} \mathrm{Te}_{3}$ & $p-1.40$ & 373 & 2008 & {$[143]$} & $\begin{array}{l}\text { Ball milling (BM), spark } \\
\text { plasma sintering (SPS), } \\
\text { preserved nanostructures }\end{array}$ \\
\hline $\mathrm{Bi}_{0.5} \mathrm{Sb}_{1.5} \mathrm{Te}_{3}$ & $p-1.56$ & 300 & 2009 & [22] & $\begin{array}{l}\text { Melt spinning+SPS, } \\
\text { nanostructures }\end{array}$ \\
\hline $\mathrm{Bi}_{0.4} \mathrm{Sb}_{1.6} \mathrm{Te}_{3}$ & $p-1.12$ & 350 & 2010 & [152] & $\begin{array}{l}\text { Hot pressing }(\mathrm{HP}), \\
\text { nanograins }\end{array}$ \\
\hline $\mathrm{Bi}_{2} \mathrm{Te}_{3}$ & $p-1.18$ & 425 & 2010 & {$[153]$} & $\begin{array}{c}\text { Mechano-chemical process, } \\
\text { nanograins }\end{array}$ \\
\hline $\mathrm{Bi}_{0.5} \mathrm{Sb}_{1.5} \mathrm{Te}_{3}$ & $p-1.40$ & 300 & 2010 & {$[38 \mathrm{~b}]$} & $\begin{array}{l}\text { Hot forging }(\mathrm{HF}), \\
\text { recrystallization formed } \\
\text { nanograins }\end{array}$ \\
\hline $\mathrm{Bi}_{2} \mathrm{Te}_{3}$ & $p-1.38$ & 473 & 2010 & {$[27 c]$} & Nanopores in the bulk \\
\hline $\mathrm{Bi}_{2} \mathrm{Se}_{0.36} \mathrm{Te}_{2.67}$ & $p-1.20$ & 300 & 2011 & {$[154]$} & Optimized single crystal \\
\hline $\mathrm{Bi}_{0.5} \mathrm{Sb}_{1.5} \mathrm{Te}_{3}$ & $p-1.10$ & 300 & 2011 & [36a] & $\begin{array}{l}\text { Slip-casting under high } \\
\text { magnetic field }\end{array}$ \\
\hline $\begin{array}{c}0.1 \text { vol\% } \\
\mathrm{SiC}+\mathrm{Bi}_{0.5} \mathrm{Sb}_{1.5} \mathrm{Te}_{3}\end{array}$ & $p-0.97$ & 323 & 2011 & [26] & $\begin{array}{l}\text { Nanograins produced by } p \text { - } \\
\text { type } \mathrm{SiC}\end{array}$ \\
\hline $\mathrm{Bi}_{0.5} \mathrm{Sb}_{1.5} \mathrm{Te}_{3}$ & $p-1.11$ & 300 & 2011 & {$[155]$} & HF caused nanograins \\
\hline $\mathrm{Bi}_{0.5} \mathrm{Sb}_{1.5} \mathrm{Te}_{3}$ & $p-1.21$ & 323 & 2012 & {$[36 b]$} & $\begin{array}{l}\text { Slip casting under high } \\
\text { magnetic field, SPS }\end{array}$ \\
\hline $\mathrm{Bi}_{0.5} \mathrm{Sb}_{1.5} \mathrm{Te}_{3}$ & $p-1.10$ & 300 & 2012 & [24a] & Wet chemical method \\
\hline $\mathrm{Bi}_{2} \mathrm{Te}_{3}$ & $p-0.97$ & 365 & 2013 & {$[156]$} & $\begin{array}{c}\text { Synthesis under high } \\
\text { pressure }\end{array}$ \\
\hline $\mathrm{Cr}_{0.1} \mathrm{Bi}_{2} \mathrm{Te}_{3}$ & $p-0.80$ & 325 & 2013 & {$[29 f]$} & Effect of $\mathrm{Cr}$ doping \\
\hline $\begin{array}{c}\mathrm{Bi}_{0.5} \mathrm{Sb}_{1.5} \mathrm{Te}_{3}+0.2 \\
\% \mathrm{Mn}\end{array}$ & $p-1.47$ & 310 & 2013 & {$[27 r]$} & $\begin{array}{l}\text { Wet chemical method, metal } \\
\text { nanoparticle decoration }\end{array}$ \\
\hline $\begin{array}{c}0.5 \mathrm{at} \% \mathrm{In}+ \\
\mathrm{Bi}_{0.4} \mathrm{Sb}_{1.6} \mathrm{Te}_{3}\end{array}$ & $p-1.20$ & 320 & 2013 & [29g] & $\begin{array}{c}\text { Effects of Ga and In doping: } \\
\text { no effect on } \sigma \text {, but modified } \\
\text { DOS }\end{array}$ \\
\hline $\mathrm{Bi}_{0.5} \mathrm{Sb}_{1.5} \mathrm{Te}_{3}$ & $p-1.79$ & 373 & 2013 & [25] & $\begin{array}{c}\text { Improved parameters for } \\
\text { ball-milling }(\mathrm{BM})+\mathrm{SPS} \\
\text { process, } \\
\text { nanograins }\end{array}$ \\
\hline $\begin{array}{c}0.4 \mathrm{vol} \% \\
\mathrm{SiC}+\mathrm{Bi}_{0.3 .} \mathrm{Sb}_{1.7} \mathrm{Te}_{3}\end{array}$ & $p-1.33$ & 373 & 2013 & {$[157]$} & Effect of SiC \\
\hline $\begin{array}{c}5 \mathrm{wt} \% \mathrm{Cu}_{7} \mathrm{Te}_{4}+\mathrm{Bi}_{0} \\
{ }_{4} \mathrm{Sb}_{1.6} \mathrm{Te}_{3}\end{array}$ & $p-1.14$ & 444 & 2013 & {$[27 \mathrm{~h}]$} & Composite, nanograins \\
\hline $\mathrm{Bi}_{0.5} \mathrm{Sb}_{1.5} \mathrm{Te}_{3}+\mathrm{Te}$ & $p-1.05$ & 425 & 2013 & {$[27 \mathrm{k}]$} & $\begin{array}{l}\text { In-situ formed Te } \\
\text { nanoparticles }\end{array}$ \\
\hline $\mathrm{Bi}_{0.3} \mathrm{Sb}_{1.7} \mathrm{Te}_{3}$ & $p-1.30$ & 380 & 2014 & [20a] & Defect engineering \\
\hline $\mathrm{Bi}_{0.5} \mathrm{Sb}_{1.5} \mathrm{Te}_{3}$ & $p-1.60$ & 323 & 2014 & [35b] & $\begin{array}{l}\mathrm{HF} \text {, led to orientation of the } \\
\text { polycrystals }\end{array}$ \\
\hline $\mathrm{Bi}_{0.5} \mathrm{Sb}_{1.5} \mathrm{Te}_{3}$ & $p-0.64$ & 300 & 2014 & [144a] & $\begin{array}{c}\text { Effect of severe plastic } \\
\text { deformation }\end{array}$ \\
\hline $\mathrm{Bi}_{0.5} \mathrm{Sb}_{1.5} \mathrm{Te}_{3}$ & $p-1.00$ & 300 & 2014 & {$[158]$} & BM+Reduction method, \\
\hline
\end{tabular}




\begin{tabular}{|c|c|c|c|c|c|}
\hline $\mathrm{Bi}_{0.4} \mathrm{Sb}_{1.6} \mathrm{Te}_{3}$ & $p-1.19$ & 373 & 2014 & [159] & $\begin{array}{l}\text { Mixture of nanopowder and } \\
\text { micropowder }\end{array}$ \\
\hline $\mathrm{Bi}_{0.4} \mathrm{Sb}_{1.6} \mathrm{Te}_{3}$ & $p-1.20$ & 673 & 2014 & {$[34 \mathrm{e}]$} & BM, hot extrusion (HE) \\
\hline $\begin{array}{c}\mathrm{Bi}_{0.48} \mathrm{Sb}_{1.52} \mathrm{Te}_{3}+4 \\
\mathrm{~mol} \% \mathrm{WSe}_{2}\end{array}$ & $p-1.27$ & 360 & 2014 & {$[27 \mathrm{~m}]$} & Composite, nanograins \\
\hline $\mathrm{Bi}_{0.48} \mathrm{Sb}_{1.52} \mathrm{Te}_{3}$ & $p-1.40$ & 340 & 2014 & {$[37]$} & In-situ exfoliation, SPS \\
\hline $\begin{array}{l}\mathrm{Bi}_{0.42} \mathrm{Sb}_{1.5535} \mathrm{Ga}_{0.02} \\
{ }_{5} \mathrm{Ag}_{0.0015} \mathrm{Te}_{3}\end{array}$ & $p-1.15$ & 360 & 2015 & {$[160]$} & Effect of co-doping \\
\hline $\begin{array}{l}\mathrm{Bi}_{0.5} \mathrm{Sb}_{1.5} \mathrm{Te}_{3}+1 \\
\mathrm{vol} \% \mathrm{Cu}_{3} \mathrm{SbSe}_{4}\end{array}$ & $p-1.60$ & 476 & 2015 & {$[270]$} & $\begin{array}{l}\text { Carrier filtering effect, } \\
\text { nanocomposite }\end{array}$ \\
\hline $\mathrm{Bi}_{0.5} \mathrm{Sb}_{1.5} \mathrm{Te}_{3}$ & $p-1.71$ & 323 & 2015 & {$[33]$} & $\begin{array}{l}\text { Melt-solidification under } \\
\text { high magnetic field }\end{array}$ \\
\hline $\begin{array}{c}1 \mathrm{at} \% \\
\mathrm{Fe}+\mathrm{Bi}_{0.48} \mathrm{Sb}_{1.52} \mathrm{Te}_{3}\end{array}$ & $p-1.09$ & 300 & 2015 & {$[29 \mathrm{i}]$} & Effect of Fe doping \\
\hline $\mathrm{Bi}_{0.5} \mathrm{Sb}_{1.5} \mathrm{Te}_{3}$ & $p-1.86$ & 320 & 2015 & [20b] & $\begin{array}{c}\text { Nanograins, dislocation } \\
\text { arrays }\end{array}$ \\
\hline $\mathrm{Ce}_{0.1} \mathrm{Bi}_{1.9} \mathrm{Te}_{3}$ & $p-1.22$ & 386 & 2015 & {$[130 \mathrm{c}]$} & $\begin{array}{l}\text { Wet chemical method, } \\
\text { nanoflowers }\end{array}$ \\
\hline $\mathrm{Bi}_{0.4} \mathrm{Sb}_{1.6} \mathrm{Te}_{3}$ & $p-1.36$ & 400 & 2015 & {$[38 f]$} & $\begin{array}{l}\text { Zone melting, hot } \\
\text { deformation }\end{array}$ \\
\hline $\mathrm{Bi}_{2} \mathrm{Te}_{3}$ & $n-0.94$ & 398 & 2009 & {$[161]$} & $\mathrm{BM}+$ Hot press, nanograins \\
\hline $\mathrm{Bi}_{2} \mathrm{Se}_{0.3} \mathrm{Te}_{2.7}$ & $n-0.93$ & 300 & 2010 & {$[34 \mathrm{~b}]$} & $\begin{array}{l}\mathrm{HE} \text {, orientation of the } \\
\text { nanocrystals }\end{array}$ \\
\hline $\mathrm{Bi}_{2} \mathrm{Se}_{0.3} \mathrm{Te}_{2.7}$ & $n-1.04$ & 398 & 2010 & {$[34 c]$} & $\begin{array}{c}\text { Deformation induced } \\
\text { defects, orientation of } \\
\text { nanograins }\end{array}$ \\
\hline $\mathrm{Bi}_{2} \mathrm{Se}_{0.21} \mathrm{Te}_{2.79}$ & $n-1.14$ & 300 & 2010 & {$[162]$} & Grown in space, less defects \\
\hline $\mathrm{Bi}_{2} \mathrm{Te}_{3}$ & $n-0.61$ & 423 & 2011 & [132] & $\begin{array}{l}\text { Wet chemical method, } \\
\text { nanoparticles }\end{array}$ \\
\hline $\mathrm{Bi}_{2} \mathrm{Te}_{\mathrm{y}} \mathrm{Se}_{3-\mathrm{y}}$ & $n-0.70$ & 373 & 2011 & [163] & $\begin{array}{l}\text { Wet chemical method, } \\
\text { nanoparticles }\end{array}$ \\
\hline $\begin{array}{c}\text { 1vol\% } \% \mathrm{Al}_{2} \mathrm{O}_{3}+\mathrm{Bi}_{2} \\
\mathrm{Te}_{3}\end{array}$ & $n-0.99$ & 400 & 2011 & {$[27 \mathrm{~d}]$} & Dispersed nanoparticles \\
\hline $\mathrm{Bi}_{2} \mathrm{Se}_{0.3} \mathrm{Te}_{2.7}$ & $n-1.11$ & 423 & 2011 & {$[26]$} & $\begin{array}{c}\text { Nanograins, } \mathrm{SiC} \text { did not } \\
\text { increase } Z T\end{array}$ \\
\hline $\begin{array}{c}0.015 \mathrm{vol} \% \\
\text { MWCNTS+Bi } \\
\left.\mathrm{e}_{0.9} \mathrm{Se}_{0.1}\right)_{3}\end{array}$ & $n-0.98$ & 423 & 2011 & [27e] & $\begin{array}{l}\text { Carbon nanotubes as } \\
\text { electron donors, composite }\end{array}$ \\
\hline $\begin{array}{c}\left(\mathrm{Bi}_{0.99} \mathrm{Ag}_{0.04}\right)_{2}\left(\mathrm{Te}_{0}\right. \\
\left.{ }_{96} \mathrm{Se}_{0.04}\right)_{3}\end{array}$ & $n-0.74$ & 373 & 2011 & {$[29 c]$} & Effect of Ag doping \\
\hline $\mathrm{Bi}_{2} \mathrm{Se}_{0.3} \mathrm{Te}_{2.7}$ & $n-1.00$ & 300 & 2012 & {$[164]$} & $\begin{array}{c}\mathrm{BM} \text {, hot press, controlled } \\
\text { nanostructures }\end{array}$ \\
\hline $\mathrm{Bi}_{2} \mathrm{Se}_{0.3} \mathrm{Te}_{2.7}$ & $n-0.54$ & 300 & 2012 & {$[24 \mathrm{~b}]$} & Wet chemical method \\
\hline $\mathrm{Bi}_{2} \mathrm{Te}_{2} \mathrm{~S} / \mathrm{Se}$ & $n-0.80$ & 573 & 2013 & {$[45 \mathrm{~b}]$} & Effect of alloying \\
\hline $\mathrm{Bi}_{2} \mathrm{Te}_{3}$ & $n-1.00$ & 430 & 2013 & {$[21]$} & $\begin{array}{c}\text { Wet chemical exfoliation, } \\
\text { SPS }\end{array}$ \\
\hline $\mathrm{Bi}_{2} \mathrm{Te}_{3}$ & $n-1.16$ & 420 & 2013 & {$[23]$} & $\begin{array}{l}\text { Wet chemical method, } \\
\text { flower-like nanostructure }\end{array}$ \\
\hline$\left(\mathrm{In}_{4} \mathrm{Se}_{3}\right)_{0.03}+\left(\mathrm{Bi}_{2} \mathrm{~T}\right.$ & $n-1.00$ & 500 & 2013 & {$[27 i]$} & Composite \\
\hline
\end{tabular}




\begin{tabular}{|c|c|c|c|c|c|}
\hline $\begin{array}{c}\mathrm{Bi}_{2} \mathrm{Te}_{2.994} \mathrm{Cl}_{0.006}+0 \\
.5 \mathrm{wt} \% \mathrm{In}_{2} \mathrm{Te}_{3}\end{array}$ & $n-0.94$ & 300 & 2013 & [27j] & Phase separation \\
\hline $\mathrm{Bi}_{2} \mathrm{Se}_{0.3} \mathrm{Te}_{2.7}$ & $n-1.20$ & 445 & 2014 & [20a] & Defect engineering \\
\hline $\begin{array}{l}1.5 \mathrm{vol} \% \mathrm{Ag} \\
\mathrm{NW}+\mathrm{Bi}_{2} \mathrm{Te}_{3}\end{array}$ & $n-0.71$ & 475 & 2014 & {$[27 n]$} & Effect of Ag nanowires \\
\hline $\mathrm{Bi}_{2} \mathrm{Te}_{3} \mathrm{Se}_{0.3} \mathrm{I}_{0.0075}$ & $n-1.13$ & 423 & 2015 & [165] & Effect of I doping \\
\hline $\mathrm{Bi}_{2} \mathrm{Te}_{2.4} \mathrm{Se}_{0.6} / \mathrm{CNT}$ & $n-0.80$ & 425 & 2015 & [27q] & $\begin{array}{l}\text { BM, SPS, carbon nanotube } \\
(\mathrm{CNT}) \text { decrease grain size }\end{array}$ \\
\hline$\left(\mathrm{Bi}_{2} \mathrm{Se}_{3}\right)_{2}\left(\mathrm{Bi}_{2} \mathrm{Te}_{3}\right)_{8}$ & $n-0.71$ & 450 & 2015 & [139] & $\begin{array}{l}\text { Wet chemical method, } \\
\text { multishell structure }\end{array}$ \\
\hline $2 \mathrm{vol} \% \mathrm{Ag}+\mathrm{Bi}_{2} \mathrm{Te}_{3}$ & $n-0.77$ & 475 & 2015 & [166] & Ag nanoparticles \\
\hline
\end{tabular}


Table 2. Thermoelectric performance of $\mathrm{Bi}-\mathrm{Se}$ and $\mathrm{Bi}-\mathrm{S}$ systems.

\begin{tabular}{|c|c|c|c|c|c|}
\hline Materials & Type-ZT & $\begin{array}{c}\text { Temperature } \\
(\mathrm{K})\end{array}$ & Date & Ref. & Comments \\
\hline $\mathrm{Bi}_{1.99} \mathrm{Ag}_{0.01} \mathrm{~S}_{3}$ & $n-0.25$ & 573 & 2011 & [42a] & Ag doping \\
\hline $\mathrm{Bi}_{1.99} \mathrm{Ag}_{0.03} \mathrm{~S}_{3}$ & $n-0.23$ & 573 & 2012 & {$[42 \mathrm{c}]$} & Ag doping \\
\hline $\begin{array}{c}\mathrm{Bi}_{2} \mathrm{~S}_{2.7} \mathrm{Se}_{0.3}+0.5 \mathrm{~mol} \% \\
\mathrm{BiCl}_{3}\end{array}$ & $n-0.60$ & 760 & 2012 & {$[42 \mathrm{~b}]$} & $\begin{array}{l}\text { Alloy, } \mathrm{Cl} \\
\text { doping }\end{array}$ \\
\hline $\mathrm{Bi}_{2} \mathrm{~S}_{2.8} \mathrm{Se}_{0.15}$ & $n-0.16$ & 573 & 2013 & {$[45 \mathrm{c}]$} & $\begin{array}{c}\text { Alloy, } \\
\text { deficiency of } \\
\text { chalcogenides }\end{array}$ \\
\hline $\mathrm{Bi}_{2} \mathrm{Te}_{3}-\mathrm{Bi}_{2} \mathrm{~S}_{3}$ & $n-0.48$ & 500 & 2013 & [45a] & $\begin{array}{l}\text { Wet chemical } \\
\text { method, EFE, } \\
\text { inorganic } \\
\text { ligand capping }\end{array}$ \\
\hline $\mathrm{Bi}_{2} \mathrm{SeS}_{2}$ & $n-0.80$ & 773 & 2013 & {$[45 \mathrm{~b}]$} & $\begin{array}{l}\text { Alloy effect, } \\
\text { low thermal } \\
\text { conductivity }\end{array}$ \\
\hline $\mathrm{Bi}_{2} \mathrm{Se}_{3}$ & $p-0.41$ & 533 & 2014 & {$[40 \mathrm{a}]$} & $\begin{array}{l}\text { Nanoplatelets, } \\
\text { thermochemical } \\
\text { method }\end{array}$ \\
\hline $1 \mathrm{~mol} \% \mathrm{BiCl}_{3}+\mathrm{Bi}_{2} \mathrm{~S}_{3}$ & $n-0.60$ & 675 & 2014 & {$[42 \mathrm{~d}]$} & $\begin{array}{l}\text { BM, SPS, Cl } \\
\text { doping }\end{array}$ \\
\hline $\mathrm{Bi}_{2} \mathrm{~S}_{3}$ & $n-0.50$ & 723 & 2014 & [41] & $\begin{array}{l}\text { Wet chemical } \\
\text { method, net- } \\
\text { like structure }\end{array}$ \\
\hline $\mathrm{Bi}_{2} \mathrm{Se}_{3}$ & $n-0.75$ & 423 & 2015 & {$[40 \mathrm{~b}]$} & Single crystal \\
\hline $\mathrm{Bi}_{2} \mathrm{~S}_{2.5}$ & $n-0.10$ & 300 & 2015 & [44] & S deficiency \\
\hline $\mathrm{Cu}_{0.01} \mathrm{Bi}_{2} \mathrm{Se}_{3}$ & $n-0.54$ & 590 & 2015 & {$[42 \mathrm{~g}]$} & $\mathrm{Cu}$ doping \\
\hline $\mathrm{Cu}_{0.02} \mathrm{Bi}_{2} \mathrm{SeS}_{2}$ & $n-0.70$ & 723 & 2015 & [42e] & $\begin{array}{l}\text { Alloy, } \mathrm{Cu} \\
\text { doping }\end{array}$ \\
\hline $\begin{array}{c}0.5 \mathrm{~mol} \% \\
\mathrm{CuBr}_{2}+\mathrm{Bi}_{2} \mathrm{~S}_{3}\end{array}$ & $n-0.72$ & 773 & 2015 & {$[42 \mathrm{f}]$} & $\begin{array}{l}\mathrm{Cu} \text { intercalation } \\
\text { and } \mathrm{Br} \text { doping }\end{array}$ \\
\hline $1 \mathrm{~mol} \% \mathrm{ZnO}+\mathrm{Bi}_{2} \mathrm{~S}_{3}$ & $n-0.66$ & 675 & 2015 & [43] & $\begin{array}{c}\text { Composite, } \\
\text { formation of } \\
\mathrm{ZnS}\end{array}$ \\
\hline
\end{tabular}


Table 3. Thermoelectric performance of the $\mathrm{Pb}-\mathrm{X}$ system.

\begin{tabular}{|c|c|c|c|c|c|}
\hline Materials & $\begin{array}{l}\text { Type- } \\
\text { ZT }\end{array}$ & $\begin{array}{l}\text { Temperature } \\
(\mathrm{K})\end{array}$ & Date & Ref. & Comments \\
\hline $\mathrm{Pb}_{0.98} \mathrm{TeTl}_{0.02}$ & $p-1.50$ & 773 & 2009 & {$[32 \mathrm{~b}]$} & $\begin{array}{c}\text { Resonant doping } \\
\text { of } \mathrm{Tl}\end{array}$ \\
\hline $1.25 \% \mathrm{~K}+0.6 \% \mathrm{Na}+\mathrm{PbTe}$ & $p-1.30$ & 700 & 2010 & {$[47 \mathrm{a}]$} & $\begin{array}{c}\text { No resonant } \\
\text { doping, } \mathrm{K} \text { induced } \\
\text { lattice expansion } \\
\text { caused distortion } \\
\text { of DOS, doping } \\
\text { effect }\end{array}$ \\
\hline $\mathrm{Pb}_{0.98} \mathrm{TeTl}_{0.02}$ & $p-1.30$ & 673 & 2010 & {$[167]$} & $\begin{array}{l}\text { BM, Tl resonant } \\
\text { doping }\end{array}$ \\
\hline $2 \% \mathrm{Na}+\mathrm{PbTe}+12 \% \mathrm{PbS}$ & $p-1.80$ & 800 & 2011 & {$[47 \mathrm{~b}]$} & $\begin{array}{l}\text { Na doping, } \mathrm{PbS} \\
\text { precipitation }\end{array}$ \\
\hline $\mathrm{Na}_{0.01} \mathrm{Tl}_{0.02} \mathrm{~Pb}_{0.98} \mathrm{Te}_{0.91} \mathrm{~S}_{0.08}$ & $p-1.60$ & 675 & 2011 & [31] & $\begin{array}{l}\text { Tl resonant DOS, } \\
\text { alloy, Na doping }\end{array}$ \\
\hline $\mathrm{Na}$ doped $\mathrm{PbTe} / \mathrm{Ag}_{2} \mathrm{Te}$ & $p-1.50$ & 650 & 2011 & {$[47 \mathrm{c}]$} & $\begin{array}{l}\text { Band engineering, } \\
\text { nanoprecipitation }\end{array}$ \\
\hline Na doped $\mathrm{PbTe}_{0.85} \mathrm{Se}_{0.15}$ & $p-1.80$ & 850 & 2011 & [46] & Band convergence \\
\hline $\mathrm{Pb}_{0.97} \mathrm{Cd}_{0.03} \mathrm{Te}$ & $p-1.70$ & 750 & 2012 & {$[47 \mathrm{e}]$} & $\begin{array}{l}\text { Modified DOS, } \\
\text { in-situ precipitates }\end{array}$ \\
\hline $4 \mathrm{~mol} \% \mathrm{SrTe}+2 \mathrm{~mol} \% \mathrm{Na}+\mathrm{PbTe}$ & $p-2.20$ & 915 & 2012 & [12] & $\begin{array}{l}\text { Full scale } \\
\text { scattering of } \\
\text { phonons }\end{array}$ \\
\hline $\mathrm{Sm}_{0.08} \mathrm{~Pb}_{0.92} \mathrm{Te}$ & $p-0.84$ & 300 & 2013 & {$[47 \mathrm{f}]$} & $\begin{array}{l}\text { Sm doping can } \\
\text { increase Seebeck } \\
\text { coefficient }\end{array}$ \\
\hline $1 \mathrm{~mol} \% \mathrm{Na}+(\mathrm{PbTe})_{0.65}(\mathrm{PbSe})_{0.1}(\mathrm{PbS})_{0.25}$ & $p-1.40$ & 650 & 2014 & [54a] & $\begin{array}{l}\text { Na doping, alloy, } \\
\text { precipitates }\end{array}$ \\
\hline $\mathrm{Na}_{0.05} \mathrm{~Pb}_{0.95} \mathrm{Te}_{0.85} \mathrm{Se}_{0.15}$ & $p-1.60$ & 760 & 2014 & {$[168]$} & Na doping, alloy \\
\hline$(\mathrm{PbTe})_{0.84}(\mathrm{PbSe})_{0.07}(\mathrm{PbS})_{0.07}+2 \% \mathrm{Na}$ & $p-2.00$ & 800 & 2014 & {$[52 \mathrm{a}]$} & $\begin{array}{l}\text { Na doping, } \\
\text { precipitation }\end{array}$ \\
\hline$\left(\mathrm{Pb}_{0.95} \mathrm{Na}_{0.05} \mathrm{Te}\right)_{0.95}\left(\mathrm{CoSe}_{2}\right)_{0.05}$ & $p-1.20$ & 723 & 2015 & {$[144 \mathrm{~b}]$} & $\begin{array}{l}\text { Na doping, } \\
\text { improved } \\
\text { mechanical } \\
\text { property }\end{array}$ \\
\hline $\mathrm{Pb}_{0.98} \mathrm{TeNa}_{0.02}$ & $p-2.00$ & 773 & 2015 & {$[47 \mathrm{~g}]$} & $\begin{array}{l}\text { Controlled } \\
\text { quench, hot } \\
\text { pressing }\end{array}$ \\
\hline $3 \% \mathrm{Na}-(\mathrm{PbTe})_{0.8}(\mathrm{PbS})_{0.2}$ & $p-2.30$ & 923 & 2015 & [53] & $\begin{array}{l}\text { Na doping, } \\
\text { precipitates }\end{array}$ \\
\hline $\mathrm{Na}_{0.03}(\mathrm{PbTe})_{0.65}(\mathrm{PbS})_{0.25}(\mathrm{PbSe})_{0.1}$ & $p-2.00$ & 850 & 2015 & {$[54 \mathrm{~b}]$} & $\begin{array}{l}\text { Modulation } \\
\text { doping, } \\
\text { precipitates }\end{array}$ \\
\hline $\mathrm{PbTe}+8 \% \mathrm{PbS}$ & $n-1.20$ & 700 & 2010 & [169] & $\begin{array}{l}\text { In-situ } \\
\text { precipitation by } \\
\text { fast quench }\end{array}$ \\
\hline
\end{tabular}




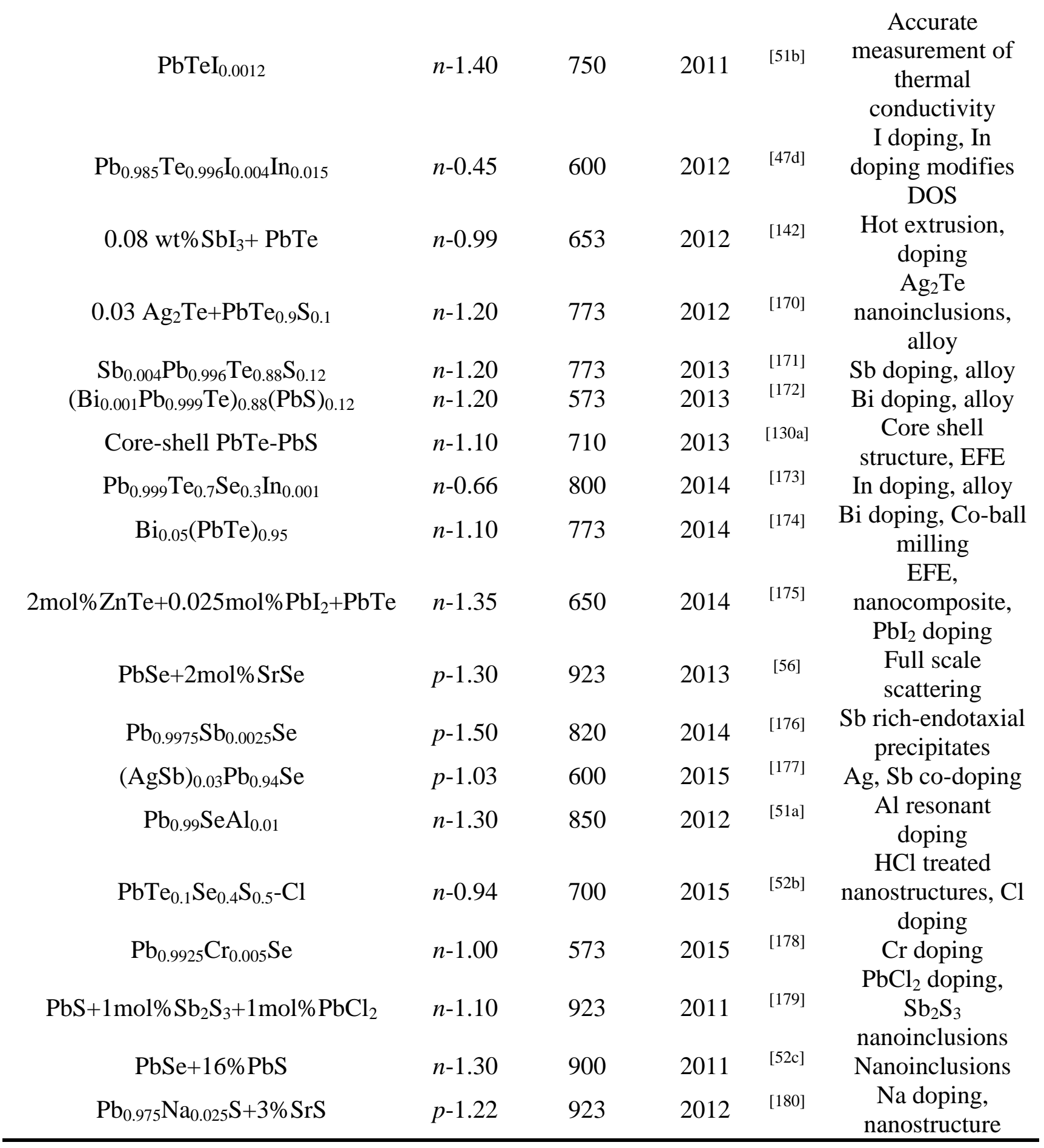


Table 4. Thermoelectric performance of MCs using crystal structure engineering.

\begin{tabular}{|c|c|c|c|c|c|}
\hline Materials & Type-ZT & $\begin{array}{l}\text { Temperature } \\
(\mathrm{K})\end{array}$ & Date & Ref. & Comments \\
\hline $\mathrm{Ag}_{0.95} \mathrm{GaTe}_{2}$ & $p-0.77$ & 850 & 2011 & [63a] & Deficiency of Ag \\
\hline $\mathrm{AgIn}_{5} \mathrm{Se}_{8}$ & $n-0.72$ & 863 & 2012 & [64] & $\begin{array}{l}\text { Microstructure } \\
\text { modulation }\end{array}$ \\
\hline $\mathrm{CuInTe}_{2}$ & $p-1.18$ & 850 & 2012 & [58] & Crystal structure \\
\hline $\mathrm{CuGaTe}_{2}$ & $p-1.40$ & 973 & 2012 & [59] & Crystal structure \\
\hline $\mathrm{CuGaTe}_{2}$ & $p-1.69$ & 950 & 2013 & [61] & Calculation \\
\hline $\mathrm{CuGaTe}_{2}$ & $p-1.00$ & 840 & 2013 & [181] & Structure \\
\hline $\mathrm{Cu}_{2} \mathrm{Zn}_{0.1} \mathrm{Ga}_{3.9} \mathrm{Te}_{7}$ & $p-0.46$ & 770 & 2014 & [62a] & Zn doping \\
\hline $\mathrm{CuIn}{ }_{0.98} \mathrm{Cd}_{0.02} \mathrm{Te}_{2}$ & $p-0.27$ & 600 & 2014 & {$[62 \mathrm{~b}]$} & Cd doping \\
\hline $\mathrm{CuGaTe}_{2}$ & $p-1.40$ & 950 & 2014 & {$[60]$} & BM, hot pressing \\
\hline $\mathrm{CuIn}_{0.98} \mathrm{Cd}_{0.02} \mathrm{Te}_{2}$ & $p-0.25$ & 600 & 2014 & [62c] & Cd doping \\
\hline $\mathrm{Ag}_{0.9} \mathrm{InZn}_{0.1} \mathrm{Se}_{2}$ & $n-1.05$ & 815 & 2014 & [62d] & Zn doping \\
\hline $\mathrm{CuAg}_{0.025} \mathrm{Ga}_{0.975} \mathrm{Te}_{2}$ & $p-0.31$ & 950 & 2014 & [62e] & Doping with Ag \\
\hline $\mathrm{CuGaTe}_{2}+3 \mathrm{vol} \% \mathrm{Cu}_{2} \mathrm{Se}$ & $p-1.20$ & 834 & 2014 & [63b] & Composite \\
\hline $\mathrm{Cu}\left[\mathrm{In}_{0.25} \mathrm{Ga}_{0.75}\right]_{0.99} \mathrm{Zn}_{0.01} \mathrm{Te}_{2}$ & $p-1.30$ & 865 & 2014 & [62f] & Doping of $\mathrm{Zn}$, alloy \\
\hline $\mathrm{Cu}_{0.985} \mathrm{Ni}_{0.015} \operatorname{InTe}_{2}$ & $p-0.35$ & 635 & 2015 & [62g] & Ni doping \\
\hline $\mathrm{CuAl}\left(\mathrm{S}_{0.25} \mathrm{Se}_{0.75}\right)_{2}$ & $p-0.85$ & 450 & 2015 & {$[63 c]$} & Alloy \\
\hline $\begin{array}{c}\mathrm{CuGa}_{0.99} \mathrm{Cd}_{0.01} \mathrm{Te}_{2}+0.7 \mathrm{vol} \% \\
\mathrm{Te}\end{array}$ & $p-0.75$ & 737 & 2015 & {$[62 \mathrm{~h}]$} & $\begin{array}{l}\text { Cd doping, Te } \\
\text { nano-inclusion }\end{array}$ \\
\hline $\mathrm{Cu}_{2} \mathrm{Ge}_{1+\mathrm{x}} \mathrm{Se}_{3}$ & $p-0.30$ & 700 & 2010 & [182] & $\begin{array}{l}\text { Crystal structure, } \\
\text { optimized carrier } \\
\text { concentration }\end{array}$ \\
\hline $\mathrm{Cu}_{2} \mathrm{Sn}_{0.8} \mathrm{Ge}_{0.2} \mathrm{Se}_{3}$ & $p-0.04$ & 300 & 2010 & [183] & $\begin{array}{l}\text { Crystal structure, } \\
\text { alloy }\end{array}$ \\
\hline $\mathrm{Cu}_{2} \mathrm{Sn}_{0.925} \operatorname{In}_{0.1} \mathrm{Se}_{3}$ & $p-1.14$ & 850 & 2010 & [66a] & In doping \\
\hline $\mathrm{Cu}_{2} \mathrm{GeSe}_{3}$ & $p-0.27$ & 750 & 2012 & [130b] & $\begin{array}{l}\text { Different crystal } \\
\text { types }\end{array}$ \\
\hline $\mathrm{Cu}_{2} \mathrm{Sn}_{0.925} \mathrm{In}_{0.075} \mathrm{Se}_{2.1} \mathrm{~S}_{0.9}$ & $p-0.62$ & 760 & 2012 & {$[66 b]$} & Doping, alloy \\
\hline $\mathrm{Cu}_{2} \mathrm{SnSe}_{3}$ & $p-0.33$ & 650 & 2013 & [184] & Crystal structure \\
\hline $\mathrm{Cu}_{2} \mathrm{Ga}_{0.075} \mathrm{Sn}_{0.925} \mathrm{Se}_{3}$ & $p-0.43$ & 700 & 2013 & [185] & Structure, doping \\
\hline $\mathrm{Cu}_{2} \mathrm{In}_{0.1} \mathrm{Ge}_{0.9} \mathrm{Se}_{3}$ & $p-0.23$ & 723 & 2014 & {$[186]$} & In doping \\
\hline $\mathrm{Cu}_{2} \mathrm{SnSe}_{3}$ & $p-0.48$ & 773 & 2014 & {$[187]$} & Structure \\
\hline $\mathrm{AgBiS}_{2}$ & $n-0.23$ & 705 & 2013 & [68b] & $\begin{array}{c}\text { Structure, } \\
\text { phase change }\end{array}$ \\
\hline $\begin{array}{c}2 \mathrm{~mol}_{\%} \\
\mathrm{Bi}+\mathrm{AgSbSe}_{2}\end{array}$ & $p-1.15$ & 680 & 2013 & [68a] & $\begin{array}{l}\text { Structure, } \\
\text { doping }\end{array}$ \\
\hline $\mathrm{Cu}_{4} \mathrm{Sn}_{7} \mathrm{~S}_{16}$ & $n-0.20$ & 600 & 2015 & {$[67]$} & Complex structure \\
\hline $\mathrm{Cu}_{3} \mathrm{Sb}_{0.98} \mathrm{Se}_{3} \mathrm{Bi}_{0.02}$ & $p-0.70$ & 600 & 2013 & {$[188]$} & Structure, doping \\
\hline $\mathrm{AgBi}_{0.08} \mathrm{Sb}_{0.95} \mathrm{Te}_{2}$ & $p-1.04$ & 570 & 2013 & [98] & $\begin{array}{l}\text { Energy filtering } \\
\text { effect }\end{array}$ \\
\hline $\mathrm{Ag}_{0.96} \mathrm{Nb}_{0.04} \mathrm{BiSe}_{2}$ & $n-1.00$ & 773 & 2013 & [115] & $\begin{array}{l}\text { Doping with } \mathrm{Nb} \\
\text { Controlled }\end{array}$ \\
\hline $\mathrm{Cu}_{15} \mathrm{As}_{30} \mathrm{Te}_{55}$ & $n-0.14$ & 365 & 2013 & [71a] & $\begin{array}{l}\text { crystallinity of } \\
\text { amorphous } \\
\text { structure }\end{array}$ \\
\hline
\end{tabular}




\begin{tabular}{|c|c|c|c|c|c|}
\hline $\mathrm{AgSbSe}_{2}+2 \mathrm{~mol} \% \mathrm{ZnSe}$ & $p-1.10$ & 635 & 2014 & [189] & $\begin{array}{c}\text { Carrier engineering, } \\
\text { nanodomains }\end{array}$ \\
\hline $\mathrm{Ag}\left(\mathrm{Sb}_{0.93} \mathrm{In}_{0.07}\right) \mathrm{Te}_{2}$ & $p-1.35$ & 650 & 2014 & [190] & In doping \\
\hline $\mathrm{Cu}_{3} \mathrm{Sb}_{0.94} \mathrm{Ge}_{0.06} \mathrm{~S}_{4}$ & $p-0.10$ & 323 & 2014 & [69a] & Doping with Ge \\
\hline $\mathrm{Cu}_{2.95} \mathrm{SbSe}_{4}$ & $p-0.50$ & 673 & 2014 & [69b] & $\mathrm{Cu}$ deficiency \\
\hline $\mathrm{Cu}_{3} \mathrm{SbSe}_{4}+5 \mathrm{vol} \% \mathrm{Zn}_{4} \mathrm{Sb}_{3}$ & $p-1.37$ & 648 & 2014 & {$[69 c]$} & EFE, composite \\
\hline $\mathrm{Cu}_{7} \mathrm{PSe}_{6}$ & $p-0.35$ & 575 & 2014 & [70] & $\begin{array}{l}\text { Extremely low } \\
\text { thermal } \\
\text { conductivity }\end{array}$ \\
\hline $\mathrm{Tl}_{9} \mathrm{BiTe}_{6}$ & $p-1.20$ & 500 & 2001 & [75a] & Structure \\
\hline $\mathrm{TlSbTe}_{2}$ & $p-0.87$ & 715 & 2005 & [191] & Structure \\
\hline $\mathrm{Tl}_{4} \mathrm{ZrTe}_{4}$ & $p-0.16$ & 420 & 2010 & [192] & Narrow band gap \\
\hline $\mathrm{TlGdTe}_{2}$ & $p-0.50$ & 550 & 2012 & [193] & Structure \\
\hline $\mathrm{Tl}_{8.98} \mathrm{Nd}_{1.02} \mathrm{Te}_{6}$ & $p-0.20$ & 550 & 2013 & [194] & Structure \\
\hline $\mathrm{Tl}_{9} \mathrm{Bi}_{0.98} \mathrm{Te}_{6}$ & $p-1.10$ & 500 & 2013 & [195] & $\begin{array}{l}\text { Deficiency of } \\
\text { element }\end{array}$ \\
\hline $\mathrm{Ag}_{9} \mathrm{TlTe}_{5}$ & $p-1.20$ & 700 & 2013 & [74b] & Structure \\
\hline $\mathrm{Tl}_{\mathrm{x}} \mathrm{Cr}_{5} \mathrm{Se}_{8}$ & $p-0.5$ & 800 & 2013 & [196] & Structure \\
\hline $\mathrm{Tl}_{10-\mathrm{x}-\mathrm{y}} \mathrm{Sn}_{\mathrm{x}} \mathrm{Bi}_{\mathrm{y}} \mathrm{Te}_{6}$ & $p-0.90$ & 500 & 2014 & [197] & Doping \\
\hline $\mathrm{Ni}_{0.06} \mathrm{Mo}_{3} \mathrm{Sb}_{5.4} \mathrm{Te}_{1.6}$ & $p-0.93$ & 1023 & 2007 & [76a] & Complex structure \\
\hline $\mathrm{Mo}_{3} \mathrm{Sb}_{5.4} \mathrm{Te}_{1.6}$ & $p-0.60$ & 1000 & 2010 & [76b] & Complex structure \\
\hline $\mathrm{Fe}_{0.05} \mathrm{Mo}_{3} \mathrm{Sb}_{5.4} \mathrm{Te}_{1.6}$ & $p-0.31$ & 673 & 2010 & {$[77]$} & Complex structure \\
\hline $\mathrm{Cr}_{1.3} \mathrm{Mo}_{6} \mathrm{~S}_{8}$ & $p-0.17$ & 973 & 2010 & [78a] & Complex structure \\
\hline $\mathrm{Ag}_{3.8} \mathrm{Mo}_{9} \mathrm{Se}_{11}$ & $p-0.70$ & 800 & 2011 & [78b] & $\begin{array}{l}\text { Chevrel phase, Ag } \\
\text { rattling }\end{array}$ \\
\hline $\mathrm{Ag}_{2} \mathrm{Tl}_{2} \mathrm{Mo}_{9} \mathrm{Se}_{11}$ & $p-0.60$ & 800 & 2014 & {$[78 c]$} & Complex structure \\
\hline
\end{tabular}


Table 5. Thermoelectric performance of Sn-X and In-X systems.

\begin{tabular}{|c|c|c|c|c|c|}
\hline Materials & Type-ZT & $\begin{array}{l}\text { Temperature } \\
(\mathrm{K})\end{array}$ & Date & Ref. & Comments \\
\hline$\left(\mathrm{In}_{1.9} \mathrm{Al}_{0.1} \mathrm{Te}_{3}\right)_{0.08}+(\mathrm{SnTe})_{0.92}$ & $p-0.28$ & 668 & 2011 & $\mid 198]$ & Doping \\
\hline $0.25 \mathrm{at} \% \mathrm{In}+\mathrm{SnTe}$ & $p-1.10$ & 873 & 2013 & {$[32 \mathrm{a}]$} & $\begin{array}{l}\text { Resonant doping } \\
\text { with In }\end{array}$ \\
\hline 1.5at\% In+ $\mathrm{SnTe}_{0.85} \mathrm{Se}_{0.15}$ & $p-0.80$ & 860 & 2014 & [199] & In doping, alloy \\
\hline $\mathrm{Pb}_{0.2} \mathrm{Sn}_{0.8} \mathrm{Te}$ & $p-0.13$ & 570 & 2014 & {$[200]$} & $\begin{array}{c}\text { Thermal } \\
\text { decomposition } \\
\text { Self- } \\
\text { compensation of } \\
\text { Sn and Cd, }\end{array}$ \\
\hline $\mathrm{SnCd}_{0.03} \mathrm{Te}+2 \% \mathrm{CdS}$ & $p-1.30$ & 873 & 2014 & [83] & $\begin{array}{c}\text { Band } \\
\text { engineering, } \\
\text { endotaxially } \\
\text { nanostructured } \\
\text { CdS }\end{array}$ \\
\hline $\mathrm{SnS}$ & $p-0.16$ & 823 & 2014 & {$[201]$} & Layer structure \\
\hline $\mathrm{SnSe}$ & $p-2.60$ & 923 & 2014 & {$[11]$} & Single crystal \\
\hline $\mathrm{SnSe}$ & $p-0.50$ & 800 & 2015 & {$[202]$} & Polycrystals \\
\hline $\mathrm{SnS}$ & $p-1.61$ & 1080 & 2015 & [203] & Calculation \\
\hline $\mathrm{SnSe}$ & $n-3.10$ & 770 & 2015 & [85] & $\begin{array}{l}\text { Calculation } \\
\text { Peierls } \\
\text { distortion, }\end{array}$ \\
\hline $\mathrm{In}_{4} \mathrm{Se}_{3-\mathrm{x}}$ & $n-1.48$ & 705 & 2009 & [15] & $\begin{array}{c}\text { charge wave } \\
\text { density (CDW), } \\
\text { Se deficiency, } \\
\text { single crystal }\end{array}$ \\
\hline $\mathrm{In}_{4} \mathrm{Se}_{3}$ & $n-0.60$ & 700 & 2010 & [204] & Polycrystals \\
\hline $\mathrm{In}_{4} \mathrm{Se}_{2.95}$ & $n-0.60$ & 700 & 2011 & [84a] & Deficiency of Se \\
\hline $80 \mathrm{wt} \% \mathrm{In}_{4} \mathrm{Se}_{3}+\mathrm{In}_{4} \mathrm{Te}_{3}$ & $n-0.56$ & 672 & 2011 & [205] & $\begin{array}{l}\text { Diffusion of Se } \\
\text { into } \mathrm{In}_{4} \mathrm{Te}_{3}\end{array}$ \\
\hline $\operatorname{In}_{1.8} \mathrm{Cu}_{0.2} \mathrm{Se}_{3}$ & $n-0.55$ & 846 & 2011 & {$[206]$} & $\begin{array}{c}\text { Formation of } \\
\mathrm{Cu}_{2} \mathrm{Se} \text { slab, } \\
\text { band } \\
\text { engineering } \\
\mathrm{Cl} \text { doping, } \mathrm{Se}\end{array}$ \\
\hline $\mathrm{In}_{4} \mathrm{Se}_{2.67} \mathrm{Cl}_{0.03}$ & $n-1.53$ & 700 & 2011 & {$[84 b]$} & $\begin{array}{l}\text { deficiency, } \\
\text { single crystal }\end{array}$ \\
\hline $\mathrm{In}_{4} \mathrm{Se}_{2.35}$ & $n-1.00$ & 698 & 2011 & {$[84 \mathrm{c}]$} & $\begin{array}{l}\text { Polycrystals, } \\
\text { BM, SPS }\end{array}$ \\
\hline $\mathrm{In}_{4} \mathrm{Se}_{2.65}$ & $n-0.93$ & 700 & 2012 & [84d] & $\begin{array}{l}\text { BM, hot } \\
\text { pressing, Se } \\
\text { deficiency }\end{array}$ \\
\hline $\mathrm{In}_{4} \mathrm{Se}_{2.35}$ & $n-0.84$ & 673 & 2012 & [207] & Se deficiency \\
\hline $\begin{array}{c}\mathrm{SrTiO}_{3}+\mathrm{InSe} / \mathrm{In}_{4} \mathrm{Se}_{3} \\
\text { composite }\end{array}$ & $n-0.25$ & 600 & 2013 & {$[138]$} & Composite \\
\hline $0.3 \mathrm{wt} \% \mathrm{Cu}+\mathrm{In}_{4} \mathrm{Se}_{3}$ & $n-0.97$ & 723 & 2013 & {$[208]$} & $\mathrm{BM}, \mathrm{Cu}$ doping \\
\hline
\end{tabular}




\begin{tabular}{cccccc}
$\mathrm{Fe}_{0.05} \mathrm{In}_{3.95} \mathrm{Se}_{3}$ & $n-0.44$ & 723 & 2013 & {$[209]$} & Fe doping \\
$\mathrm{In}_{1.25} \mathrm{Sn}_{0.05} \mathrm{Se}$ & $n-0.66$ & 700 & 2013 & {$[84 \mathrm{e}]$} & Sn doping, \\
structure \\
$\mathrm{In}_{4} \mathrm{Se}_{3-\mathrm{x}} \mathrm{Cl}_{\mathrm{y}}+\mathrm{BaIn}_{2} \mathrm{Se}_{4}$ & $n-0.75$ & 675 & 2014 & {$[210]$} & Phase separation \\
$\mathrm{In}_{4} \mathrm{~Pb}_{0.01} \mathrm{Sn}_{0.03} \mathrm{Se}_{2.9}$ & $n-1.20$ & 723 & 2014 & {$[84 \mathrm{f}]$} & Doping \\
\hline
\end{tabular}


Table 6. Thermoelectric performance of metal chalcogenides with layered structure.

\begin{tabular}{|c|c|c|c|c|c|}
\hline Materials & Type-ZT & $\begin{array}{c}\text { Temperature } \\
(\mathrm{K})\end{array}$ & Date & Ref. & Comments \\
\hline $\mathrm{CuCrS}_{2}$ & $p-2.00$ & 300 & 2010 & [88a] & Structure \\
\hline $\mathrm{AgCrSe}_{2}$ & $p-1.00$ & 848 & 2011 & {$[88 \mathrm{~b}]$} & $\begin{array}{l}\text { Structure, } \\
\text { PLEC }\end{array}$ \\
\hline $\mathrm{CuCrS}_{2}$ & $p-0.90$ & 350 & 2011 & {$[211]$} & Structure \\
\hline $\mathrm{CuCrS}_{2}$ & $p-0.11$ & 673 & 2012 & {$[90]$} & Structure \\
\hline$\left(\mathrm{AgCrSe}_{2}\right)_{0.5}\left(\mathrm{CuCrSe}_{2}\right)_{0.5}$ & $p-1.40$ & 773 & 2014 & [89] & Nanocomposite \\
\hline $\mathrm{NiCrS}_{2}, \mathrm{CuCrS}_{2}$ & $\begin{array}{l}n-0.024, p- \\
\quad 0.023\end{array}$ & 313 & 2014 & {$[212]$} & Structure \\
\hline $\mathrm{CuCrSe}_{2}$ & $p-0.17$ & 300 & 2014 & [213] & Structure \\
\hline$(\mathrm{SnS})_{1.2}\left(\mathrm{TiS}_{2}\right)_{2}$ & $n-0.37$ & 700 & 2010 & {$[91 \mathrm{e}]$} & $\begin{array}{l}\text { Misfit layer } \\
\text { structure }\end{array}$ \\
\hline $\mathrm{Cu}_{0.1} \mathrm{TiS}_{2}$ & $n-0.50$ & 800 & 2011 & [91a] & $\begin{array}{c}\text { Intercalation of } \\
\mathrm{Cu}\end{array}$ \\
\hline $\mathrm{Co}_{0.3} \mathrm{Ti}_{0.7} \mathrm{~S}_{2}$ & $n-0.03$ & 310 & 2011 & {$[91 b]$} & $\begin{array}{c}\text { Intercalation of } \\
\mathrm{Cu}\end{array}$ \\
\hline $\mathrm{Ti}_{1.008} \mathrm{~S}_{2}$ & $n-0.34$ & 663 & 2012 & [92] & $\begin{array}{c}\text { Near } \\
\text { stoichiometric }\end{array}$ \\
\hline $\mathrm{Cu}_{0.11} \mathrm{TiSe}_{2}$ & $n-0.15$ & 650 & 2013 & {$[214]$} & $\begin{array}{l}\text { Intercalation of } \\
\mathrm{Cu}\end{array}$ \\
\hline $\mathrm{Li}_{\mathrm{x}} \mathrm{ZrSe}_{2}$ & $n-0.26$ & 300 & 2013 & {$[91 \mathrm{f}]$} & $\begin{array}{c}\text { Electrical } \\
\text { chemical } \\
\text { insertion of } \mathrm{Li}\end{array}$ \\
\hline $\mathrm{Ti}_{1.025} \mathrm{~S}_{2}$ & $n-0.48$ & 700 & 2014 & [93] & $\begin{array}{c}\text { Intercalation of } \\
\mathrm{Ti}\end{array}$ \\
\hline$(\mathrm{LaS})_{1.2} \mathrm{NbS}_{2}$ & $n-0.15$ & 950 & 2014 & {$[91 \mathrm{~g}]$} & $\begin{array}{l}\text { Misfit layered } \\
\text { structure }\end{array}$ \\
\hline $\mathrm{TiS}_{2}$ & $n-0.28$ & 373 & 2015 & [91d] & $\begin{array}{l}\text { Flexible, } \\
\text { electrical, } \\
\text { chemical } \\
\text { insertion of } \\
\text { organics }\end{array}$ \\
\hline $\mathrm{Cu}_{0.05} \mathrm{TiSe}_{0.5} \mathrm{~S}_{1.5}$ & $n-0.54$ & 700 & 2015 & {$[91 \mathrm{c}]$} & $\begin{array}{c}\text { Alloy, } \\
\text { intercalation of } \\
\mathrm{Cu}\end{array}$ \\
\hline $\mathrm{Bi}_{2} \mathrm{O}_{2} \mathrm{Se}$ & $n-0.20$ & 800 & 2010 & [95] & Structure \\
\hline $\mathrm{Bi}_{4} \mathrm{O}_{4} \mathrm{~S}_{3}$ & $n-0.03$ & 300 & 2012 & [215] & Structure \\
\hline $\mathrm{Bi}_{2} \mathrm{O}_{2} \mathrm{Se}$ & $n-0.0073$ & 460 & 2013 & [216] & Structure \\
\hline $\mathrm{Bi}_{1.9} \mathrm{O}_{2} \mathrm{Se}$ & $n-0.12$ & 773 & 2015 & {$[96]$} & $\begin{array}{l}\text { Deficiency of } \\
\text { Bi }\end{array}$ \\
\hline
\end{tabular}


Table 7. Thermoelectric performance of spinodal systems.

\begin{tabular}{|c|c|c|c|c|c|}
\hline Materials & Type-ZT & $\begin{array}{c}\text { Temperature } \\
(\mathrm{K})\end{array}$ & Date & Ref. & Summary \\
\hline $\mathrm{Cu}_{0.2} \mathrm{Ag}_{2.8} \mathrm{SbSeTe}_{2}$ & $p>1.50$ & 675 & 2010 & [217] & $\begin{array}{c}\text { In-situ } \\
\text { precipitation, } \mathrm{Cu} \\
\text { doping }\end{array}$ \\
\hline $\mathrm{Ag}_{0.84} \mathrm{Sb}_{1.16} \mathrm{Te}_{2.16}$ & $p-1.53$ & 500 & 2010 & [97] & $\begin{array}{l}\text { In-situ } \mathrm{Ag}_{2} \mathrm{Te} \\
\text { precipitate }\end{array}$ \\
\hline$\left(\mathrm{Ag}_{2} \mathrm{Te}\right)_{50}\left(\mathrm{Sb}_{2} \mathrm{Te}_{3}\right)_{50}$ & $p-1.55$ & 533 & 2010 & {$[218]$} & $\begin{array}{l}\text { Wet chemical } \\
\text { method, } \\
\text { nanostructure }\end{array}$ \\
\hline$\left(\mathrm{Ag}_{2} \mathrm{Te}\right)_{50}\left(\mathrm{Sb}_{2} \mathrm{Te}_{3}\right)_{50}$ & $p-1.22$ & 593 & 2011 & [219] & $\begin{array}{c}\text { Nanodomain, EFE } \\
\text { In-situ }\end{array}$ \\
\hline $\mathrm{Cu}_{0.2} \mathrm{Ag}_{2.8} \mathrm{SbSeTe}_{2}$ & $p>1.50$ & 675 & 2010 & {$[217]$} & $\begin{array}{l}\text { precipitation, } \mathrm{Cu} \\
\text { doping }\end{array}$ \\
\hline $\mathrm{Ag}_{0.84} \mathrm{Sb}_{1.16} \mathrm{Te}_{2.16}$ & $p-1.53$ & 500 & 2010 & [97] & $\begin{array}{l}\text { In-situ } \mathrm{Ag}_{2} \mathrm{Te} \\
\text { precipitate }\end{array}$ \\
\hline $\mathrm{Ag}_{20} \mathrm{~Pb}_{5} \mathrm{Sb}_{25} \mathrm{Te}_{50}$ & $p-0.80$ & 425 & 2012 & [220] & Nanodomains \\
\hline $\mathrm{AgPb}_{9} \mathrm{Sn}_{9} \mathrm{SbTe}_{20}$ & $p-0.70$ & 675 & 2012 & [221] & Nanodomains \\
\hline $\mathrm{AgPb}_{18} \mathrm{SbTe}_{18}$ & $p-1.10$ & 573 & 2013 & {$[222]$} & $\mathrm{Ag} / \mathrm{Sb}$ ratio \\
\hline $\mathrm{Ag}_{25} \mathrm{Sb}_{25} \mathrm{Se}_{10} \mathrm{Te}_{40}$ & $p-1.40$ & 680 & 2015 & [223] & Nanodomains \\
\hline $\mathrm{Ag}_{0.8} \mathrm{~Pb}_{18} \mathrm{SbTe}_{20}$ & $n-1.02$ & 673 & 2010 & {$[224]$} & Nanodomains \\
\hline $\mathrm{K}_{0.95} \mathrm{~Pb}_{20} \mathrm{Sb}_{1.2} \mathrm{Te}_{22}$ & $n-1.60$ & 750 & 2010 & {$[225]$} & $\begin{array}{l}\text { Nanodomains, } \mathrm{Sb} \\
\text { resonant doping, } \mathrm{K} \\
\text { substitution }\end{array}$ \\
\hline $\mathrm{Ag}_{0.4} \mathrm{~Pb}_{22.5} \mathrm{SbTe}_{20}$ & $n-1.50$ & 700 & 2011 & [226] & $\begin{array}{l}\text { Composition } \\
\text { control }\end{array}$ \\
\hline $\mathrm{Ag}_{0.4} \mathrm{~Pb}_{22.5} \mathrm{SbTe}_{20}$ & $n-1.50$ & 700 & 2011 & [226] & Nanodomains \\
\hline $\mathrm{AgPb}_{18} \mathrm{SbTe}_{18} \mathrm{Se}_{2}$ & $n-0.82$ & 523 & 2012 & [227] & $\begin{array}{l}\text { Hydrothermal, } \\
\text { composition } \\
\text { control }\end{array}$ \\
\hline $\mathrm{AgPb}_{20} \mathrm{SbTe}_{20}$ & $n-1.20$ & 675 & 2012 & {$[228]$} & $\begin{array}{c}\text { BM+Oxygen level } \\
\text { control }\end{array}$ \\
\hline $\mathrm{Ag}_{0.8} \mathrm{~Pb}_{22.5} \mathrm{SbTe}_{18} \mathrm{~S}_{2}$ & $n-0.97$ & 673 & 2012 & [229] & S substitution \\
\hline $\mathrm{AgPb}_{18} \mathrm{SbSe}_{19.928} \mathrm{Cl}_{0.072}$ & $n-1.30$ & 873 & 2013 & [230] & Cl doping \\
\hline $\mathrm{AgPb}_{22.5} \mathrm{SbTe}_{20}$ & $n-1.54$ & 723 & 2014 & {$[100]$} & $\begin{array}{c}\text { Repeated BM, } \\
\text { SPS }\end{array}$ \\
\hline $\mathrm{Ge}_{12} \mathrm{Sb}_{2} \mathrm{Te}_{14}$ & $p-1.00$ & 673 & 2013 & [106a] & Nanodomains \\
\hline$(\mathrm{GeTe})_{11}\left(\mathrm{LiSbTe}_{2}\right)_{2}$ & $p-1.00$ & 723 & 2013 & {$[107]$} & Nanodomains \\
\hline $\begin{array}{c}(\mathrm{GeTe})_{0.82}\left(\mathrm{Mn}_{0.6} \mathrm{Sn}_{0.4} \mathrm{Te}\right)_{0.15}\left(\mathrm{Bi}_{2} \mathrm{Te}_{3}\right. \\
)_{0.03}\end{array}$ & $p-1.54$ & 700 & 2013 & {$[231]$} & $\begin{array}{c}\text { Composite with } \\
\text { nanostructured } \\
\mathrm{Bi}_{2} \mathrm{Te}_{3}\end{array}$ \\
\hline$\left(\mathrm{Pb}_{0.9} \mathrm{Yb}_{0.1} \mathrm{Te}\right)_{0.15}(\mathrm{GeTe})_{0.85}$ & $p-1.40$ & 723 & 2014 & [104a] & $\mathrm{Yb}$ doping \\
\hline $\mathrm{Ge}_{0.95} \mathrm{Mn}_{0.05} \mathrm{Te}$ & $p-1.30$ & 773 & 2014 & {$[104 b]$} & Mn doping \\
\hline $\mathrm{Ge}_{0.75} \mathrm{~Pb}_{0.25} \mathrm{Te}_{0.5} \mathrm{Se}_{0.5}$ & $p-1.60$ & 673 & 2014 & [109] & Nanodomains \\
\hline $\mathrm{Ge}_{12} \mathrm{Sb}_{2}\left(\mathrm{Te}_{0.2} \mathrm{Se}_{0.8}\right)_{10}$ & $p-1.20$ & 698 & 2014 & {$[105]$} & Se substitution \\
\hline$(\mathrm{GeTe})_{85}\left(\mathrm{Ag}_{0.6} \mathrm{SbTe}_{1.8}\right)_{15}$ & $p-1.50$ & 700 & 2014 & {$[101]$} & Nanodomains \\
\hline $\mathrm{Ge}_{0.85} \mathrm{Te}\left(\mathrm{Pb}_{0.9} \mathrm{Yb}_{0.1}\right)_{0.15}$ & $p-1.40$ & 723 & 2015 & [103] & Yb doping \\
\hline
\end{tabular}




\begin{tabular}{cccccc}
$\left(\mathrm{Ge}_{0.8} \mathrm{~Pb}_{0.2}\right)_{0.9} \mathrm{Mn}_{0.1} \mathrm{Te}$ & $p-1.30$ & 723 & 2015 & ${ }^{[104 \mathrm{c}]}$ & Nanodomains \\
$\mathrm{GeSbTe}$ & $p-1.48$ & 670 & 2014 & {$[106 \mathrm{~b}]$} & Nanodomains \\
$\left(\mathrm{CoGe}_{2}\right)_{0.2}(\mathrm{GeTe})_{17} \mathrm{Sb}_{2} \mathrm{Te}_{3}$ & $p-1.90$ & 723 & 2015 & {$[108]$} & $\begin{array}{c}\text { Herringbone-like } \\
\text { nanostructure }\end{array}$ \\
\hline
\end{tabular}


Table 8. Thermoelectric performance of PLEC materials.

\begin{tabular}{|c|c|c|c|c|c|}
\hline Materials & Type-ZT & $\begin{array}{c}\text { Temperature } \\
(\mathrm{K})\end{array}$ & Date & Ref. & Comments \\
\hline $\mathrm{Cu}_{2-\mathrm{x}} \mathrm{Se}$ & $p-0.38$ & 750 & 2011 & 11181 & PLEC \\
\hline $\mathrm{Cu}_{2} \mathrm{Se}$ & $p-1.50$ & 1000 & 2012 & {$[16]$} & PLEC \\
\hline $\mathrm{Cu}_{2} \mathrm{Se}$ & $p-1.60$ & 973 & 2012 & [232] & PLEC \\
\hline $\mathrm{Cu}_{1.97} \mathrm{Ag}_{0.03} \mathrm{Se}$ & $p-1.00$ & 400 & 2013 & [116a] & $\begin{array}{l}\text { Phase } \\
\text { transition }\end{array}$ \\
\hline $\mathrm{Cu}_{2} \mathrm{SeI}_{x}$ & $p-2.30$ & 400 & 2013 & [17] & $\begin{array}{c}\text { Critical } \\
\text { scattering }\end{array}$ \\
\hline $5 \mathrm{wt} \% \mathrm{SiO}_{2}+\mathrm{Cu}_{1.8} \mathrm{~S}$ & $p-0.28$ & 623 & 2013 & {$[121]$} & Nanocomposite \\
\hline $\mathrm{CuAgSe}$ & $p-0.80$ & 623 & 2014 & {$[116 b]$} & Structure \\
\hline $\mathrm{Cu}_{1.97} \mathrm{~S}$ & $p-1.70$ & 1000 & 2014 & {$[233]$} & PLEC \\
\hline $\mathrm{CuAgSe}$ & $p-0.95$ & 623 & 2014 & {$[116 c]$} & Structure \\
\hline $\mathrm{Cu}_{1.85} \mathrm{~S}$ & $p-0.11$ & 623 & 2014 & {$[117 \mathrm{a}]$} & $\begin{array}{c}\text { Percolation } \\
\text { effect }\end{array}$ \\
\hline $\mathrm{Cu}_{2} \mathrm{Se}$ & $p-1.35$ & 900 & 2014 & {$[119 b]$} & $\begin{array}{l}\text { Wet chemical } \\
\text { method }\end{array}$ \\
\hline $\mathrm{Cu}_{1.75} \mathrm{Te}$ & $p-0.04$ & 650 & 2014 & [114] & $\begin{array}{l}\text { Wet chemistry } \\
\text { method }\end{array}$ \\
\hline $\mathrm{Cu}_{1.96} \mathrm{Se}$ & $p-1.23$ & 773 & 2014 & {$[234]$} & PLEC \\
\hline $\mathrm{Cu}_{2-\mathrm{x}} \mathrm{Se}$ & $p-0.30$ & 723 & 2015 & {$[119 \mathrm{c}]$} & $\begin{array}{l}\text { Wet chemical } \\
\text { method, } \\
\text { nanowires }\end{array}$ \\
\hline $\mathrm{Cu}_{2} \mathrm{Se}$ & $p-2.10$ & 973 & 2015 & {$[122]$} & $\begin{array}{l}\text { Full scale } \\
\text { scattering }\end{array}$ \\
\hline $\mathrm{Cu}_{2} \mathrm{Se}$ & $p-1.40$ & 973 & 2015 & [119d] & $\begin{array}{c}\text { BM, SPS, Cu } \\
\text { deficiency }\end{array}$ \\
\hline $\mathrm{CuAgSe}$ & $p-0.60$ & 450 & 2015 & [117b] & $\begin{array}{l}\text { Element } \\
\text { deficiency }\end{array}$ \\
\hline $\mathrm{Cu}_{2} \mathrm{~S}_{0.5} \mathrm{Te}_{0.5}$ & $p-2.20$ & 1000 & 2015 & {$[123]$} & Mosaic crystal \\
\hline $\mathrm{Cu}_{1.97} \mathrm{~S}$ & $p-1.90$ & 970 & 2015 & {$[113]$} & PLEC \\
\hline $\mathrm{Cu}_{2-\mathrm{x}} \mathrm{Te}_{0.16} \mathrm{Se}_{0.84}$ & $p-1.00$ & 973 & 2015 & {$[120 \mathrm{~b}]$} & Alloying \\
\hline $\mathrm{Cu}_{2-\mathrm{x}} \mathrm{Se}$ & $p-1.80$ & 973 & 2015 & [235] & $\begin{array}{l}\text { Quench } \\
\text { method }\end{array}$ \\
\hline $\mathrm{Ag}_{1.37} \mathrm{Cu}_{0.6} \mathrm{Te}$ & $p-1.39$ & 832 & 2015 & {$[236]$} & $\begin{array}{c}\text { Substitution of } \\
\mathrm{Cu}\end{array}$ \\
\hline $\mathrm{Ag}_{2} \mathrm{Te}$ & $n-0.64$ & 575 & 2010 & [237] & $\begin{array}{l}\text { High purity } \\
\text { raw materials, } \\
\text { high density }\end{array}$ \\
\hline $\mathrm{Ag}_{2} \mathrm{Se}$ & $n-0.60$ & 300 & 2011 & [119a] & $\begin{array}{l}\text { Hydrothermal, } \\
\text { SPS }\end{array}$ \\
\hline $\mathrm{Ag}_{2} \mathrm{Se}_{0.5} \mathrm{Te}_{0.5}$ & $n-1.00$ & 520 & 2013 & [120a] & Alloying \\
\hline $\mathrm{Ag}_{2} \mathrm{Se}_{1.08}$ & $n-1.00$ & 400 & 2014 & [116d] & $\begin{array}{l}\text { Deficiency of } \\
\text { Ag }\end{array}$ \\
\hline $\mathrm{AgBiSe}_{2}$ & $p-1.50$ & 700 & 2012 & {$[111]$} & Phase change \\
\hline
\end{tabular}


Table 9. Thermoelectric performance of other metal chalcogenides.

\begin{tabular}{|c|c|c|c|c|c|}
\hline Materials & $\begin{array}{l}\text { Type- } \\
\text { ZT }\end{array}$ & $\begin{array}{c}\text { Temperature } \\
(\mathrm{K})\end{array}$ & Date & Ref. & Comments \\
\hline $\mathrm{Ga}_{2} \mathrm{Te}_{3}$ & $p-0.16$ & 850 & 2009 & [126a] & $\begin{array}{l}\text { 2D-vacancy } \\
\text { plane }\end{array}$ \\
\hline $\mathrm{Ga}_{2} \mathrm{Cu}_{0.05} \mathrm{Sb}_{0.2} \mathrm{Te}_{2.75}$ & $p-0.50$ & 700 & 2012 & {$[126 \mathrm{~b}]$} & $\begin{array}{c}\text { Tuning of } \\
\text { vacancy plane }\end{array}$ \\
\hline $\mathrm{Cu}_{0.05} \mathrm{Sb}_{0.1} \mathrm{Ga}_{1.9} \mathrm{Te}_{2.95}$ & $p-0.21$ & 631 & 2012 & [127] & $\begin{array}{l}\text { Band } \\
\text { engineering, } \\
\text { doping }\end{array}$ \\
\hline $\mathrm{Ga}_{1.9} \mathrm{Cu}_{0.05} \mathrm{Sb}_{0.1} \mathrm{Te}_{3}$ & $p-0.41$ & 750 & 2014 & [125] & $\begin{array}{l}\text { Engineering of } \\
\text { vacancy plane }\end{array}$ \\
\hline $\mathrm{Au}_{2} \mathrm{Te}$ & $n-0.09$ & 450 & 2010 & [128b] & Telluride \\
\hline $\mathrm{Ce}_{3} \mathrm{Te}_{4}$ & $p-13.5$ & 1200 & 2011 & {$[128 \mathrm{~h}]$} & Calculation \\
\hline $\mathrm{Mn}_{0.51} \mathrm{Te}_{0.49}$ & $p-0.41$ & 773 & 2013 & [128i] & $\begin{array}{c}\text { Broad band } \\
\text { semiconductor }\end{array}$ \\
\hline $\mathrm{MnTe}_{0.9} \mathrm{~S}_{0.1}$ & $p-0.65$ & 773 & 2014 & [128m] & Solid solution \\
\hline $\mathrm{TmCuTe}_{2}$ & $p-0.81$ & 745 & 2014 & {$[128 \mathrm{k}]$} & Layer structure \\
\hline $\mathrm{CdTe}_{0.97} \mathrm{Cl}_{0.03}$ & $n-0.20$ & 630 & 2014 & [1281] & $\mathrm{Cl}$ doping \\
\hline $\mathrm{BaCu}_{5.7} \mathrm{Se}_{0.6} \mathrm{Te}_{6.4}$ & $p-0.13$ & 650 & 2011 & {$[128 \mathrm{e}]$} & $\begin{array}{l}\text { Complex } \\
\text { structure }\end{array}$ \\
\hline $\mathrm{Cs}_{\mathrm{x}} \mathrm{LaCu}_{6-\mathrm{x}} \mathrm{Te}_{6}$ & $p-0.26$ & 614 & 2011 & {$[128 f]$} & $\begin{array}{l}\text { Complex } \\
\text { structure }\end{array}$ \\
\hline $\mathrm{Ce}_{0.9} \mathrm{Cu}_{0.1} \mathrm{Se}_{2}$ & $p-0.18$ & 800 & 2010 & {$[128 c]$} & $\begin{array}{c}\text { Band } \\
\text { engineering, } \\
\text { CDW }\end{array}$ \\
\hline $\mathrm{K}_{2} \mathrm{Bi}_{8} \mathrm{Se}_{13}$ & $n-0.58$ & 673 & 2013 & {$[128 \mathrm{j}]$} & $\begin{array}{l}\text { Complex } \\
\text { structure }\end{array}$ \\
\hline $\mathrm{Ba}_{0.7} \mathrm{Cu}_{0.3} \mathrm{Cu}_{2} \mathrm{Se}_{2}$ & $p-0.32$ & 800 & 2015 & [128n] & Layer structure \\
\hline $\mathrm{LaGd}_{1.02} \mathrm{~S}_{3}$ & $n-0.4$ & 953 & 2011 & {$[128 \mathrm{~g}]$} & Self-doping \\
\hline $\mathrm{NdGd}_{1.02} \mathrm{~S}_{3}$ & $n-0.51$ & 950 & 2011 & [128a] & Self-doping \\
\hline $\mathrm{CoFeS}$ & $n-0.35$ & 773 & 2013 & [128o] & $\begin{array}{l}\text { Complex } \\
\text { structure }\end{array}$ \\
\hline $\mathrm{Cu}_{11} \mathrm{MnSb}_{4} \mathrm{~S}_{13}$ & $p-1.13$ & 575 & 2014 & [128p] & $\begin{array}{l}\text { Tetrahedrite } \\
\text { structure }\end{array}$ \\
\hline $5 \% \mathrm{Co}+\mathrm{FeS}_{2}$ & $n-0.02$ & 600 & 2014 & [128q] & Low cost \\
\hline$(\mathrm{BiAgSeS})_{0.5}\left(\mathrm{BiAgSeS}_{0.97} \mathrm{Cl}_{0.03}\right)_{0.5}$ & $n-1.23$ & 773 & 2014 & {$[128 r]$} & $\begin{array}{l}\text { Modulation } \\
\text { doped }\end{array}$ \\
\hline $\mathrm{Co}_{3} \mathrm{Sn}_{1.6} \mathrm{In}_{0.4} \mathrm{~S}_{2}$ & $n-0.32$ & 673 & 2015 & [128s] & Structure \\
\hline
\end{tabular}




\section{WILEY-VCH}

\section{The table of contents}

Metal chalcogenides, with extremely complex compositions and structures, usually feature both lower cost and higher performance than other thermoelectric materials. This paper provides a comprehensive review on the different kinds of metal chalcogenides as heatelectricity conversion materials. Several new strategies to further enhance their performance are also summarized.

Keywords: metal chalcogenides, thermoelectrics, enhancement of ZT, new strategies

Chao Han, Qiao Sun, Zhen Li,* and Shi Xue Dou

Thermoelectric enhancement of different kinds of metal chalcogenides

ToC figure

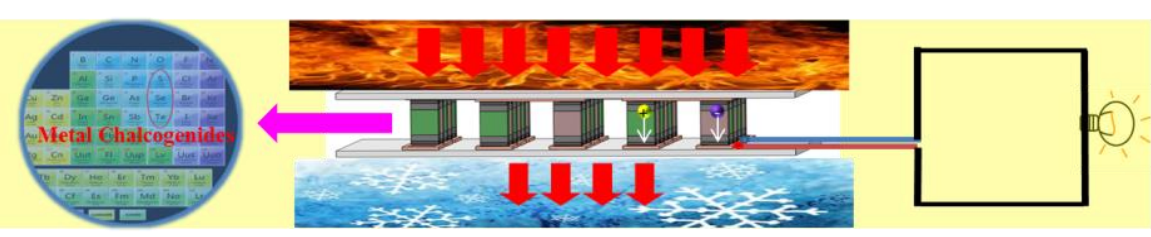

